\title{
VARIAÇÃO DA TEMPERATURA INTRAMUSCULAR DURANTE E APÓS A APLICAÇÃO CUTÂNEA DE FRIO E CALOR SUPERFICIAL
}

Elizabete Dias Flauzino Gaspar Gomes

Dissertação apresentada à Escola de Engenharia de São Carlos, Faculdade de Medicina de Ribeirão Preto e Instituto de Química de São Carlos, da Universidade de São Paulo, como parte dos requisitos para obtenção do título de Mestre em Bioengenharia.

ORIENTADOR: José B. Volpon 
G633v Variação da temperatura intramuscular durante e após a aplicação cutânea de frio e calor superficial / Elizabete Dias Flauzino Gaspar Gomes. -- São Carlos, 2001 .

Dissertação (Mestrado) -- Escola de Engenharia de São Carlos/Faculdade de Medicina de Ribeirão Preto/Instituto de Química de São Carlos-Universidade de São Paulo, 2001 .

Área Interunidades : Biongenharia.

Orientador: Prof. Dr. José B. Volpon.

1. Variação de temperatura. 2. Frio. 3. Calor superficial. I. Título. 
Autora: Elizabete Dias Flauzino Gaspar Gomes

Título: Variação da temperatura intramuscular durante e após a aplicação cutânea de frio e calor superficial

Dissertação defendida e aprovada em pela comissão julgadora:

(Assinatura)

(Nome/Instituição)

(Assinatura)

(Nome/Instituição)

(Assinatura)

(Nome/Instituição)

Coordenador de Área

Presidente da CPG 
(...) E quaisquer que sejam os seus trabalhos e aspirações na fatigante confusão da vida, mantenham-se em paz com sua própria alma. O sucesso que você busca não poderá ser em momento algum, maior do que você mesmo.(...)

Autor desconhecido 
Às queridas filhas, Letícia e Bárbara, razão de minha busca e evolução. 
Ao Prof. Dr. José B. Volpon pelos conhecimentos, dedicação e paciência dispensados.

Aos funcionários e amigos do Laboratório de Bioengenharia da Faculdade de Medicina de Ribeirão Preto/USP que colaboraram direta ou indiretamente para a confecção deste trabalho.

Aos funcionários da Secretaria de Bioengenharia (São Carlos).

A todos os funcionários do Centro Universitário Claretiano pelo apoio e pela confiança.

A todos amigos e familiares pelo apoio e entusiasmo durante esta trajetória. 


\section{SUMÁRIO}

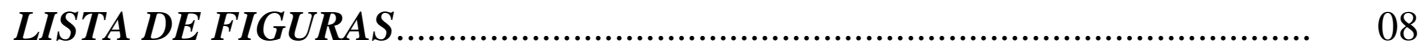

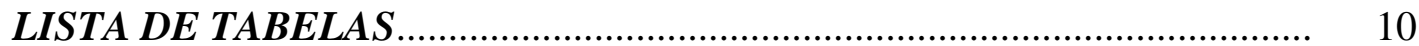

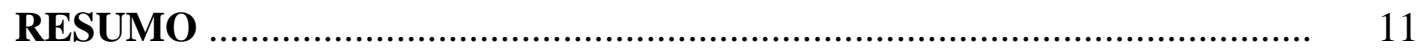

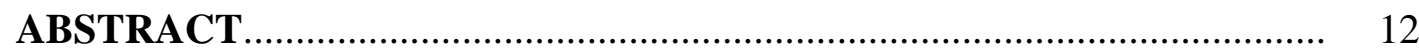

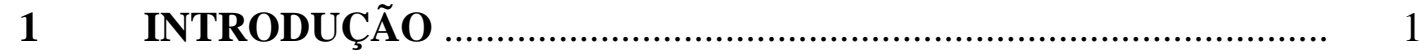

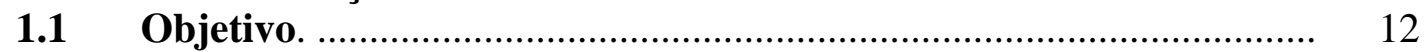

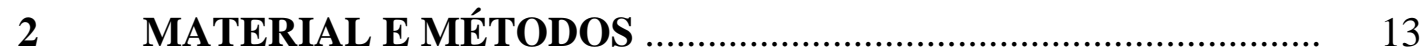

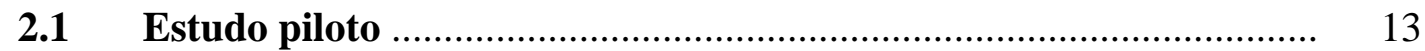

2.2 Estudo das variações térmicas ........................................................ 16

2.3 Implantação do sensor em cães.................................................... 17

2.3.1 Sensor Intramuscular .................................................................. 17

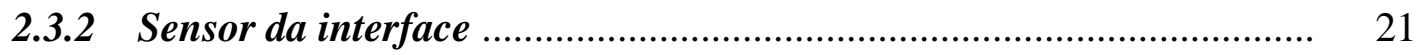

2.4 Medida de temperatura retal......................................................... 21

2.5 Aplicação de frio ......................................................................... 21

2.5.1 Medida de registro de temperatura dos sensores térmicos ................... 24

2.6 Aplicação de calor ...................................................................... 24

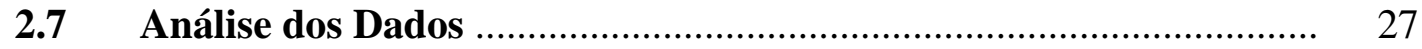

2.7.1 Aplicação de Frio ............................................................................. 27

2.7.2 Aplicação de Calor ............................................................................ 29

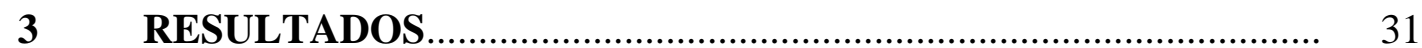

3.1 Aplicação de frio ............................................................................. 31

3.1.1 Variação da temperatura na interface bolsa-pele .............................. 31

3.1.2 Variação da temperatura na região muscular .................................... 34

3.2 Aplicação de calor........................................................................ 38

3.2.1 Variação da temperatura na interface bolsa-pele ............................... 38

3.2.2 Variação da temperatura na região muscular...................................... 41

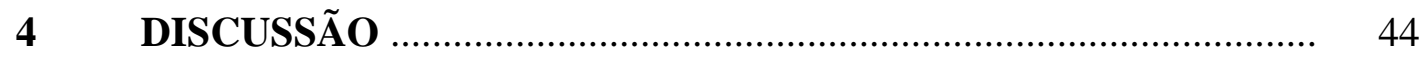

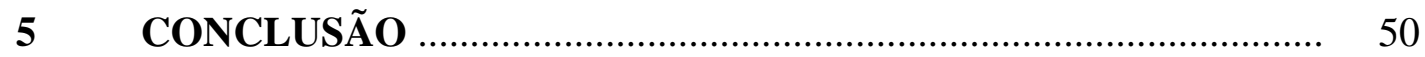

REFERÊNCIAS BIBLIOGRÁFICAS …............................................ 51

BIBLIOGRAFIA COMPLEMENTAR ................................................ 54

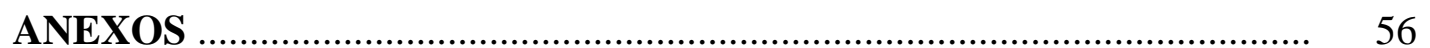




\section{LISTA DE FIGURAS}

FIGURA 1 Panorama histórico da crioterapia ............................................ 4

FIGURA 2 Dissecção do dorso de um cão adulto, rebatendo um retângulo de pele e tecido celular subcutâneo. Abaixo está a fáscia muscular $(*)$

FIGURA 3 Dissecção e rebatimento do músculo cutâneo, localizado imediatamente ao tecido celular subcutâneo (seta)

FIGURA 4 Fotografia mostrando o rebatimento da pele (1), do músculo cutâneo (2) e músculo grande dorsal (3)

FIGURA 5 Fotografia mostrando o levantamento do músculo grande dorsal (*) e abaixo dele, o músculo longo do tronco (,),em que foi inserido o sensor térmico.

FIGURA 6 Equipamento usado para a medida da temperatura - aTermômetro digital modelo IM- 01 da marca CONTEMP, bsensor interface (preto), c- sensor intramuscular (branco), dsensor retal, e- termômetro digital tipo martelo, fcronômetro.

FIGURA 7 Cirurgia no cão para colocação do sensor térmico. (A) Limpeza com solução desgermante PVPI $1 \%$ de iodo ativo. (B) Antissepsia com solução álcool-iodada $2 \%$. (C) Incisão maior na pele e sobre a projeção do corpo muscular do longo do tronco; incisão menor a uma distância de $12 \mathrm{~cm}$ da maior. (D) Passagem do sensor pelo túnel iniciado pela menor incisão. (E) Introdução do sensor no músculo longo do tronco.

(F) Curativo oclusivo das incisões

FIGURA 8 Delimitação da área a ser resfriada com cinto de couro. Observa-se a incisão transversal usada para a implantação intramuscular do sensor (I), o fio de conexão saindo pela segunda incisão e fora da área da aplicação térmica $(F)$ e o sensor da interface colocado na região a receber o tratamento térmico $(\mathrm{S})$.

FIGURA 9 Colocação da "bolsa" de gelo e medida da temperatura da interface bolsa de gelo-plástico-pele.

FIGURA 10 Bolsa de gelo fixada com atadura na região de estudo................. 
FIGURA 11 Colocação da bolsa de gel aquecida na região de estudo........... 25

FIGURA 12 Bolsa de gel aquecida fixada com atadura .............................. 25

FIGURA 13 Sequiência experimental de aplicações de frio e calor superficial

FIGURA 14 Gráfico ilustrativo da variação térmica medida na pele ou no músculo com a aplicação de frio. TI - temperatura inicial, antes da aplicação do frio; A- ponto que marca o final da queda rápida de temperatura e início da fase de queda mais lenta; B- ponto de início elevação térmica, após a retirada do frio; C- temperatura no ponto "A", E- tempo no ponto "A", Dtemperatura no ponto "B", F- tempo no ponto " $\mathrm{B}$ "

FIGURA 15 Gráfico ilustrativo da variação térmica medida na pele ou no músculo com a aplicação do calor superficial. TI - temperatura inicial, antes da aplicação de calor superficial; A- ponto que marca o final da elevação rápida de temperatura e início da fase de elevação mais lenta; B- ponto de início da queda térmica após a retirada co calor superficial; $\mathrm{C}$ - temperatura no ponto "B"; D- temperatura no ponto "A"; E- tempo no ponto "A"; F- tempo no ponto "B".

FIGURA 16 Variação da temperatura na interface bolsa-pele com aplicação de frio durante 30 minutos e, depois, retirada (seta) ....

FIGURA 17 Parâmetros da variação da temperatura na interface bolsa-pele durante a aplicação de frio.

FIGURA 18 Tempo decorrido para obtenção dos parâmetros de pico na interface bolsa-pele com aplicação de frio.

FIGURA 19 Variação da temperatura intramuscular com aplicação de frio durante 30 min e, depois, retirada (seta)

FIGURA 20 Parâmetros da variação de temperatura intramuscular durante a aplicação de frio na região cutânea.

FIGURA 21 Tempo decorrido para obtenção dos parâmetros de pico na região intramuscular com aplicação de frio na região cutânea...

FIGURA 22 Variação da temperatura na interface bolsa-pele com aplicação de calor superficial durante $20 \mathrm{~min}$ e, depois, retirada (seta) ....

FIGURA 23 Parâmetros da variação de temperatura na interface bolsa-pele durante aplicação de calor superficial.

FIGURA 24 Tempo decorrido para obtenção dos parâmetros de pico na interface bolsa-pele com aplicação de calor superficial.

FIGURA 25 Variação da temperatura intramuscular com aplicação de calor superficial durante 20 min e, depois, retirada (seta).

FIGURA 26 Parâmetros da variação de temperatura intramuscular durante a aplicação de calor superficial na região cutânea.......................

FIGURA 27 Tempo decorrido para obtenção dos parâmetros de pico na região intramuscular com aplicação de calor superficial na região cutânea 


\section{LISTA DE TABELAS}

TABELA 1 Parâmetros de variação da temperatura na interface bolsa-pele com aplicação de frio durante $30 \mathrm{~min}$

TABELA 2 Parâmetros de variação de tempo na interface bolsa-pele na aplicação de frio.

TABELA 3 Parâmetros de variação da temperatura intramuscular durante a aplicação de frio na região cutânea.

TABELA 4 Parâmetros da variação de tempo na região intramuscular durante a aplicação de frio na região cutânea.

TABELA 5 Parâmetros de variação de temperatura na interface bolsa-pele durante a aplicação de calor superficial.

TABELA 6 Parâmetros da variação de tempo durante aplicação de calor superficial na interface

TABELA 7 Parâmetros de variação da temperatura intramuscular durante a aplicação de calor superficial na região cutânea.

TABELA 8 Parâmetros de variação de tempo na região intramuscular, durante a aplicação de calor superficial na região cutânea 
GOMES, Elizabete Dias Flauzino Gaspar. Variação da temperatura intramuscular durante e após a aplicação cutânea de frio e calor superficial. Ribeirão Preto, 2001. 67 p. Dissertação (Mestrado em Bioengenharia) - Escola de Engenharia de São Carlos, Faculdade de Medicina de Ribeirão Preto, Instituto de Química de São Carlos - Universidade de São Paulo.

\section{RESUMO}

A utilização do frio e calor superficial, com propósitos terapêuticos é antiga, e seus efeitos ainda apresentam inúmeras controvérsias. Este experimento objetivou determinar as variações de temperatura em planos musculares profundos durante e após aplicação de frio e calor superficial na região cutânea adjacente. Foram usados 5 cães mestiços submetidos à implantação cirúrgica (músculo longo do tronco) de sensor térmico (PT100), em profundidade de $3 \mathrm{~cm}$. Foi aplicado frio na pele adjacente, durante $30 \mathrm{~min}$, em 3 dias consecutivos, em área delimitada, usando bolsa de gelo triturado, verificando temperatura a cada 5 min durante a aplicação e 30 min após cessar a aplicação. No $4^{\circ}$ dia (pós-operatório) foram iniciadas as aplicações de calor superficial, durante 20 min (bolsa de gel a $55^{\circ} \mathrm{C}$ ), por 3 dias, verificando temperatura a cada 5 min durante a aplicação e mais 20 min após cessar a aplicação. Os dados de temperatura $x$ tempo foram analisados descritivamente. Durante a aplicação de frio houve uma queda rápida da temperatura na interface com variação média de $23^{\circ} \mathrm{C}$, com tempo médio de alcance da temperatura mínima em 24 min. A região intramuscular apresentou variação lenta (média de $4,30^{\circ} \mathrm{C}$ ), com tempo médio de alcance da temperatura mínima em 27 min. Durante a aplicação de calor superficial no sensor da interface houve aumento brusco da temperatura média de $8,8^{\circ} \mathrm{C}$, com o tempo de alcance de temperatura máxima em 9 min. Na região intramuscular houve discreto aumento da temperatura média de $1,75^{\circ} \mathrm{C}$ com tempo médio de alcance da temperatura em $8 \mathrm{~min}$. A partir destes resultados foi concluído que existem modificações reais da temperatura em planos musculares profundos com aplicação de frio e calor superficial, na superfície cutânea.

Palavras- chave: temperatura; frio; calor superficial. 
GOMES, Elizabete Dias Flauzino Gaspar. Variation of the intramuscular temperature during and after cutaneous application of cold and superficial heat. Ribeirão Preto, 2001. 67 p. Dissertação (Mestrado em Bioengenharia) - Escola de Engenharia de São Carlos, Faculdade de Medicina de Ribeirão Preto, Instituto de Química de São Carlos - Universidade de São Paulo.

\section{ABSTRACT}

The utilization of cold and superficial heat with therapeutical purposes is ancient and its effects are still controversial. This experiment aimed to determine the temperature variations in deep muscle plans during and after cold and superficial heat applications on the adjacent skin region. Five half-breed dogs were used and undergone surgical implantantion (trunk long muscle) of thermal sensor (PT 100) three centimeter deep. Cold was applied on the adjacent skin for three consecutive days, in a delimited area, during 30 minutes, using a plastic bag with grinded ice checking the temperature each 5 minutes and 30 minutes after finishing the application. On the $4^{\text {th }}$ day (after surgery) superficial heat applications $\left(55^{\circ} \mathrm{C}\right.$ gel bag) were performed for three days, during 20 minutes, checking temperature each 5 minutes and 20 minutes after finishing the application. Data about temperature $x$ time were analyzed descriptively. During cold application there was rapid temperature decrease in the interface $23^{\circ} \mathrm{C}$ average variation with average reaching time of the minimum temperature in 24 minutes. The intramuscular region presented slow decrease $\left(4,3^{\circ} \mathrm{C}\right.$ average $)$ with average reaching time of minimum temperature in 27 minutes. During superficial heat application in the interface sensor there was a sudden increase of $8,8^{\circ} \mathrm{C}$ average temperature, with maximum temperature reaching time in 9 minutes. In the intramuscular region there was a discrete increase of average temperature of $1,75^{\circ} \mathrm{C}$ with average reaching time of temperature in 8 minutes. Considering the results above it was concluded that there are actual temperature variations in deep muscle plans with the use of cold and superficial heat therapies.

Keywords: temperature; cold, superficial heat. 


\section{INTRODUÇÃO}

A utilização do frio e do calor superficial, com propósitos terapêuticos é antiga, mas seus efeitos apresentam inúmeras controvérsias que ainda perduram. A aplicação de frio e calor superficial modifica a temperatura cutânea, subcutânea e intramuscular. Ocorrem variações nas técnicas utilizadas, no tempo de aplicação e suas áreas tratadas. Como são realizadas as medidas de variações dessas temperaturas? Ainda hoje, quantificar essas variações de temperaturas intramusculares trazem questionamentos.

Uma revisão do panorama histórico da crioterapia ilustra a trajetória da utilização de frio, iniciando com antigos gregos e romanos, que utilizavam neve e gelo para tratar as mais variadas afecções (Figura 1).

O termo crioterapia é definido como a aplicação terapêutica de várias substâncias em partes do corpo, para remoção de calor, diminuindo, assim, a temperatura local.

No século XVIII surgiram publicações sobre crioterapia, com utilização de compressas congeladas em afecções inflamatórias e como auxiliares nas cirurgias. 
Em 1930, Dehn defendeu a mobilização precoce, com utilização de exercícios associado ao uso do frio, denominando a técnica de criocinética.

A aplicação moderna do frio no tratamento de lesões traumáticas agudas surgiu em torno de 1940, sendo utilizada nos primeiros 30 minutos após o trauma, seguida por aplicações de calor no período subseqüente.

As teorias de tratamento com modalidades físicas, como calor, luz e eletricidade predominaram em meados do século $\mathrm{XX}$, em que se relacionava a velocidade de cicatrização tecidual ao aumento de fluxo sangüíneo, como resposta ao calor.

Em 1950, o frio passou a ser usado por 24 a 72 horas após a lesão, e o calor, apenas na fase subaguda (DAYTON, 1960).

Em 1970, foi proposta a teoria de vasodilatação induzida pelo frio (VIF) para explicar a ação da criocinética. O frio foi utilizado em Medicina Desportiva no atendimento imediato, porém a Medicina convencional ainda utiliza calor para tratar lesões do esporte.

Em 1976, Knigth introduziu a teoria da hipóxia secundária à lesão, onde o frio atuaria de forma benéfica nas lesões músculo-esqueléticas agudas, diminuindo o metabolismo nos tecidos adjacentes à lesão e possibilitando que muitas células sobrevivessem a este período de deficiência de oxigênio causada pela alteração da circulação sanguiínea local e pelo processo inflamatório. A presença de edema, segundo essa teoria, estaria relacionada com o aumento de proteínas livres e pressão oncótica no tecido lesado, e pouco influenciada pela hemorragia que seria detida pela coagulação. 
Somente em 1980 os pesquisadores interessam-se pelas modificações de temperaturas decorrentes da aplicação de frio. As práticas empíricas, até então, necessitavam de confirmações científicas, e o assunto requeria embasamento teórico e científico.

Nesta mesma época foi comprovado que a teoria da vasodilatação induzida pelo frio não explicava o sucesso da criocinética, pois o frio, na verdade, diminuia o fluxo sangüíneo (JOHNSON, 1991).

As respostas tanto física como fisiológicas à aplicação do frio ou calor superficial são decorrentes, inicialmente, da variação de temperatura. Assim, na aplicação de frio, há os seguintes efeitos fisiopatológicos propostos por KNIGHT (2000):

- Diminuição da temperatura

- Diminuição do metabolismo

- Efeitos inflamatórios e circulatórios (diminuição ou aumento)

- Diminuição da dor

- Diminuição do espasmo muscular

- Aumento da rigidez tecidual

A diminuição de temperatura apresenta variações que estão relacionadas com as diferentes modalidades de aplicação, tempo de aplicação, temperatura inicial do agente terapêutico, tecido a ser resfriado e a localização (superficial ou profunda) LEHMANN (1974); KAUL \& HERRING (1994); SWENSON (1996); MYRER (1998); JOHNSON \& KITCHEN in KITCHEN \& BAZIN (1998); KNIGHT (2000). 


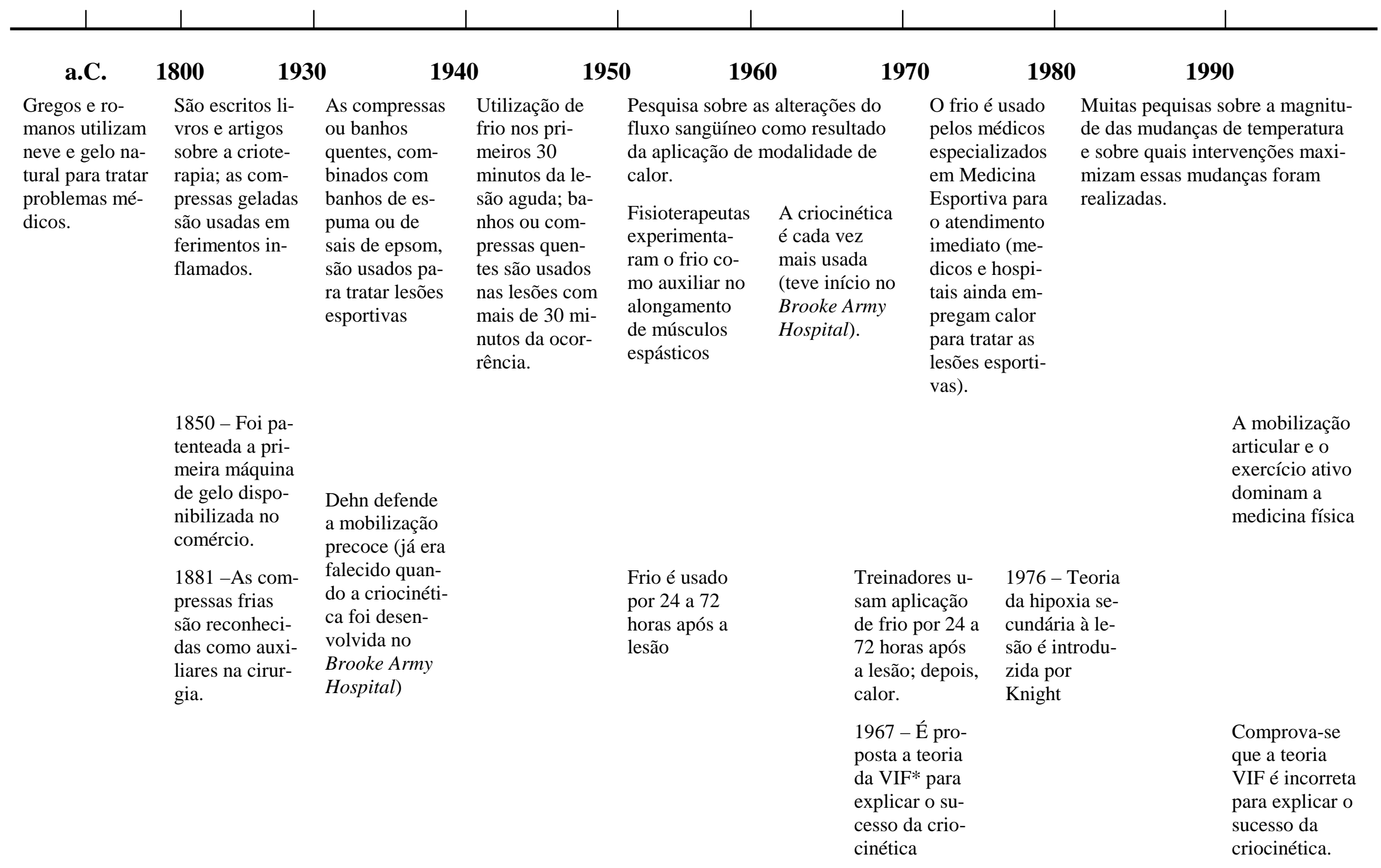

FIGURA 1 - Panorama histórico da crioterapia (KNIGHT, 2000, p. 14). *VIF - Vasodilatação induzida pelo frio 
A temperatura é definida como o grau de calor de uma dada substância, medida em uma escala padronizada com diferentes parâmetros referenciais. A escala Fahrenheit (F) considera o ponto de congelamento da água 32 graus e o ponto de ebulição 212 graus, enquanto que na escala Celsius o congelamento corresponde a 0 grau e a ebulição a 100 graus.

Então, energia térmica é “o resultado do movimento aleatório das partículas que compõem todas as substâncias" KNIGTH (2000) e os diferentes movimentos das partículas e alterações da energia térmica ocorrem simultaneamente.

O frio não é uma entidade física quantificável, mas refere-se à perda de calor, que pode ser exemplificada com as estações do ano. No inverno a temperatura diminui, portanto, está frio, no verão a temperatura aumenta, então está quente (KNIGHT, 2000).

A medida de temperatura depende da precisão do termômetro, bem como da maneira como ele é utilizado. A segurança de leitura em termômetros de bulbo de mercúrio depende do tamanho de sua escala, pois termômetros pequenos dificultam a precisão de leitura . Já, os termopares e termistores são conectados a um dispositivo eletrônico chamado teletermômetro com leitura digital e são mais adequados que os de bulbo de mercúrio. A precisão do instrumento não dispensa a calibração, pois ela garante a aferição da temperatura correta.

A temperatura da interface localiza-se entre a temperatura da superfície e do meio ambiente ou do agente aplicado, calor ou frio, dividido por dois, supondo a interface uniforme com a superfície (KNIGHT, 2000).

A transferência do calor dos tecidos para modalidade de frio se faz por condução e depende de fatores como: diferença de temperatura entre o corpo e a 
modalidade, recuperação de calor corporal e modalidade de frio, condições de armazenar calor da modalidade de frio, tamanho e modalidade usada, região aplicada, duração e variações individuais.

O comportamento das temperaturas superficiais e profundas quando da aplicação de frio vem sendo estudado por diversos autores, que demonstram variações em tempo de aplicação, modalidade, profundidade e instrumento de leitura.

WOLF (1973) aplicou frio na face cutânea do músculo gastrocnêmio humano, por 5 minutos, onde um sensor tipo agulha foi introduzido a $4,3 \mathrm{~cm}$ de profundidade. A redução de temperatura intramuscular foi de $1,2^{\circ} \mathrm{C}$ e a temperatura da interface foi de $9,98^{\circ} \mathrm{C}$.

JOHNSON (1979) investigou a temperatura intramuscular de ambos gastrocnêmios humanos, submergindo uma perna em água a $10^{\circ} \mathrm{C}$, por 30 minutos. Utilizou eletrodos de agulha a uma profundidade de $25,3 \mathrm{~mm}$. A alteração da temperatura na perna submersa $\left(12^{\circ} \mathrm{C}\right)$ foi maior que a da perna contralateral $\left(2,78^{\circ} \mathrm{C}\right)$. Essa queda de temperatura perdurou por 4 horas.

MYER (1997) pesquisou as alterações de temperatura intramuscular e subcutânea na panturrilha humana. Utilizou dois eletrodos de agulha colocados a 1 $\mathrm{cm}$ abaixo da pele e tecido subcutâneo, e o segundo aproximadamente 0,5 cm logo abaixo da pele. Realizou aplicação cutânea, com bolsa de frio (gelo triturado) e bolsa de gel aquecida para o grupo de contraste, ou seja, durante 20 minutos foram aplicados calor e frio, respectivamente, a cada cinco minutos. Em outro grupo foi aplicada bolsa de frio (gelo triturado) durante 20 minutos. Os resultados mostraram que a temperatura intramuscular não se modificou significativamente com o contraste térmico. Entretanto, a temperatura subcutânea variou de $8^{\circ} \mathrm{C}$ a $14^{\circ} \mathrm{C}$ em 
cada intervalo de cinco minutos. No grupo em que foi aplicada a bolsa de frio isoladamente houve decréscimo de $7^{\circ} \mathrm{C}$ na região intramuscular e $17^{\circ} \mathrm{C}$ na região subcutânea.

LEVY (1997) estudou a penetração do frio no espaço gleno-umeral e subacromial em 15 pacientes que foram submetidos à artroscopia de ombro e desbridamento do espaço subacromial. O frio foi aplicado com "Cryo/Cuff", durante 90 minutos. Entre os pacientes, dez foram submetidos à aplicação de frio e cinco utilizados como controle. A temperatura intra-articular antes da aplicação do frio foi de $34^{\circ} \mathrm{C}$ na articulação gleno-umeral e $31^{\circ} \mathrm{C}$ na região subacromial. Os resultados não mostraram diferença significativa entre as temperaturas intraarticulares do grupo submetido à aplicação de frio e do grupo controle. Em todos os casos, o espaço subacromial apresentou $1^{\circ} \mathrm{C}$ de resfriamento em relação à glenoumeral. Assim, concluiu o autor, que o frio aplicado na superfície não penetrou na articulação gleno-umeral.

MYER (1998) comparou as modificações de temperatura subcutânea e intramuscular da panturrilha humana com duas modalidades distintas de aplicação de frio, ou seja, bolsa de gelo triturado e imersão em turbilhão com água fria a $10^{\circ} \mathrm{C}$, ambas durante 20 minutos. Utilizou a mesma metodologia de seu trabalho anterior. Os resultados de temperatura intramuscular não apresentaram modificação significativa nos dois procedimentos. Entretanto, no período após aplicação durante 30 minutos em intervalos de 5 minutos, no grupo da bolsa de gelo houve aumento de $\pm 3,1^{\circ} \mathrm{C}$, e no grupo de imersão em turbilhão, houve queda da temperatura de $\pm 1,4^{\circ} \mathrm{C}$.

A temperatura subcutânea apresentou maior queda com aplicação de bolsa de

\footnotetext{
${ }^{1}$ É a combinação de frio e compressão desenvolvido pela Aircast Corporation. O equipamento consiste em uma bota de nylon ligada por um tubo de borracha a uma caixa térmica.
} 
gelo, quando comparado com imersão em turbilhão. Porém, o reaquecimento do grupo da bolsa de gelo $\left( \pm 3,3^{\circ} \mathrm{C}\right)$ foi maior em relação ao grupo de imersão $\left( \pm 2,1^{\circ} \mathrm{C}\right)$.

O autor conclui que houve maior eficiência com a imersão em turbilhão de água fria $\left(10^{\circ} \mathrm{C}\right)$ do que com o uso de bolsa de gelo triturado, por manter redução da temperatura após o tratamento.

Segundo KNIGHT (2000), a temperatura da superfície modifica-se imediatamente à aplicação de frio, até ficar estável, alguns graus acima da temperatura do frio aplicado. A escolha da técnica de frio aplicado interfere diretamente nos resultados da temperatura da superfície. A temperatura intramuscular responde à aplicação de frio na superfície, de acordo com a profundidade, tipo de tecido e técnica aplicada. Os tecidos subcutâneos reagem como a pele, mas em menor velocidade, já, os profundos reduzem menos a temperatura e mais lentamente, pelo tempo necessário do calor para atravessar as várias camadas dos tecidos. Já, o reaquecimento está provavelmente, relacionado a quantidade de calor retirado do corpo e a quantidade de tecido disponível para aquece-lo.

Para seqüenciar o estudo, apresentamos uma revisão do calor superficial, analisando, fundamentalmente, as modificações de temperatura decorrentes da aplicação.

\section{CALOR SUPERFICIAL}

"O calor é a quantidade de energia térmica transferida entre duas substâncias ou sistemas que estão em contato térmico, cujas temperaturas são diferentes” (KNIGHT, 2000, p.), é medido em Joule ou caloria. 
As formas de aquecimento superficial são classificadas em três grupos (Quadro 1): calor aplicado por condução, convecção e conversão, dependendo da propriedades térmicas e profundidade do tecido LEHMANN (1974); JOHNSON \& KITCHEN in KITCHEN \& BAZIN (1998).

QUADRO 1 - Modalidades de aquecimento e seu modo principal de transferência de calor (segundo LEHMANN \& DE LATEUR apud JOHNSON \& KITCHEN in KITCHEN \& BAZIN, 1998, p. 93).

\begin{tabular}{|ll|}
\hline $\begin{array}{l}\text { Modo principal de } \\
\text { transferência térmica }\end{array}$ & Modalidade \\
\hline Condução & Bolsas quentes \\
Banho de parafina & Fluidoterapia \\
& Hidroterapia \\
& Ar umidificado \\
& Calor radiante \\
& Laser \\
& Microondas \\
& Ondas curtas \\
& Ultra-som \\
&
\end{tabular}

As modificações de temperatura são resultantes de transferência de calor por condução (Quadro 1) e estão diretamente relacionadas à intensidade do calor, tempo de aplicação e meio térmico.

A função básica dos diferentes métodos de calor superficial em fisioterapia, é a elevação de temperatura dos tecidos.

LEHMANN et al. (1966) constataram aumento de temperatura utilizando calor superficial sobre a região do músculo quadríceps humano, com bolsa quente. $\mathrm{O}$ experimento registrou a temperatura a $1 \mathrm{~cm}$ de profundidade, em relação à pele. $\mathrm{O}$ resultado foi elevação de $1,5^{\circ} \mathrm{C}$ em 8 min e $3,0^{\circ} \mathrm{C}$ em 20 minutos. 
ABRAMSON et al. (1967) estudaram o calor superficial úmido e seco e verificaram maior aceitação dos pacientes para o aquecimento seco em relação ao úmido. Ao compararem calor seco e úmido, em temperaturas semelhantes, o calor úmido produziu temperaturas significativamente mais elevadas na pele, região subcutânea e região intramuscular. Porém, o calor seco, em temperaturas mais elevadas, apresentou a mesma eficiência.

LEHMANN \& DE LATEUR (1990) relataram que a temperatura dos tecidos com aplicação de calor superficial deve estar entre $40^{\circ} \mathrm{C}$ e $45^{\circ} \mathrm{C}$ para que se possa obter resultados terapêuticos. A temperatura superficial subcutânea apresentou elevação máxima entre 6 e 8 minutos de aplicação. Já, a região intramuscular com profundidade de $3 \mathrm{~cm}$ elevou $1^{\circ} \mathrm{C}$ aproximadamente (JOHNSON \& KITCHEN in KITCHEN \& BAZIN, 1998).

KAUL \& HERRING (1994) verificaram aumento de temperatura nos tecidos com aplicação de calor superficial. A distribuição da temperatura nos tecidos depende da quantidade de energia convertida, profundidade e propriedades térmicas do tecido e método de aplicação.

PORTER (1998) analisou a grande incidência de tendinites, bursites e artrites em cavalos, e a dificuldade de diagnóstico e tratamento. Em relação ao tratamento recomendou utilização de frio e compressão na fase aguda, e calor superficial na fase crônica. Observou a utilização do calor superficial como uma técnica com múltiplos benefícios, porém atuando diretamente na dor. A dor está presente pelo espasmo muscular, redução da circulação e pressão da inervação periférica, causada por alterações do tecido conectivo, assim sendo, a utilização de calor superficial pode 
atuar em todas essas causas, estimular o processo de reparo, como também preparando os tecidos para os exercícios de mobilização.

WORKMAN (1999) afirmou que a denominação "calor superficial” refere-se ao aumento da temperatura da pele $\left(40^{\circ} \mathrm{C}\right.$ a $\left.43^{\circ} \mathrm{C}\right)$, produzindo efeitos terapêuticos.

O calor superficial pode ser aplicado por pacotes quentes, bolsa de água quente, compressas quentes e úmidas, almofada elétrica de aquecimento (seca ou úmida), pacotes quentes e químicos disponíveis comercialmente, e imersão em água (tanque ou turbilhão) (MCCAFFERY \& WOLFF apud CUTANEOUS STIMULATION, 2000). Deve ser tomado cuidado para todos os tipos de pacotes quentes como embrulhá-los para evitar queimaduras. Na maioria dos casos, a proteção de uma toalha entre a pele e o aparelho de calor é suficiente. Se o paciente tem sensibilidade diminuída são necessárias mais camadas de proteção.

Calor superficial é comumente usado por pacientes para reduzir dor (BARBOUR, MCGUIRE, KIRCHOFF; DAVIS, CÓRTEX \& RUBIN; DONOVAN \&DILLON; RHINER, FERRELL, FERRELL et al.; WILKIE, LVEJOY, DODD et al. apud CUTANEOUS STIMULATION, 2000), e alguns autores recomendam calor para reduzir dor e desconforto (FERRELL, RHINER \& FERRELL; MCCAFFERY \& WOLFF; VASUDEVAN, HEGMANN, MOORE et al. apud CUTANEOUS STIMULATION, 2000). Outros autores, porém, alertam contra a utilização de calor por causa da preocupação do seu uso sobre tumor causando aumento e expansão metastática (LEE, ITOH, YANG et al. apud CUTANEOUS STIMULATION, 2000).

A revisão bibliográfica mostrou-nos que a aplicação de frio e calor superficial atua primariamente modificando a temperatura superficial e intramuscular. Porém, as 
variações das temperaturas estão diretamente relacionadas com a técnica de aplicação e com o tipo de tecido a ser resfriado e ou aquecido.

Assim, quantificar essas variações da temperatura superficial e intramuscular, bem como o tempo necessário para alcançá-las e sua duração foi a motivação que nos levou à presente investigação.

\subsection{Objetivo}

Esta investigação tem como objetivo avaliar as mudanças térmicas ocorridas em plano muscular, durante e após a aplicação cutânea de frio ou calor superficial. 


\section{MATERIAL E MÉTODO}

\subsection{Estudo piloto}

Como estudo piloto foi realizada uma dissecação dos elementos anatômicos do dorso do tronco de um cão adulto de $18 \mathrm{~kg}$, sacrificado com dose excessiva de tiopental. A finalidade deste estudo foi observar detalhes da anatomia para seleção da região a ser estudada e das estruturas de interesse.

Os principais passos técnicos da dissecação estão ilustrados seqüencialmente nas Figuras 2,3, 4 e 5. 


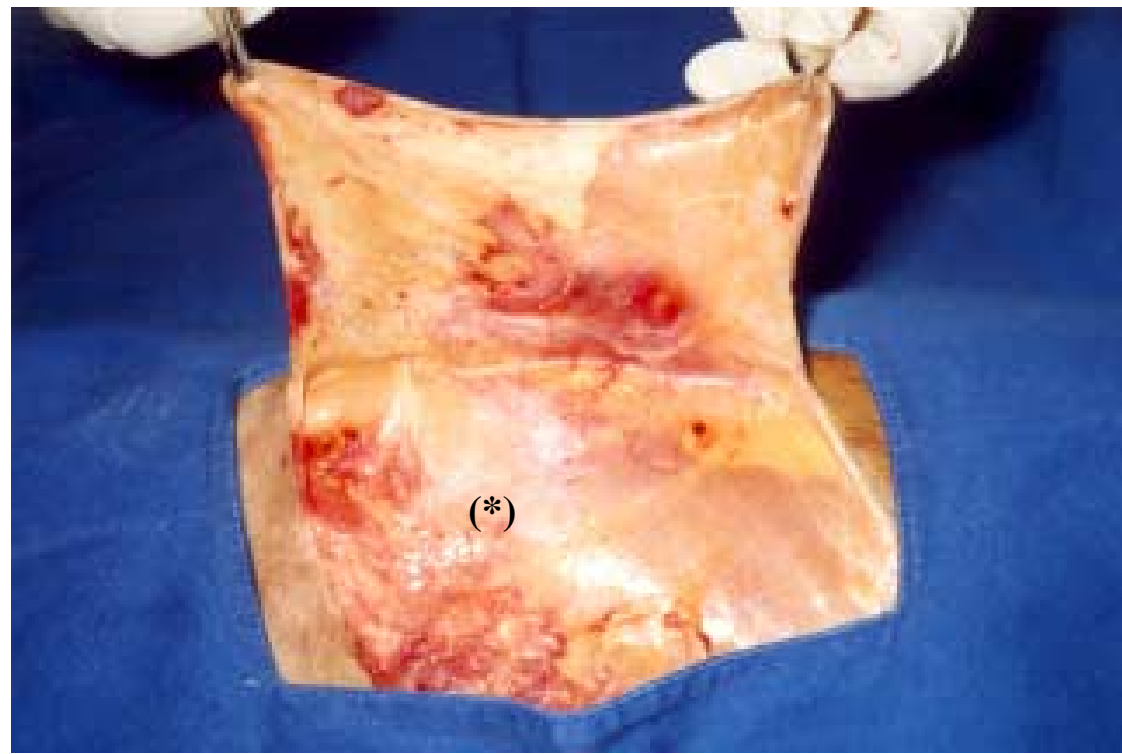

FIGURA 2 -Dissecção do dorso de um cão adulto, rebatendo um retângulo de pele e tecido celular subcutâneo. Abaixo está a fáscia muscular (*)

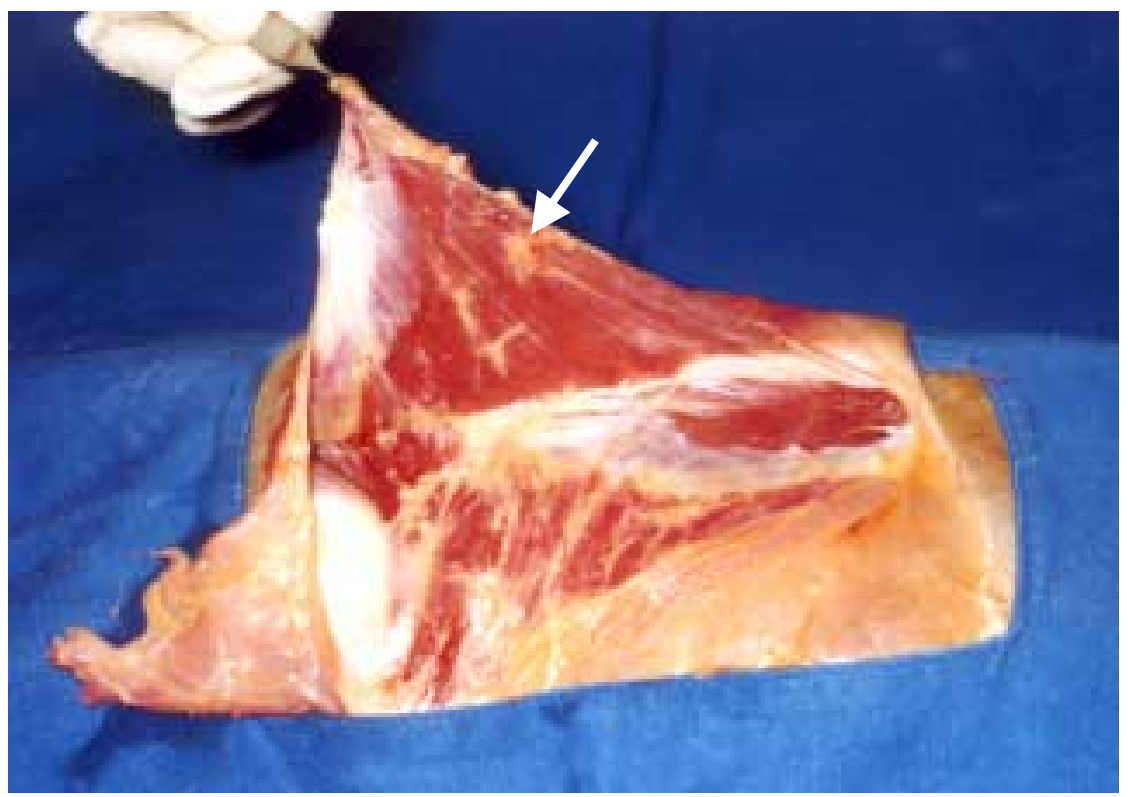

FIGURA 3 - Dissecção e rebatimento do músculo cutâneo, localizado imediatamente ao tecido celular subcutâneo (seta). 


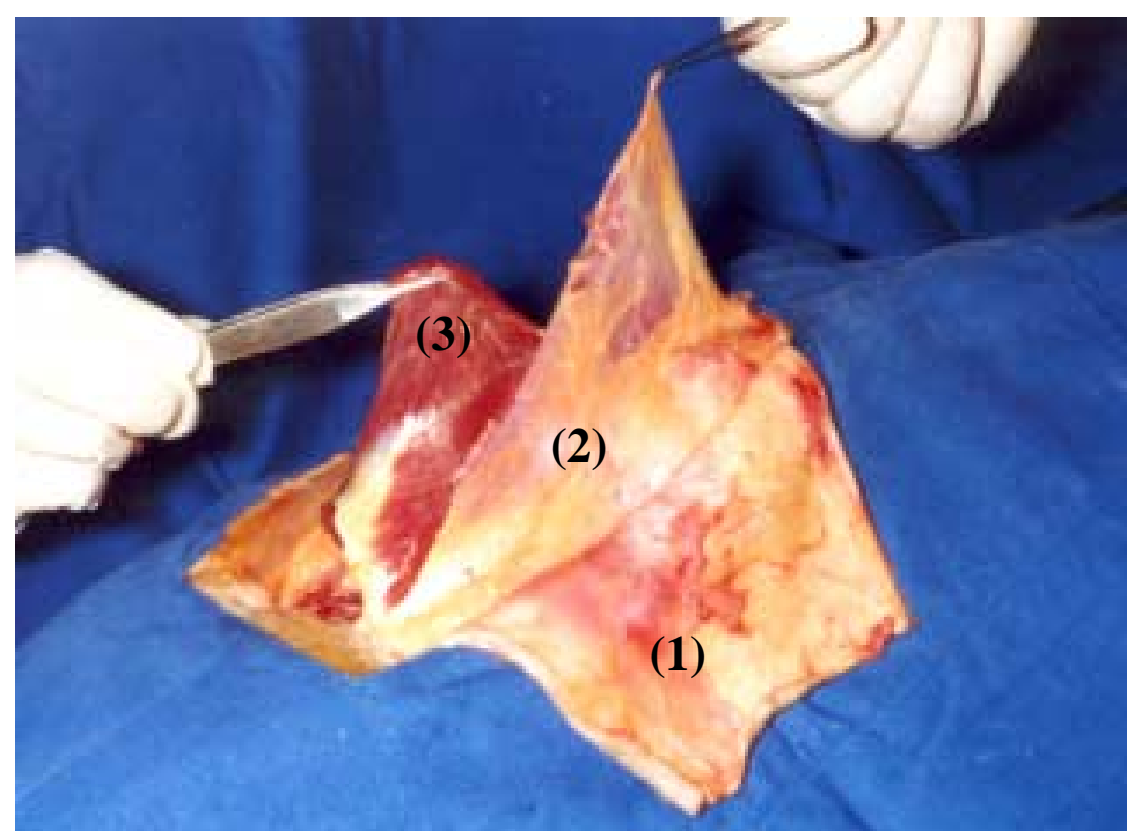

FIGURA 4 - Fotografia mostrando o rebatimento da pele (1), do músculo cutâneo (2) e músculo grande dorsal (3)

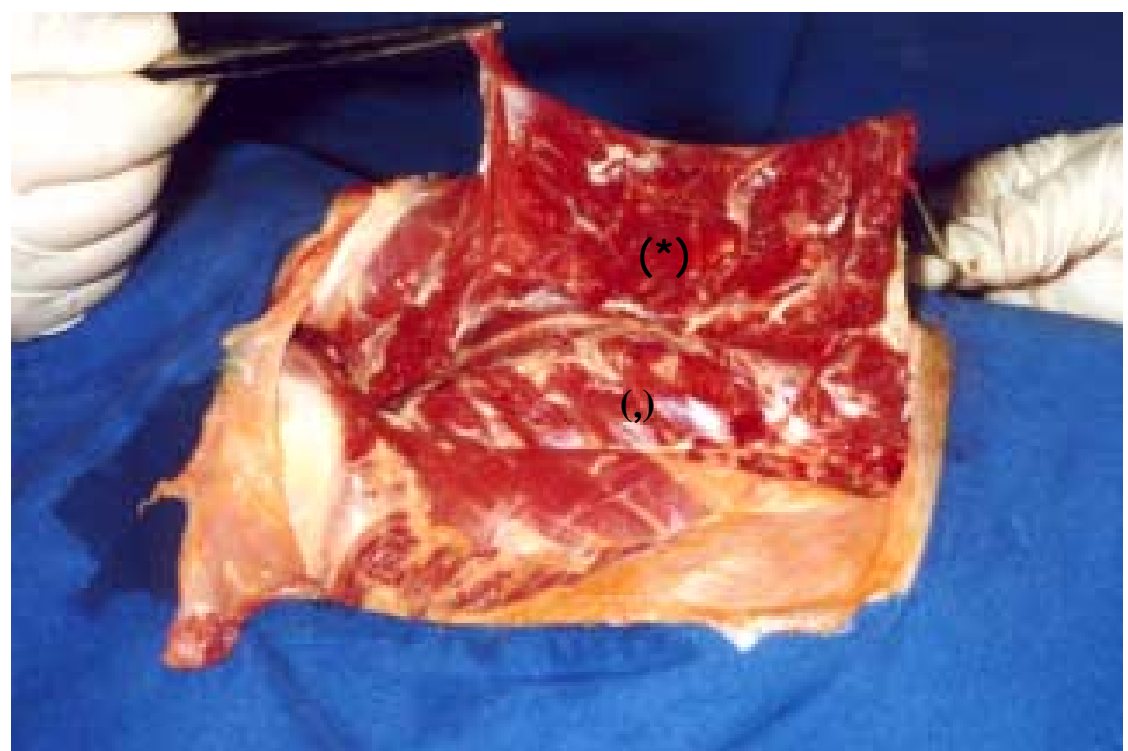

FIGURA 5 - Fotografia mostrando o levantamento do músculo grande dorsal (*) e abaixo dele, o músculo longo do tronco (,), em que foi inserido o sensor térmico. 


\subsection{Estudo das variações térmicas}

Foram usados cinco cães mestiços, de ambos os gêneros, pesando, em média, $18 \mathrm{~kg}$ e fornecidos pelo Biotério Geral da Prefeitura do Campus Administrativo de Ribeirão Preto. Nestes animais foram estudadas as mudanças térmicas em plano muscular profundo, produzidas pela aplicação de frio e calor superficial na pele adjacente. Em quatro dos cinco animais utilizados foi realizada a experimentação em apenas um hemicorpo. $\mathrm{O}$ quinto animal foi submetido à experimentação bilateral, havendo um intervalo de 28 dias entre os experimentos que foram independentes.

Para a medida da temperatura intramuscular, foram confeccionados transdutores de temperatura no Laboratório de Bioengenharia da Faculdade de Medicina de Ribeirão Preto, utilizando sensor termopar (PT100), que foi conectado a um termômetro digital modelo IM-01, por meio de fios de cobre esmaltado $\mathrm{n}^{\mathbf{o}} 30$ AWG. Estes foram revestidos com cateteres de silicone usados em derivação ventrículo peritonial (DVP) de $2,5 \mathrm{~mm}$ de calibre com suas extremidades vedadas com silicone (Fig.6). Antes da utilização os componentes a serem implantados foram esterilizados em oxido de etileno.

Foram, também, confeccionados sensores para medida de temperatura retal e da interface, com os mesmos procedimentos básicos, já descritos, porém, revestidos com silicone comum (Fig 6).

A leitura da temperatura foi realizada com termômetro digital modelo IM-01 com entrada PT100, escala de $-70^{\circ} \mathrm{C}$ a $600^{\circ} \mathrm{C}$ da marca CONTEMP, calibrado previamente, com termômetro digital decimal (Fig 6) 


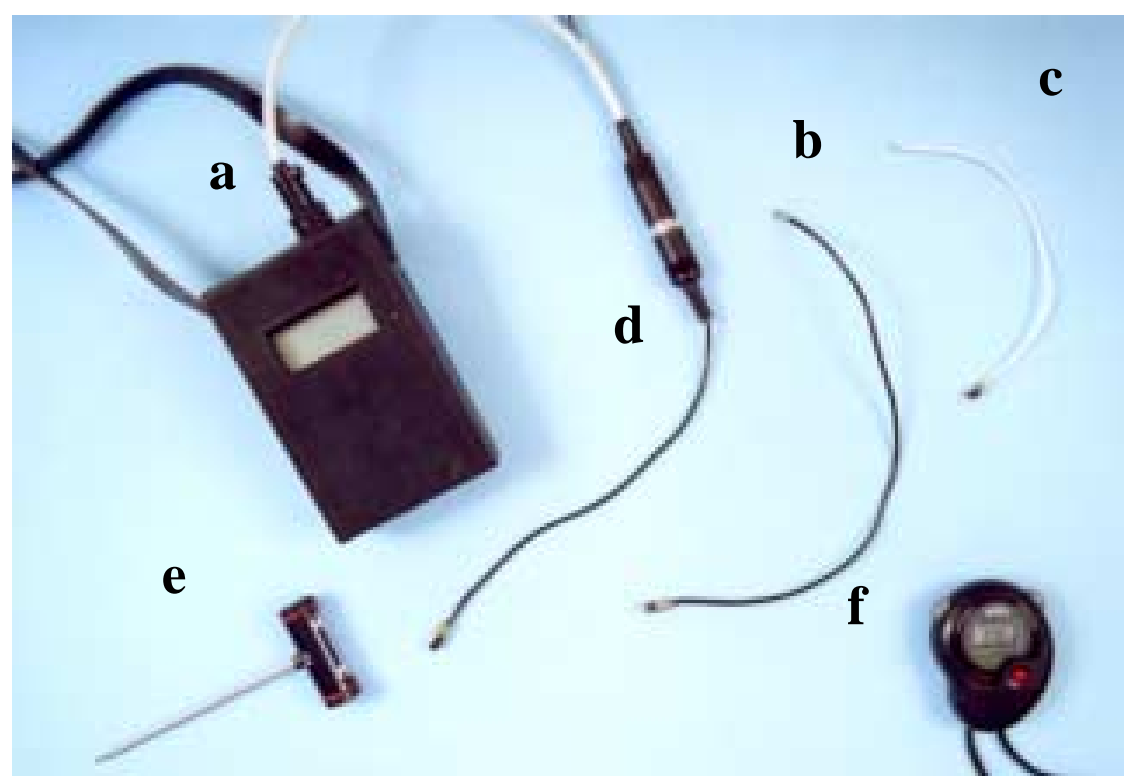

FIGURA 6 - Equipamento usado para a medida da temperatura - a- Termômetro digital modelo IM- 01 da marca CONTEMP, b- sensor interface (preto), c- sensor intramuscular (branco), d- sensor retal, e- termômetro digital tipo martelo, $\mathrm{f}$ - cronômetro.

\subsection{Implantação do sensor em cães}

\subsubsection{Sensor Intramuscular}

O procedimento cirúrgico para a implantação do sensor foi realizado na sala de cirurgia experimental do Laboratório de Bioengenharia da Faculdade de Medicina de Ribeirão Preto da Universidade de São Paulo.

Todos os animais foram anestesiados com tiopental $\left(\mathrm{Nembutal}^{\circledR}\right)$, na dose aproximada de $40 \mathrm{mg} / \mathrm{kg}$ de peso corporal, injetados na veia cubital. Doses 
adicionais do anestésico foram administradas durante o procedimento cirúrgico, quando necessário.

A colocação do sensor foi realizada segundo as técnicas cirúrgicas rotineiras de assepsia e antissepsia e seguiu os principais passos, como mostra a figura 7.

- Tricotomia na região dorsal do tronco.

- Posicionamento do animal em decúbito lateral.

- Limpeza da pele com solução desgermante de polivinil pirrolidona iodo (PVPI) $1 \%$ de iodo ativo.

- Antissepsia com solução álcool-iodada $2 \%$.

- Colocação do campo cirúrgico fenestrado, esterilizado.

- Incisão na pele da região dorsal, distalmente à escápula, sobre a projeção cutânea do corpo muscular do músculo longo do tronco, identificado por palpação, atingindo inicialmente, pele e subcutâneo.

- Aprofundamento da incisão por divulsão romba até identificar a fáscia muscular, que foi exposta em uma área aproximada de $4 \mathrm{~cm}^{2}$.

- Incisão da fáscia muscular e divulsão romba das fibras musculares até o plano ósseo (costelas).

- Medida da profundidade da incisão com provador metálico, tendo o cuidado de tocar a extremidade na costela.

- Nova incisão situada caudalmente à primeira, a uma distância aproximada de $12 \mathrm{~cm}$ e em alinhamento distal com a primeira incisão, que foi aprofundada até o plano da fáscia muscular.

- Comunicação entre as duas incisões por meio da realização de uma divulsão romba entre elas, de modo a criar um túnel subcutâneo. 
- Introdução do sensor através do túnel, iniciando pela incisão distal e saindo pela proximal $(3 \mathrm{~cm})$.

- Implantação do sensor em profundidade na primeira incisão até que fosse atingido o plano muscular profundo.

- A outra extremidade do sensor (cateter) permaneceu na superfície externa, saindo pela incisão distal.

- Fixação do cateter com fío cirúrgico de algodão 2-0, junto da incisão.

- Revisão da hemostasia.

- Fechamento das incisões cutâneas com pontos simples e fio cirúrgico de náilon 3-0.

- Curativo oclusivo de modo a manter exposta em torno de $3 \mathrm{~cm}$ de extremidade do sensor para conexão com o termômetro.

- Realização da primeira medida de prova.

- Administração intramuscular de benzil penicilina (600.000 unidades).

O animal recuperou-se da anestesia em compartimento individual, onde foi, depois, mantido sem restrição de ração e água.

A região da incisão do sensor foi protegida com uma cinta de couro, e colocado um colar elizabetiano para impedir que o animal alcançasse a região operada com as patas ou focinho.

O curativo foi retirado no dia seguinte. Depois disto, não houve a preocupação em realizar outros curativos sendo, apenas, a região mantida em condições higiênicas. 


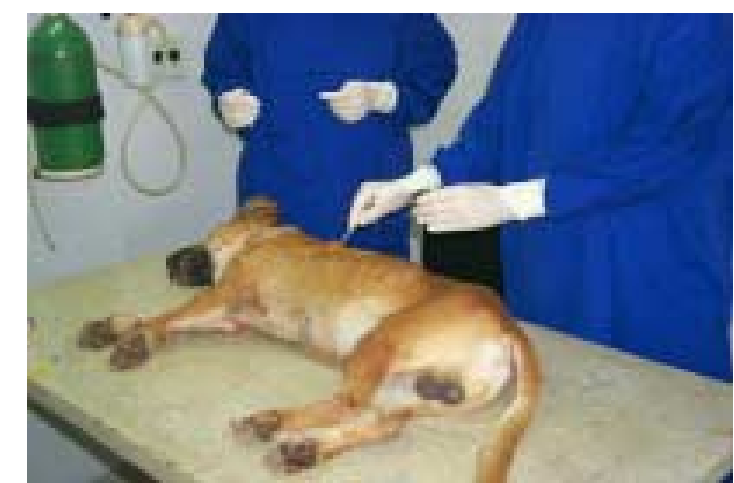

(A)

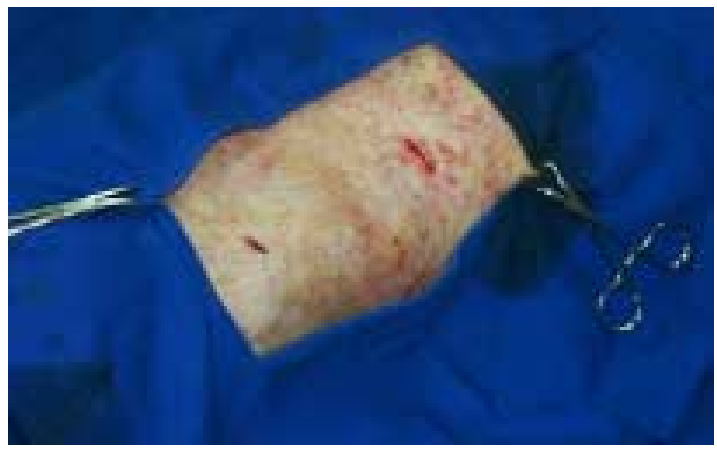

(C)

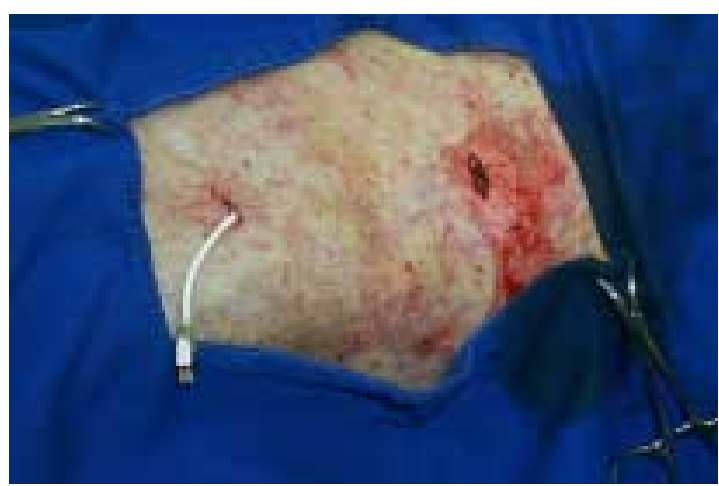

(E)

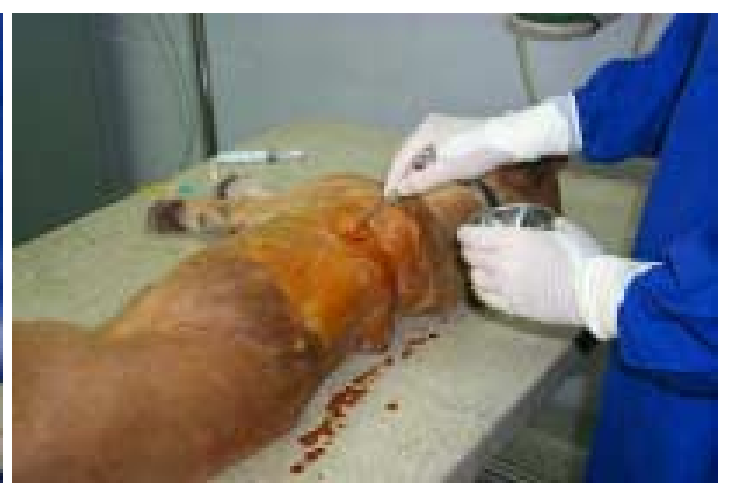

(B)

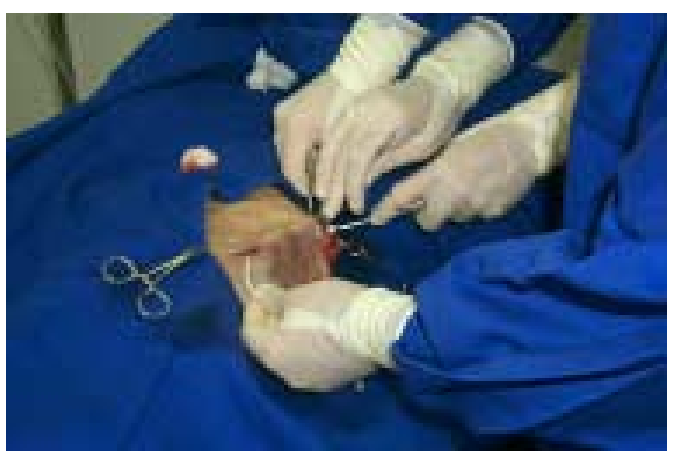

(D)

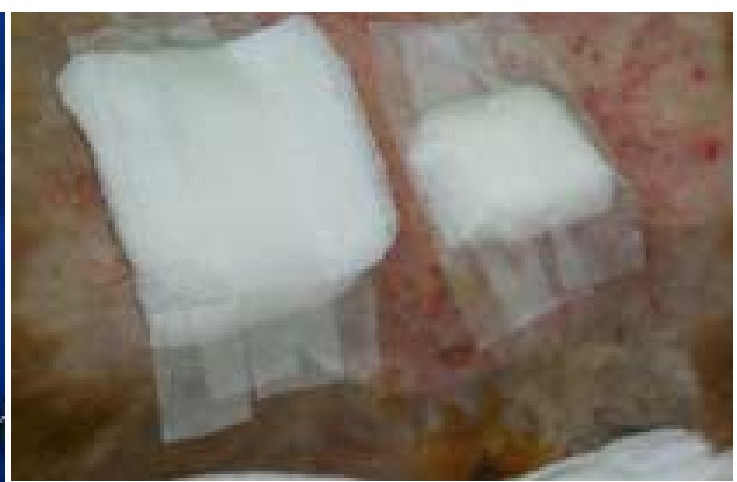

(F)

FIGURA 7 - Cirurgia no cão para colocação do sensor térmico. (A) Limpeza com solução desgermante PVPI 1\% de iodo ativo. (B) Antissepsia com solução álcool-iodada 2\%. (C) Incisão maior na pele e sobre a projeção do corpo muscular do longo do tronco; incisão menor a uma distância de $12 \mathrm{~cm}$ da maior. (D) Passagem do sensor pelo túnel iniciado pela menor incisão. (E) Introdução do sensor no músculo longo do tronco. (F) Curativo oclusivo das incisões. 


\subsubsection{Sensor da interface}

Este sensor foi fixado temporariamente com esparadrapo na pele, tendo como referência a região de sutura do sensor intramuscular.

O objetivo deste sensor foi avaliar a temperatura na interface da fonte fria ou quente com a pele, durante a aplicação.

\subsection{Medida de temperatura retal}

Antes de cada aplicação de frio ou calor, foi feita a medida da temperatura retal, utilizando um termômetro digital. Esta temperatura foi medida 27 vezes e a média foi $38,85^{\circ} \mathrm{C}$, que representou a temperatura corporal durante esse período.

\subsection{Aplicação de frio}

Para aplicação do frio ou calor, os cães foram mantidos no mesmo posicionamento, porém, os animais ficaram contidos com uma focinheira, durante as medidas de temperatura retais. 
No primeiro dia após a cirurgia, foi iniciada a aplicação de frio, por três dias consecutivos, no mesmo período do dia.

A área a ser resfriada foi delimitada por um cinto de couro que continha uma abertura circular, medindo $78,5 \mathrm{~cm}^{2}$, centrada sobre a incisão cirúrgica que recebeu o sensor. Sobre a pele, neste mesmo local, foi colocado um sensor de temperatura que foi fixado por esparadrapo. (Figura 8).

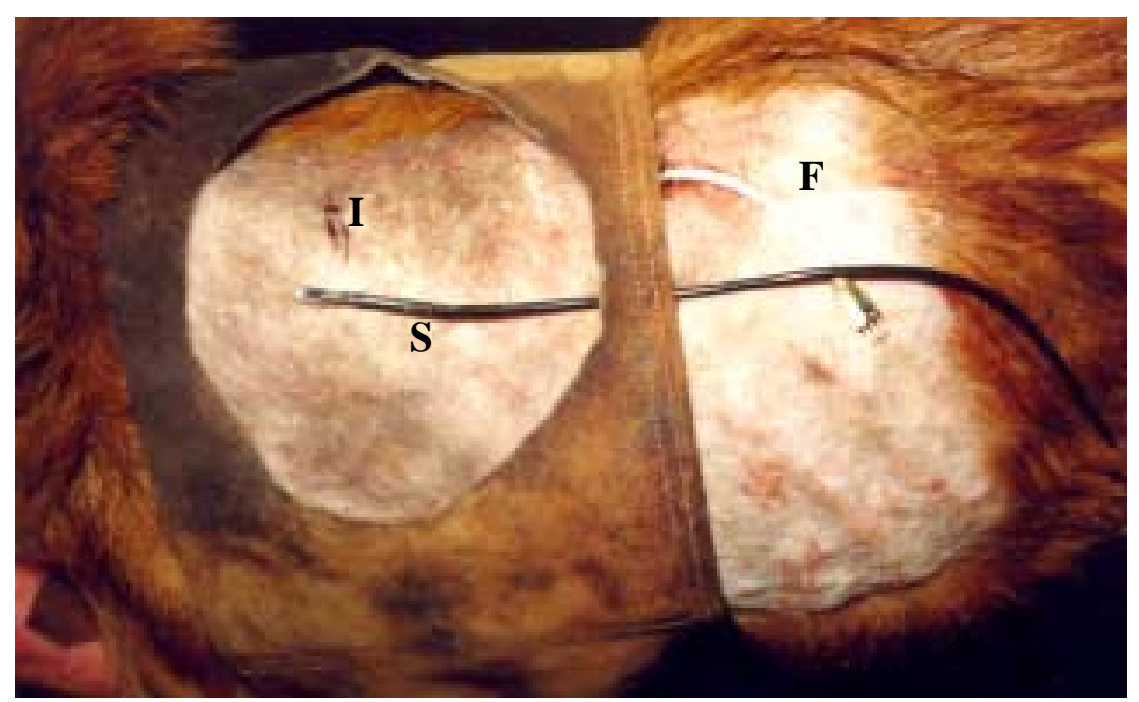

FIGURA 8 - Delimitação da área a ser resfriada com cinto de couro. Observa-se a incisão transversal usada para a implantação intramuscular do sensor (I), o fio de conexão saindo pela segunda incisão e fora da área da aplicação térmica $(F)$ e o sensor da interface colocado na região a receber o tratamento térmico $(\mathrm{S})$.

A fonte de frio foi constituída de gelo de água destilada (1 litro) triturado e colocado em um saco plástico BING (1945), medindo $35 \mathrm{~cm}$ por $20 \mathrm{~cm}$, aproximadamente com $1 \frac{1}{2} 2$ litro de capacidade, e que foi colocado sobre a região delimitada pelo círculo de couro e fixada com auxílio de ataduras (Figuras 9 e 10).

O tempo de aplicação do frio foi de 30 minutos MEEUSEN (1986). 


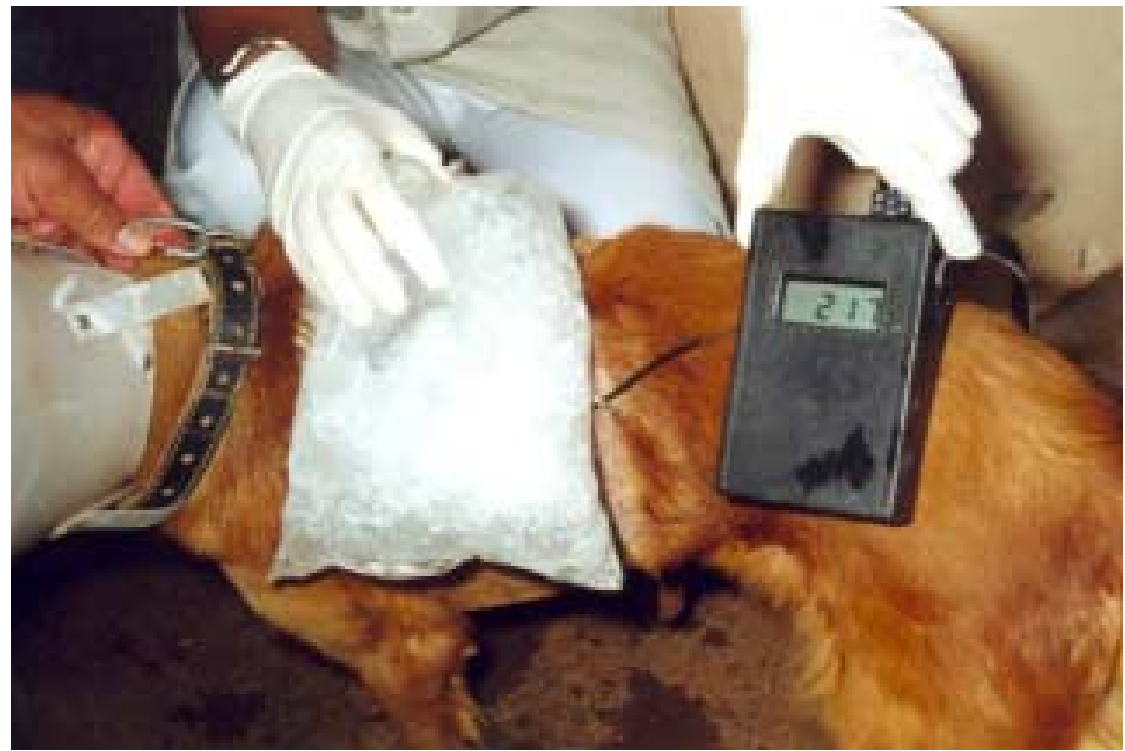

FIGURA 9 - Colocação da "bolsa" de gelo e medida da temperatura na interface bolsa de gelo-pele

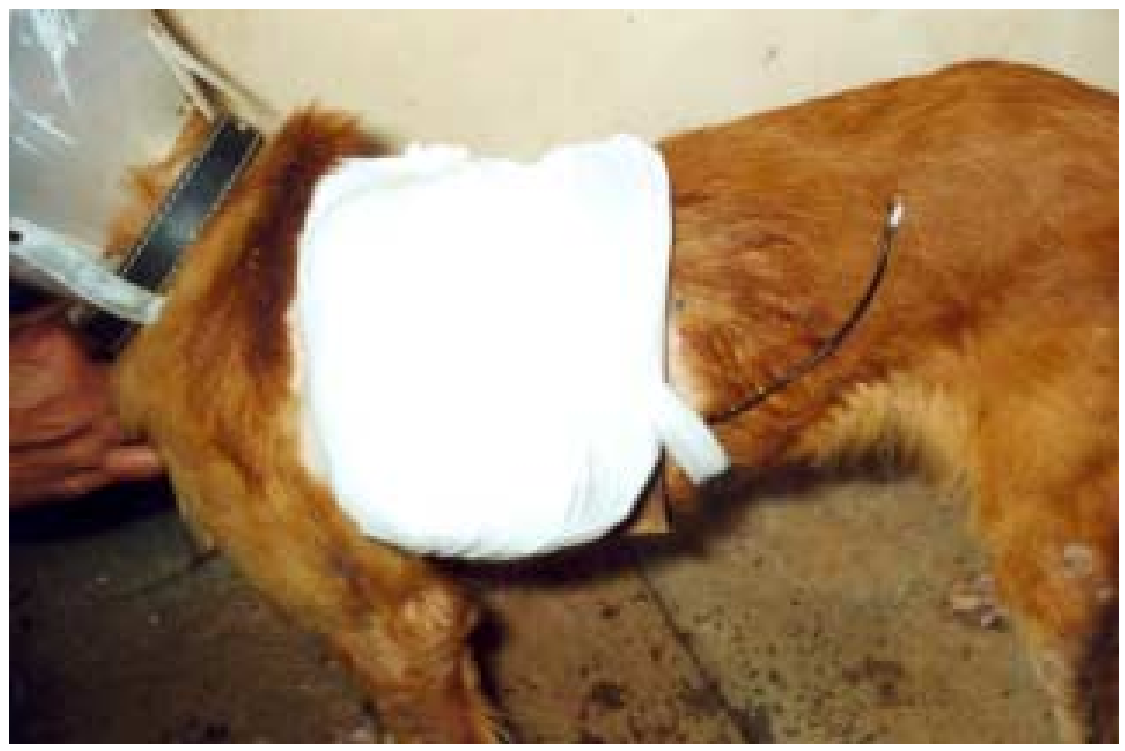

FIGURA 10 - Bolsa de gelo fixada com atadura no tronco do animal. 


\subsubsection{Registro de temperatura}

Foi realizada a leitura de temperatura no sensor térmico intramuscular e da interface antes da colocação de frio (temperatura inicial).

A aplicação de gelo foi mantida por 30 minutos e, durante este período, a temperatura foi aferida em intervalos de 5 minutos, em ambos os sensores.

Aos 30 minutos, a bolsa de gelo foi retirada, sendo mantidas as aferições a cada 5 minutos, até ser obtida a temperatura inicial nos dois sensores (30 minutos).

\subsection{Aplicação de calor superficial}

Foram seguidos os procedimentos de posicionamento do animal, leitura de temperatura dos sensores e da delimitação da área de aplicação, já descritos. A aplicação de calor superficial teve início no quarto dia pós-operatório.

Para aplicação de calor, foi utilizada uma bolsa de gel, de formato retangular, de $23 \mathrm{~cm}$ de comprimento por $14 \mathrm{~cm}$ de largura, com $400 \mathrm{~g}$ de peso aproximado, a uma temperatura aproximada de $55^{\circ} \mathrm{C}$ (Figura 11). O aquecimento dessa bolsa foi obtido imergindo-a em água em ebulição por 10 minutos, aferida com termômetro digital após a retirada da água quente e fixado à bolsa por ataduras. 


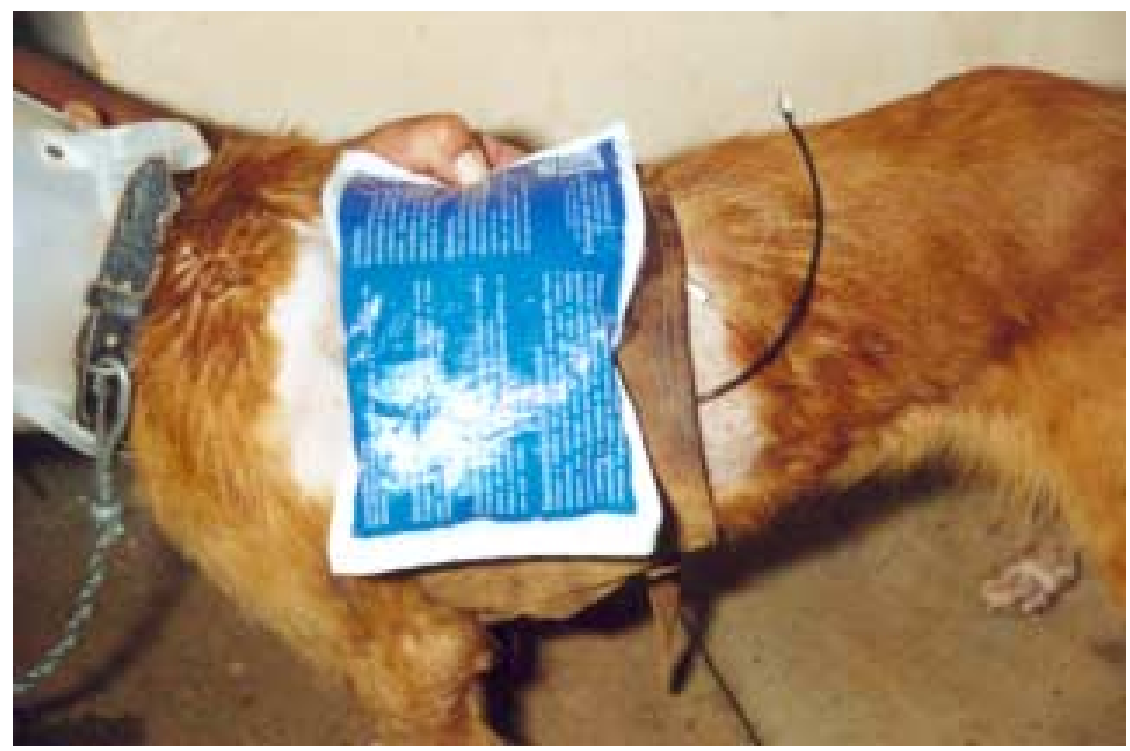

FIGURA 11 - Colocação da bolsa de gel aquecida na região de estudo.

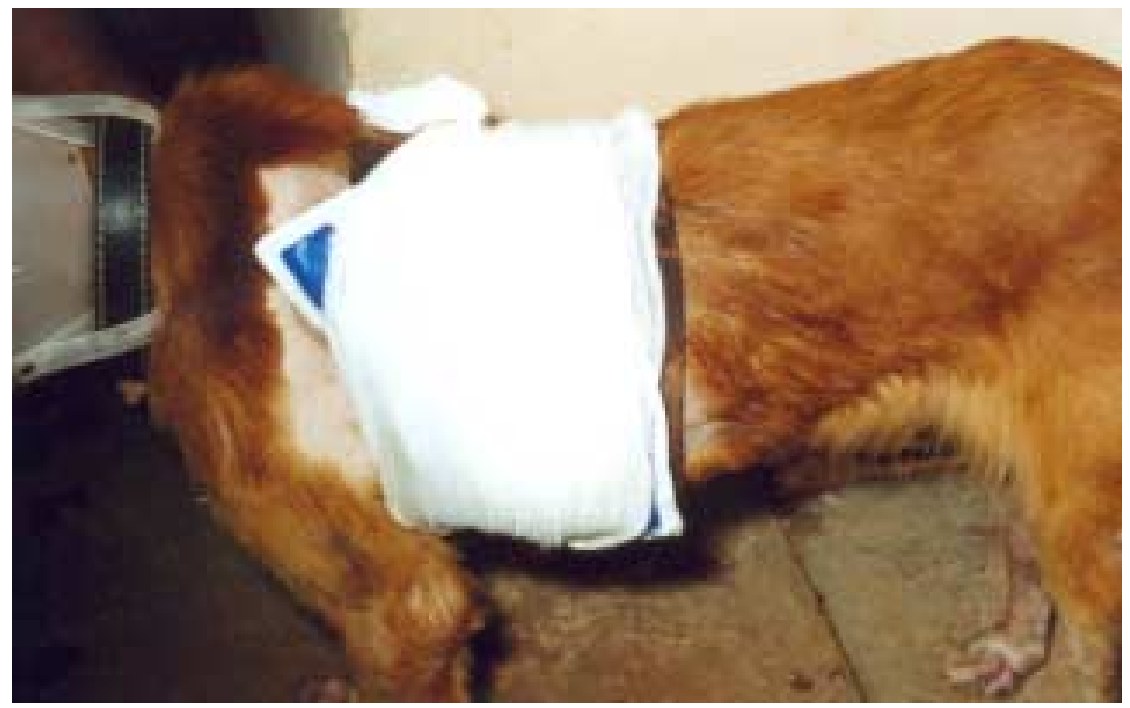

FIGURA 12 - Bolsa de gel aquecida fixada com atadura.

A bolsa quente foi acoplada ao tronco do animal com auxílio de ataduras. A aplicação de calor foi mantida por 20 minutos, e durante esse período, foram medidas as temperaturas dos sensores intramuscular e interface, em intervalos de 5 minutos Fig (12). Após esse intervalo, a bolsa aquecida foi retirada e as medidas de temperaturas tiveram seqüências em 20 minutos, no mesmo intervalo. Esse tempo foi suficiente para o retorno à temperatura inicial. 
Após cada sessão o animal retornava ao canil.

A sequiência experimental está representada na figura 13, onde cada experimento foi realizado no prazo de sete dias.

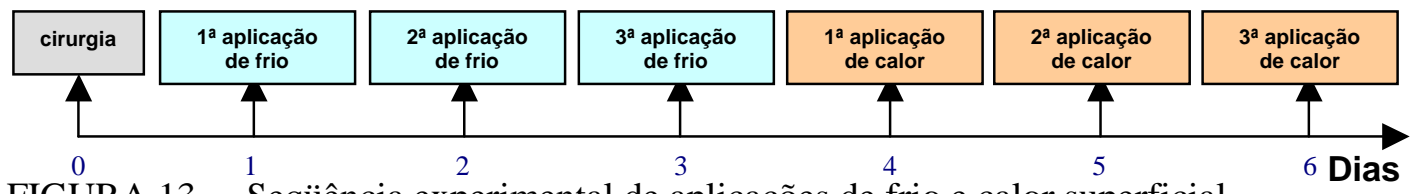

FIGURA 13 - Seqüência experimental de aplicações de frio e calor superficial.

Os experimentos foram realizados conforme mostra o (QUADRO 2)

utilizando cinco animais, realizando uma cirurgia no hemicorpo esquerdo em quatro animais. E no $5^{\circ}$ animal realizamos o procedimento bilateral.

QUADRO 2 - Número de animais e aplicações de frio e calor

\begin{tabular}{|cccc|}
\hline Animal & Hemicorpo & $\begin{array}{c}\text { Número de } \\
\text { aplicações }\end{array}$ & Aplicação \\
\hline 01 & Esquerdo & 1 & Frio \\
\hline 02 & Esquerdo & 3 & Frio \\
\hline \multirow{2}{*}{03} & Esquerdo & 3 & Frio \\
& \multirow{2}{*}{04} & 3 & Calor \\
\hline \multirow{2}{*}{05} & Esquerdo & 3 & Frio \\
& \multirow{2}{*}{ Direito } & 3 & Calor \\
\hline \multirow{2}{*}{05} & \multirow{2}{*}{ Esquerdo } & 3 & Frio \\
& & 2 & Calor \\
\hline
\end{tabular}




\subsection{Análise dos Dados}

Com os valores obtidos de temperatura e tempo na aplicação de frio e calor, foram confeccionados gráficos (variação de temperatura versus tempo), utilizando o programa de computação EXCEL ${ }^{\circledR}$.

Os dados foram analisados descritivamente, observando a variação da temperatura durante e após a aplicação do frio e do calor para os sensores intramuscular e da interface.

\subsubsection{Aplicação de Frio}

Nos gráficos foram estabelecidos parâmetros para analisar a variação da temperatura na interface bolsa-pele e no músculo.

A figura 14 ilustra o formato geral da variação térmica durante e após a aplicação do frio.

Inicialmente, há queda rápida da temperatura e, depois, mais lenta. Com a suspensão da aplicação do frio, há, novamente, elevação térmica.

Nesta curva básica foram selecionados os seguintes parâmetros:

$\mathrm{T} 1=$ temperatura inicial, antes da aplicação do frio

$\mathrm{A}=$ ponto que marca o final da queda rápida de temperatura e início da fase de queda mais lenta 
$\mathrm{B}=$ ponto de início da elevação térmica após a retirada do frio

$\mathrm{C}=$ temperatura no ponto "A" (pico inicial de temperatura)

$\mathrm{E}=$ tempo no ponto 'A" (pico inicial de tempo)

$\mathrm{D}=$ temperatura no ponto " $\mathrm{B}$ " (pico final de temperatura e temperatura mínima)

$\mathrm{F}=$ tempo gasto para atingir ponto "B" (pico final de tempo)

A relação destes parâmetros nos permitiu obter:

$\Delta \mathrm{T}=(\mathrm{D}-\mathrm{C})=$ variação de temperatura durante a aplicação de frio

$\Delta \mathrm{t}=(\mathrm{F}-\mathrm{E})=$ variação de tempo durante a aplicação de frio

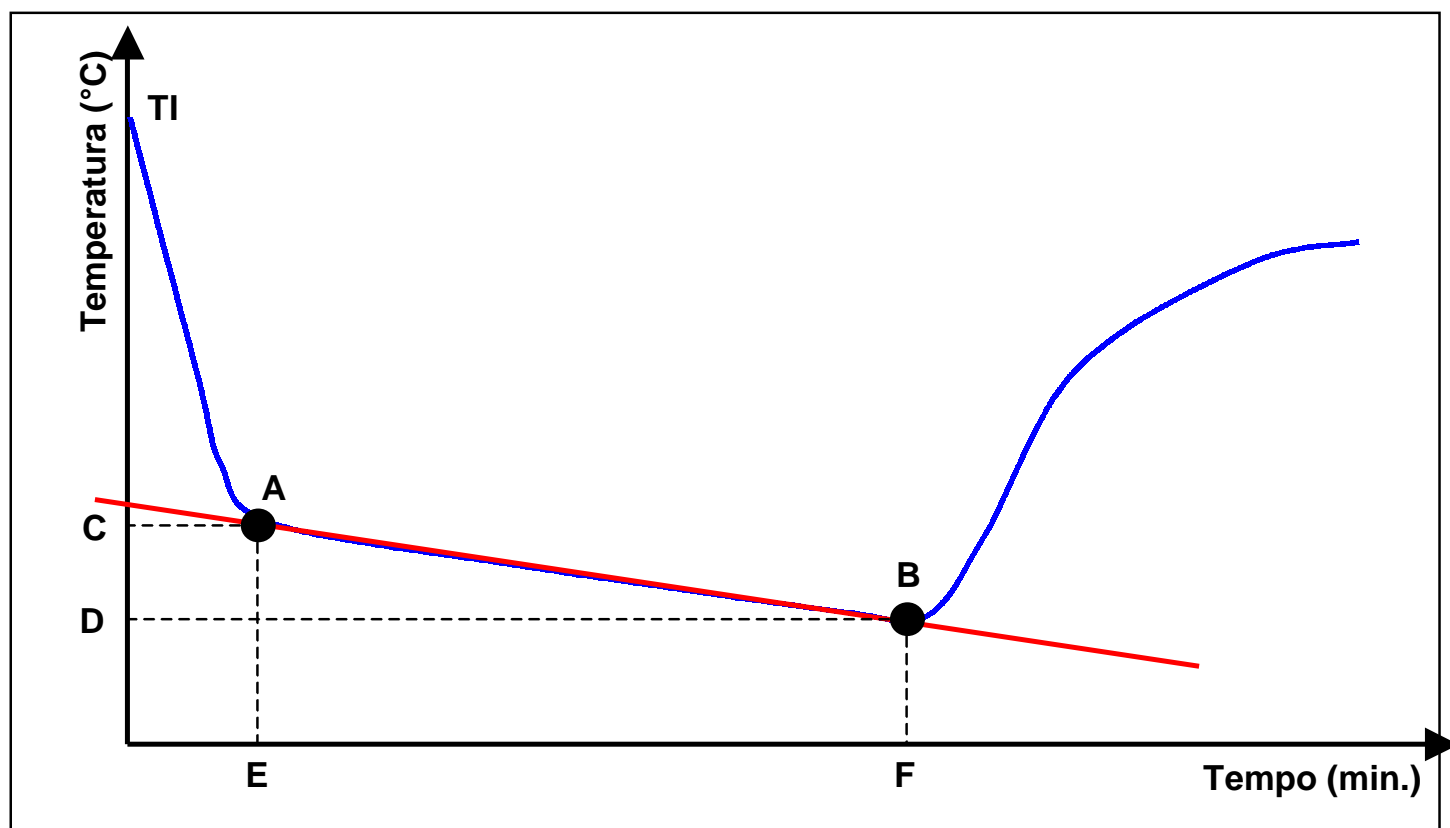

FIGURA 14 - Gráfico ilustrativo da variação térmica medida na pele ou no músculo com a aplicação de frio. TI - temperatura inicial, antes da aplicação do frio; A- ponto que marca o final da queda rápida de temperatura e início da fase de queda mais lenta; B- ponto de início elevação térmica, após a retirada do frio; C- temperatura no ponto "A", E- tempo no ponto "A", D- temperatura no ponto "B", F- tempo no ponto "B". 


\subsubsection{Aplicação de Calor Superficial}

$\mathrm{Na}$ aplicação de calor construímos uma curva temperatura $x$ tempo para analisar suas variações.

A figura 15 ilustra o formato geral da variação térmica durante e após a aplicação de calor superficial.

Inicialmente, há aumento rápido da temperatura e, depois, mais lento. Com a retirada do calor, há, novamente, queda da temperatura.

Nesta curva básica foram selecionados os seguintes parâmetros:

$\mathrm{T} 1=$ temperatura inicial, antes da aplicação do calor superficial

$\mathrm{A}=$ ponto que marca $\mathrm{o}$ final da elevação rápida de temperatura e início da fase de elevação mais lenta

$\mathrm{B}=$ ponto de início da queda da temperatura após a retirada do calor

$\mathrm{D}=$ temperatura no ponto " $\mathrm{A}$ " (pico inicial de temperatura)

$\mathrm{E}=$ tempo no ponto "A" (pico inicial de tempo)

$\mathrm{C}=$ temperatura no ponto "B" (pico final de temperatura e temperatura máxima)

$\mathrm{F}=$ tempo gasto para atingir o ponto "B" (pico final de tempo)

A relação destes parâmetros nos permitiu obter:

$\Delta \mathrm{T}=(\mathrm{C}-\mathrm{D})=$ variação de temperatura durante a aplicação de frio

$\Delta \mathrm{t}=(\mathrm{F}-\mathrm{E})=$ variação de tempo durante a aplicação de frio. 


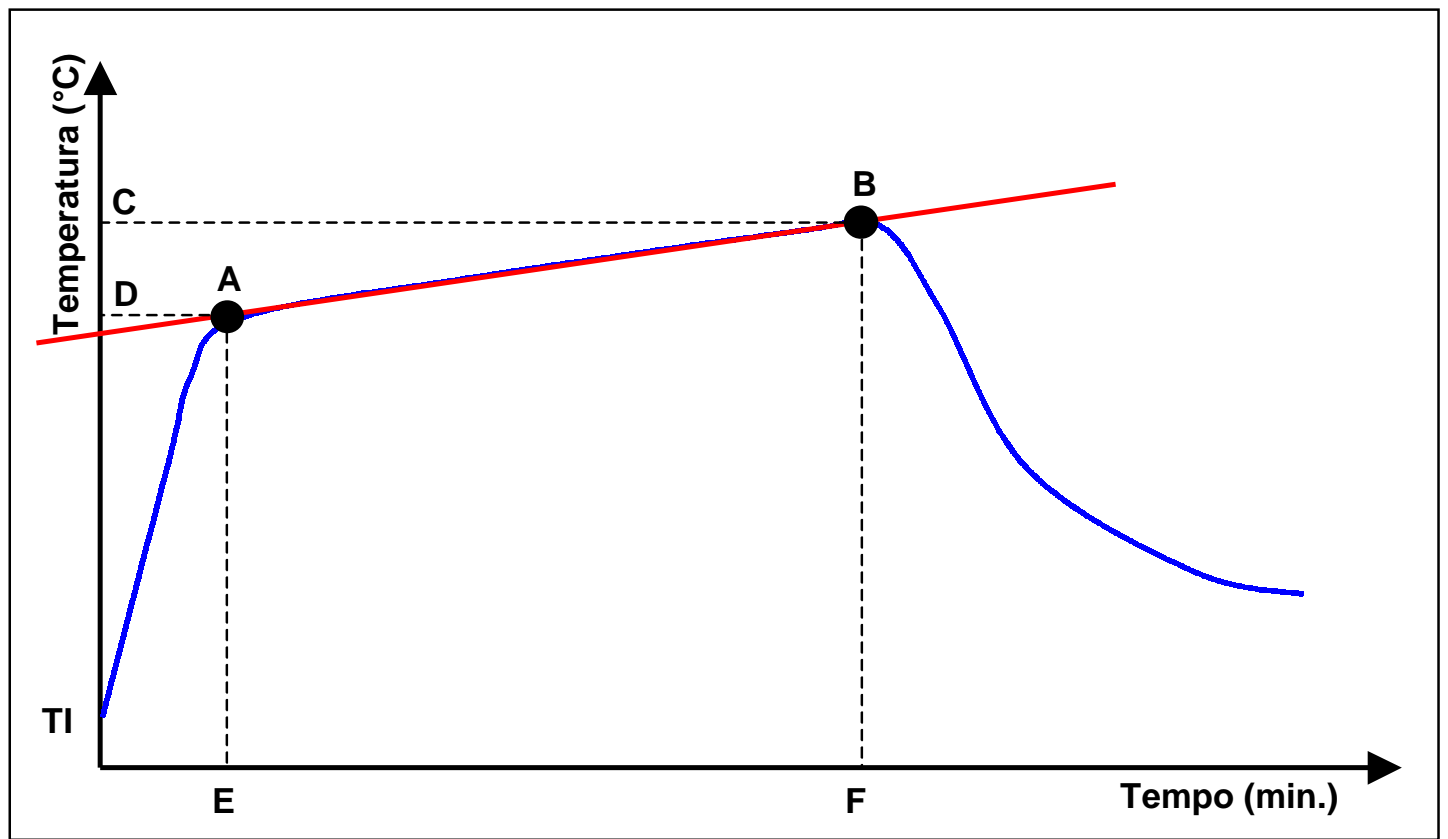

FIGURA 15 - Gráfico ilustrativo da variação térmica medida na pele ou no músculo com a aplicação do calor superficial. TI - temperatura inicial, antes da aplicação de calor superficial; A- ponto que marca o final da elevação rápida de temperatura e início da fase de elevação mais lenta; B- ponto de início da queda térmica após a retirada co calor superficial; C- temperatura no ponto "B"; D- temperatura no ponto "A"; E- tempo no ponto "A"; F- tempo no ponto "B". 


\title{
3 RESULTADOS
}

\begin{abstract}
Foram utilizados cinco cães, sendo quatro submetidos ao procedimento cirúrgico no hemicorpo esquerdo, e um animal bilateralmente, em períodos diferentes, como já descritos.
\end{abstract}

\subsection{Aplicação de Frio Cutâneo}

\subsubsection{Variação da temperatura na interface bolsa-pele}

O sensor fixado na interface, durante a aplicação do frio, mostrou, graficamente uma curva descendente com rápido declive e leves oscilações conforme padrão descrito anteriormente (Figura 16). A média da temperatura inicial foi $31,84^{\circ} \mathrm{C}(\mathrm{dp}=3,58)$ e mediana $33,30^{\circ} \mathrm{C}$. A variação da temperatura mínima foi $23,23^{\circ} \mathrm{C}(\mathrm{dp}=4,52)$ e mediana $24,19^{\circ} \mathrm{C}$. A temperatura mínima média foi $9,43^{\circ} \mathrm{C}$ $(\mathrm{dp}=3,42)$ e mediana $10,30^{\circ} \mathrm{C}$. A média de pico inicial de temperatura foi $14,39^{\circ} \mathrm{C}$ $(d p=3,33)$ e mediana $15,16^{\circ} \mathrm{C}$. A temperatura de pico final apresentou média de 
$10,55^{\circ} \mathrm{C}(\mathrm{dp}=2,53)$ e mediana $10,65^{\circ} \mathrm{C}$. A variação entre os picos iniciais e finais de temperatura apresentou média $4,45^{\circ} \mathrm{C}(\mathrm{dp}=2,12)$ e mediana $4,83^{\circ} \mathrm{C}$ (Tabela $1 \mathrm{e}$ Figura 17).

\section{Variação da temperatura na interface bolsa-pele, com aplicação de frio na região} cutânea

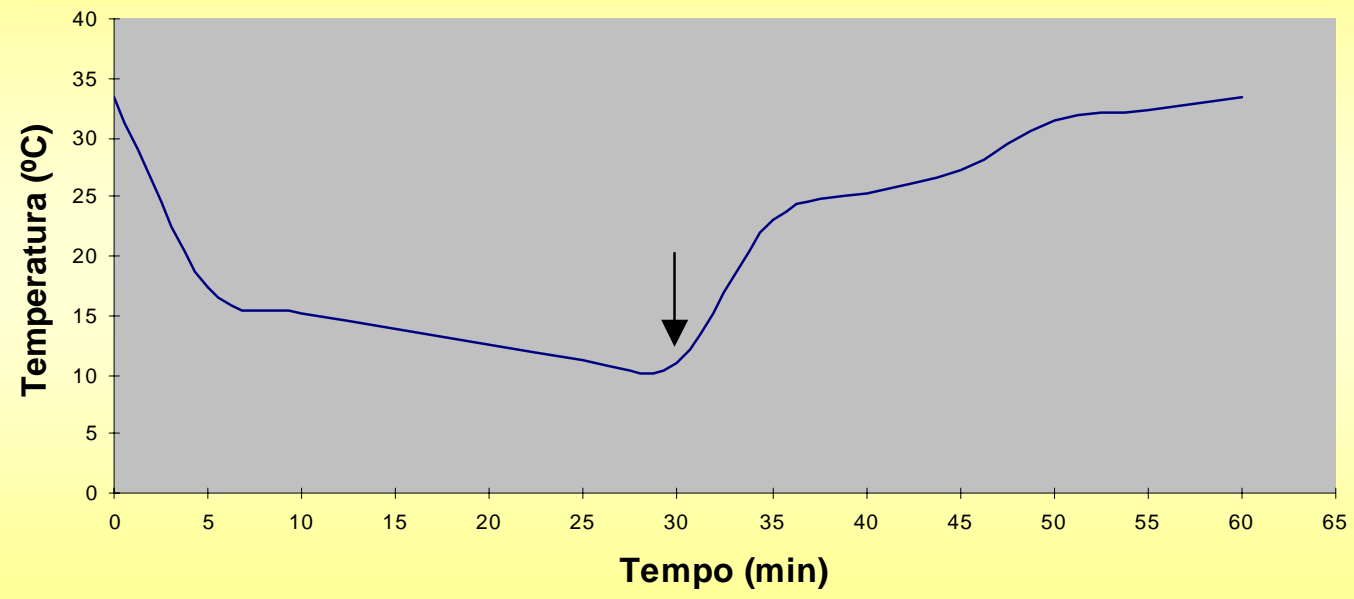

FIGURA 16 - Variação da temperatura na interface bolsa-pele com aplicação de frio durante 30 minutos e, depois, retirada (seta).

TABELA 1 - Parâmetros de variação da temperatura na interface bolsa-pele com aplicação de frio durante $30 \mathrm{~min}$.

\begin{tabular}{crc}
\hline TEMPERATURA $^{\circ} \mathrm{C}$ & MÉDIA (dp) & MEDIANA \\
\hline Inicial & $31,84(3,58)$ & 33,30 \\
Mínima & $9,43(3,42)$ & 10,30 \\
Variação & $23,23(4,52)$ & 24,19 \\
Pico inicial & $14,39(3,33)$ & 15,16 \\
Pico final & $10,55(2,53)$ & 10,65 \\
Variação entre picos & $-3,84(2,12)$ & $-4,51$ \\
\hline
\end{tabular}




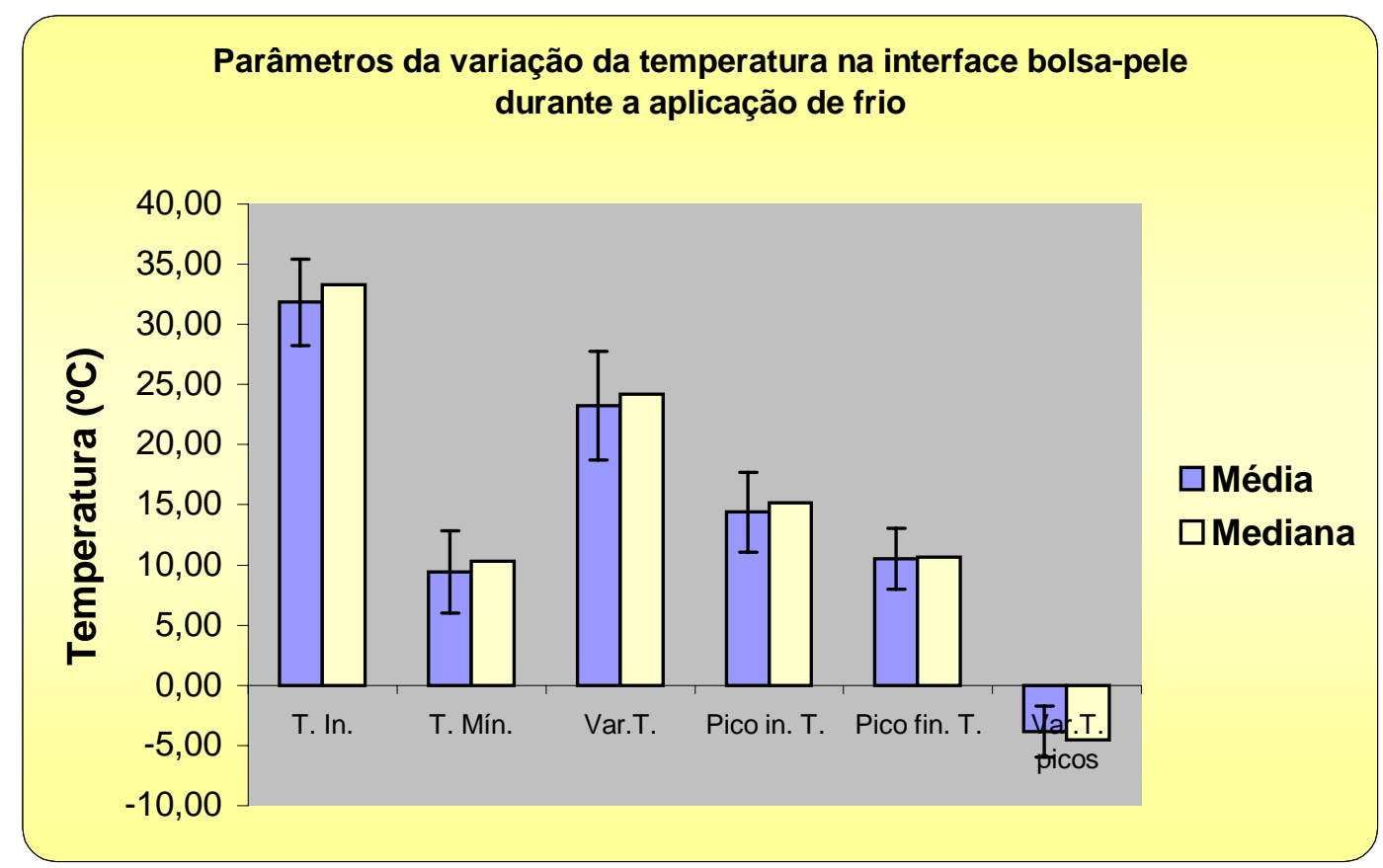

FIGURA 17 - Parâmetros da variação da temperatura na interface bolsa-pele durante a aplicação de frio.

O tempo médio para atingir a temperatura mínima foi de 24 min e $43 \mathrm{~s}$ (dp = 7 min e 46 s), mediana 28 min e 37 s. A média de tempo para o pico inicial 8 min e $01 \mathrm{~s}(\mathrm{dp}=3 \mathrm{~m} \mathrm{e} 17 \mathrm{~s})$, mediana 6 min e $44 \mathrm{~s}$. O tempo de pico final teve média de 28 min e $56 \mathrm{~s}(\mathrm{dp}=1$ min e $42 \mathrm{~s})$, mediana 28 min e $47 \mathrm{~s}$. A variação do tempo de entre os picos apresentou média $20 \min$ e $55 \mathrm{~s}(\mathrm{dp}=2 \min$ e $46 \mathrm{~s})$, mediana 21 min e $21 \mathrm{~s}$. A curva muda bruscamente sua inclinação após retirada do frio, tomando sentido ascendente (Tabela 2 e Figura 18).

TABELA 2 - Parâmetros de variação de tempo na interface bolsa-pele na aplicação de frio

\begin{tabular}{ccc}
\hline TEMPO (MIN) & MÉDIA (dp) & MEDIANA \\
\hline $\begin{array}{c}\text { Tempo para atingir } \\
\text { temperatura mínima }\end{array}$ & $0: 24: 43(0: 07: 46)$ & $0: 28: 37$ \\
Pico inicial & $0: 08: 01(0: 03: 17)$ & $0: 06: 44$ \\
Pico final & $0: 28: 56(0: 01: 42)$ & $0: 28: 47$ \\
Variação entre picos & $0: 20: 55(0: 02: 46)$ & $0: 21: 21$ \\
\hline
\end{tabular}




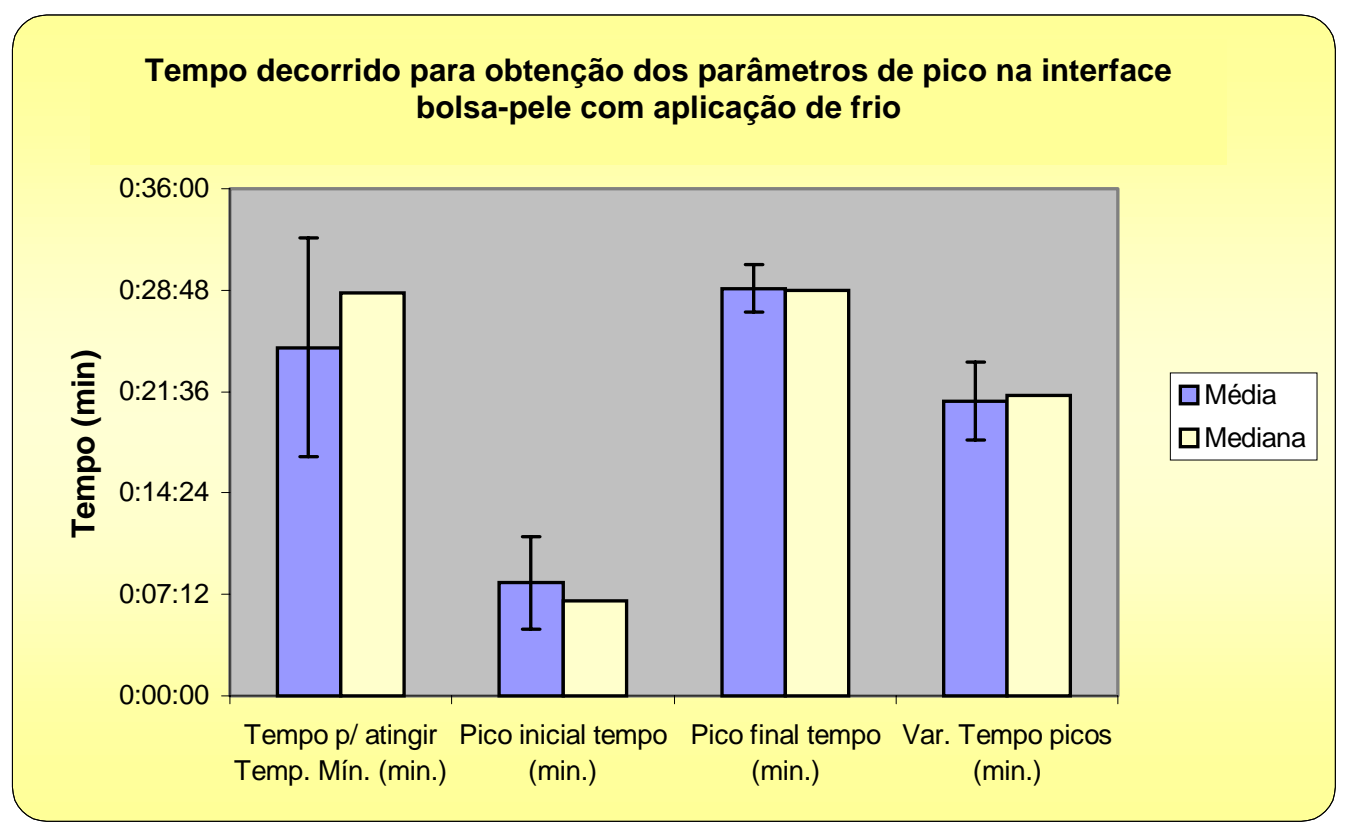

FIGURA 18 - Tempo decorrido para obtenção dos parâmetros de pico na interface bolsapele com aplicação de frio.

\subsubsection{Variação da temperatura na região muscular}

Durante aplicação de frio houve queda de temperatura na região muscular, graficamente representada por uma curva descendente com declínio lento e contínuo (Figura 19). A média da temperatura inicial foi $39,03^{\circ} \mathrm{C}(\mathrm{dp}=0,71)$ e mediana $39,15^{\circ} \mathrm{C}$. A média de temperatura retal foi $38,85^{\circ} \mathrm{C}(\mathrm{dp}=3,69)$. A média de variação de temperatura foi $4,30^{\circ} \mathrm{C}(\mathrm{dp}=1,30)$ e mediana $3,79^{\circ} \mathrm{C}$. A temperatura mínima média foi $34,73^{\circ} \mathrm{C}(\mathrm{dp}=1,57)$ e mediana $35,21^{\circ} \mathrm{C}$. A média de pico temperatura inicial $35,92^{\circ} \mathrm{C}(\mathrm{dp}=1,14)$ e mediana $35,76^{\circ} \mathrm{C}$. A temperatura de pico final apresentou média de $35,01^{\circ} \mathrm{C}(\mathrm{dp}=1,67)$ e mediana $35,56^{\circ} \mathrm{C}$. A variação da 
temperatura apresentou média $0,91^{\circ} \mathrm{C}(\mathrm{dp}=1,13)$ e mediana $1,36^{\circ} \mathrm{C}$ (Tabela $3 \mathrm{e}$ Figura 20).

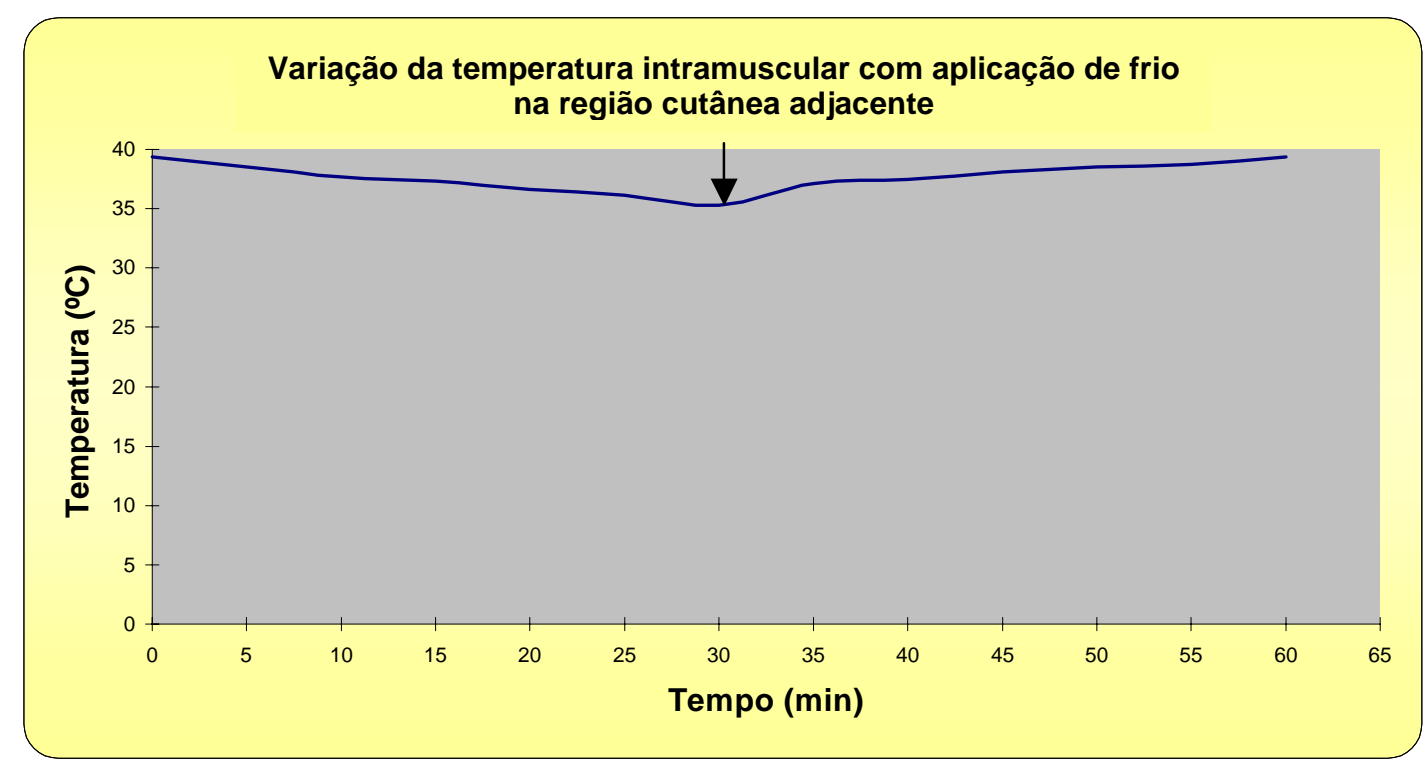

FIGURA 19- Variação da temperatura intramuscular com aplicação de frio durante 30 min e, depois, retirada (seta).

TABELA 3 - Parâmetros de variação da temperatura intramuscular durante a aplicação de frio na região cutânea.

\begin{tabular}{ccc}
\hline TEMPERATURA $^{\circ} \mathrm{C}$ & MÉDIA (dp) & MEDIANA \\
\hline Inicial & $39,03(0,71)$ & 39,15 \\
Mínima & $34,73(1,57)$ & 35,21 \\
Variação & $4,30(1,30)$ & 3,79 \\
Pico inicial & $35,92(1,14)$ & 35,76 \\
Pico final & $35,01(1,67)$ & 35,56 \\
Variação entre picos & $-0,91(1,13)$ & $-1,36$ \\
\hline
\end{tabular}




\section{Parâmetros da variação de temperatura intramuscular durante a aplicação de frio na região cutânea adajcente}

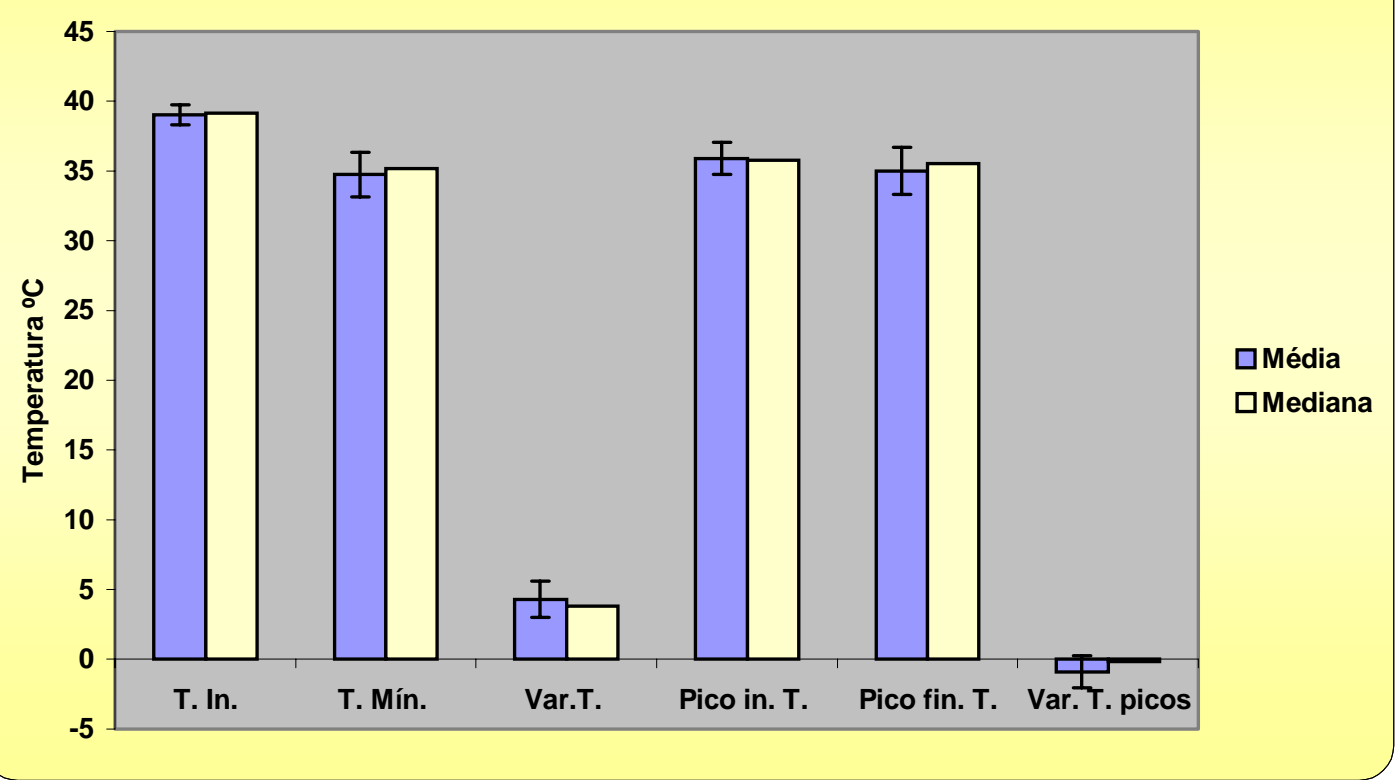

FIGURA 20 - Parâmetros da variação de temperatura intramuscular durante a aplicação de frio na região cutânea.

O tempo médio para atingir a temperatura mínima foi de 27 min e $12 \mathrm{~s}(\mathrm{dp}=$ 4 min $41 \mathrm{seg}$ ) e mediana 28 min e $47 \mathrm{~s}$. A média de tempo de pico inicial 13 min e 43 $\mathrm{s}(\mathrm{dp}=5 \mathrm{~min}$ e $11 \mathrm{~s})$ e mediana 14 min e $12 \mathrm{~s} . \mathrm{O}$ tempo de pico final apresentou média $30 \min$ e $56 \mathrm{~s}(\mathrm{dp}=3 \min$ e $53 \mathrm{~s})$ e mediana $29 \min$ e $25 \mathrm{~s}$. A variação do tempo, entre os picos iniciais e finais, apresentou média $17 \min$ e $18 \mathrm{~s}(\mathrm{dp}=4 \min$ e $51 \mathrm{~s})$ e mediana 17 min e 33 s (Tabela 4 e Figura 21).

Ocorreu inclinação ascendente da curva, após a retirada do frio. A região intramuscular levou em média 26 min e a interface 25 min para retornarem à temperatura inicial . 
TABELA 4 - Parâmetros da variação de tempo na região intramuscular durante a aplicação de frio na região cutânea.

\begin{tabular}{ccc}
\hline TEMPO (MIN) & MÉDIA (dp) & MEDIANA \\
\hline $\begin{array}{c}\text { Tempo para atingir } \\
\text { temperatura mínima }\end{array}$ & $0: 27: 12(0: 04: 41)$ & $0: 28: 47$ \\
Pico inicial & $0: 13: 43(0: 05: 11)$ & $0: 14: 12$ \\
Pico final & $0: 30: 56(0: 03: 53)$ & $0: 29: 25$ \\
& $0: 17: 18(0: 04: 51)$ & $0: 17: 33$ \\
\hline
\end{tabular}

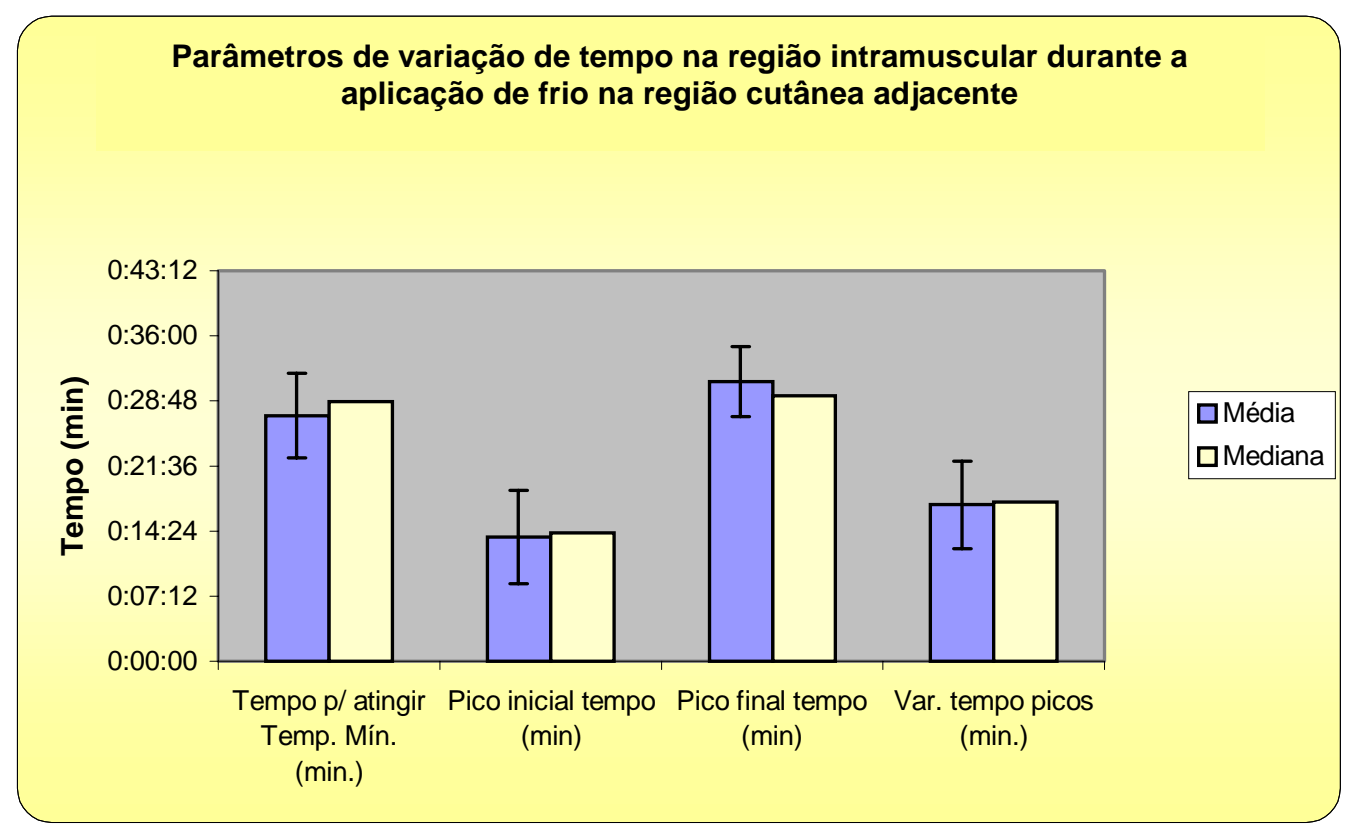

FIGURA 21 - Tempo decorrido para obtenção dos parâmetros de pico na região intramuscular com aplicação de frio na região cutânea. 


\subsection{Aplicação de Calor Superficial}

\subsubsection{Variação da temperatura na interface bolsa-pele}

O sensor fixado na interface, durante aplicação de calor, registrou uma mudança rápida de temperatura, demonstrada graficamente por uma curva ascendente (Figura 22). A média de temperatura inicial foi $32,09^{\circ} \mathrm{C}(\mathrm{dp}=2,61) \mathrm{e}$ mediana $33^{\circ} \mathrm{C}$. A média de variação de temperatura foi $8,83^{\circ} \mathrm{C}(\mathrm{dp}=2,62)$ e mediana $8,90^{\circ} \mathrm{C}$. A temperatura máxima média foi $40,92^{\circ} \mathrm{C}(\mathrm{dp}=1,06)$ e mediana $40,43^{\circ} \mathrm{C}$.

A média de pico de temperatura inicial foi $41,10^{\circ} \mathrm{C}(\mathrm{dp}=1,75)$ e mediana 40,43ํำ $\mathrm{C}$ A temperatura de pico final apresentou média $39,84^{\circ} \mathrm{C}(\mathrm{dp}=1,77)$ e mediana $40^{\circ} \mathrm{C}$. A variação entre os picos iniciais e finais da temperatura teve média $-1,26^{\circ} \mathrm{C}(\mathrm{dp}=1,89)$ e mediana $-0,76^{\circ} \mathrm{C}($ Tabela 5 e Figura 23$)$.

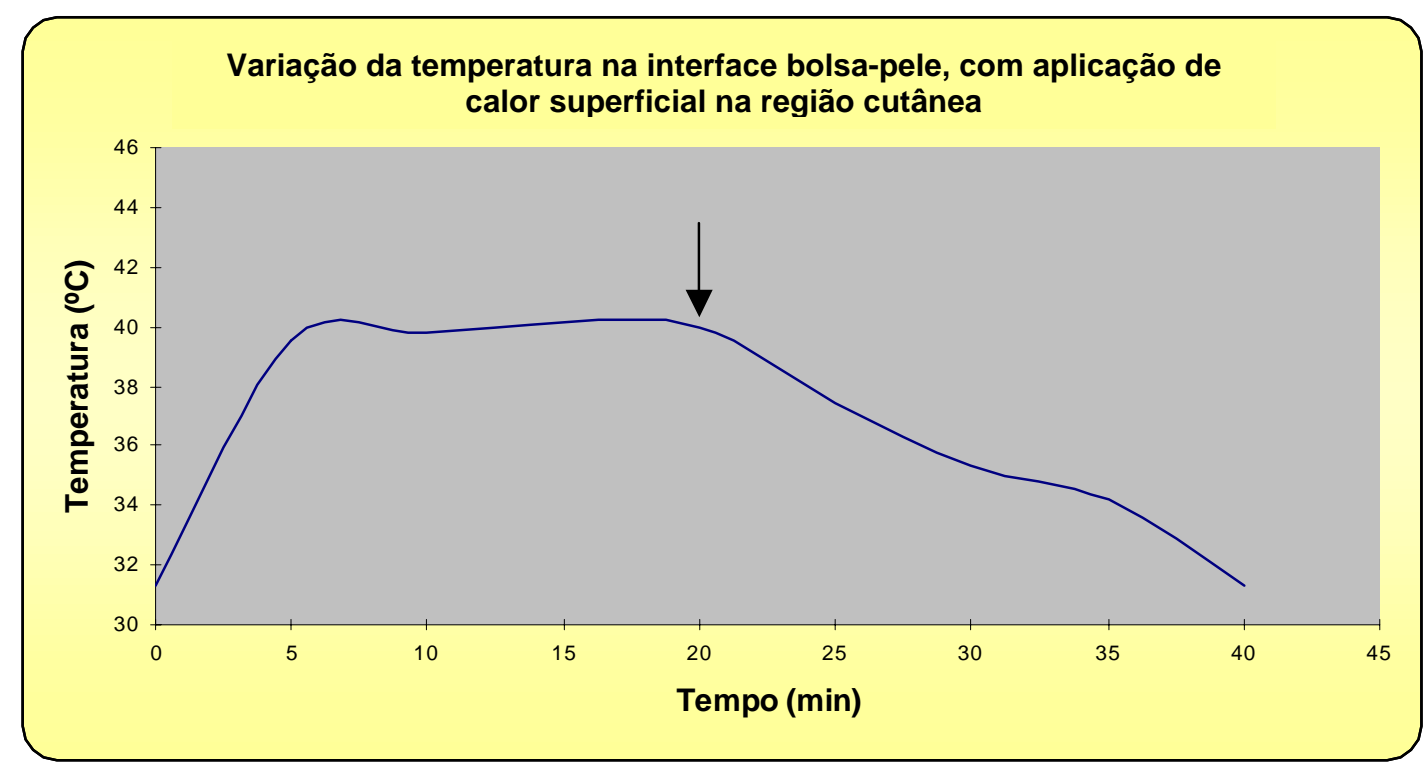

FIGURA 22 - Variação da temperatura na interface bolsa-pele com aplicação de calor superficial durante 20 min e, depois, retirada (seta). 
TABELA 5 - Parâmetros de variação de temperatura na interface bolsa-pele durante a aplicação de calor superficial.

\begin{tabular}{crc}
\hline TEMPERATURA $^{\circ} \mathrm{C}$ & MÉDIA (dp) & MEDIANA \\
\hline Inicial & $32,09(2,61)$ & 33,00 \\
Máxima & $40,92(1,06)$ & 40,43 \\
Variação & $8,83(2,62)$ & 8,90 \\
Pico inicial & $41,10(1,75)$ & 40,43 \\
Pico final & $39,84(1,77)$ & 40,00 \\
Variação entre picos & $-1,26(1,89)$ & $-0,76$ \\
\hline
\end{tabular}

FIGURA 23 - Parâmetros da variação de temperatura na interface bolsa-pele durante aplicação de calor superficial.

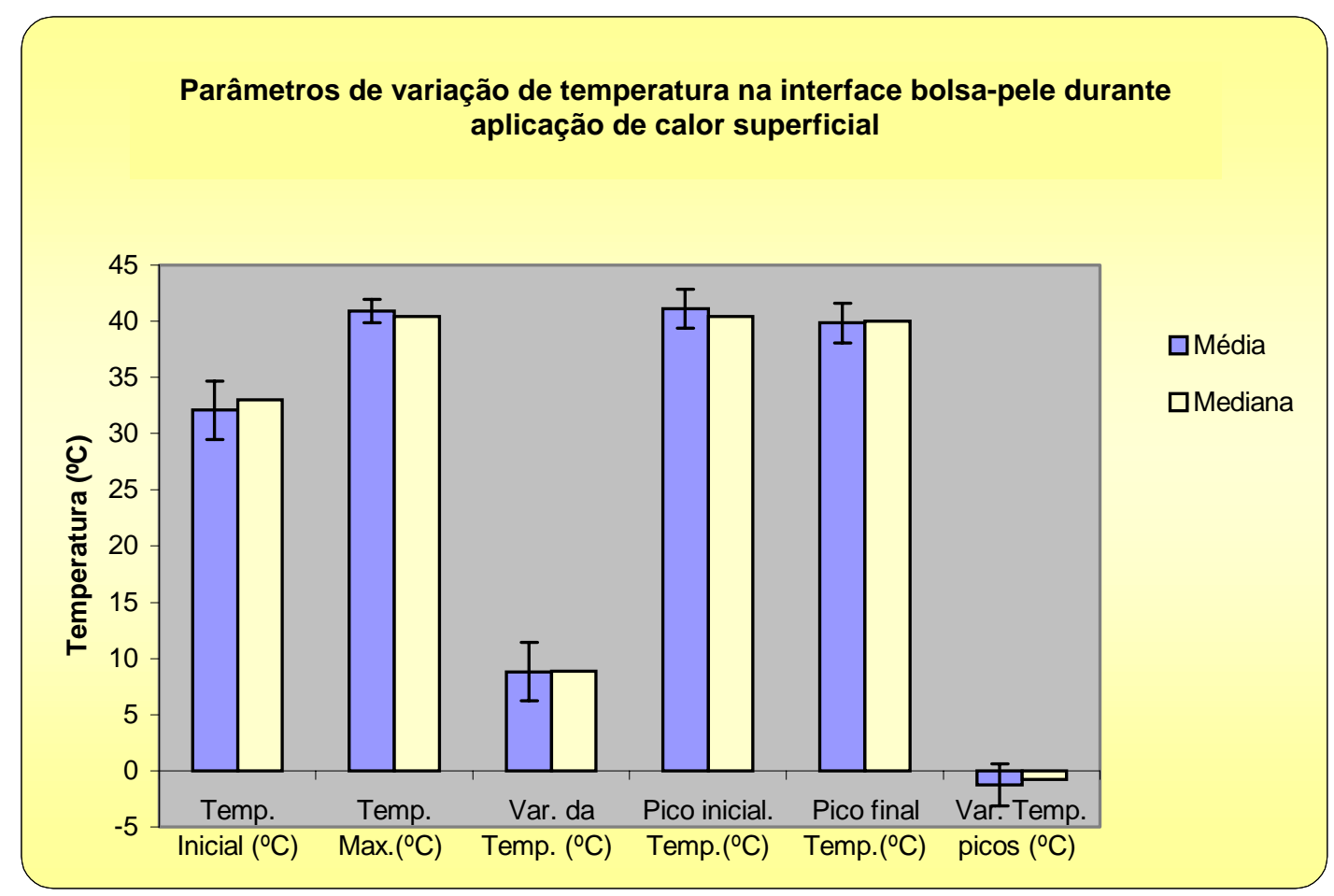

O tempo médio para a temperatura atingir o pico inicial foi 7 min e $18 \mathrm{~s}(\mathrm{dp}=$ 1 min e 27 s) e mediana 6 min e 45 s. O tempo de pico final de máxima temperatura apresentou média 21 min e $50 \mathrm{~s}(\mathrm{dp}=4$ min e $01 \mathrm{~s})$ e mediana 20 min. A variação do tempo entre os picos iniciais e finais apresentou média $12 \mathrm{~min}$ e $31 \mathrm{~s}(\mathrm{dp}=1 \mathrm{~min}$ e $57 \mathrm{~s}) \mathrm{e}$ mediana $12 \min$ e $45 \mathrm{~s}$. 
A média do tempo de alcance da temperatura máxima foi 9 min e $25 \mathrm{~s}(\mathrm{dp}=4$ min e 47 s) e mediana 7 min e 15 s. Após 20 minutos, ou seja, a partir da retirada do calor, a curva mudou rapidamente para descendente, com leves oscilações, até voltar à temperatura inicial (Tabela 6 e Figura 24).

TABELA 6 - Parâmetros da variação de tempo durante aplicação de calor superficial na interface.

\begin{tabular}{ccc}
\hline TEMPO (MIN) & MÉDIA & MEDIANA \\
\hline $\begin{array}{c}\text { Tempo para atingir } \\
\text { temperatura mínima }\end{array}$ & $0: 09: 25(0: 04: 47)$ & $0: 07: 15$ \\
Pico inicial & $0: 07: 18(0: 01: 27)$ & $0: 06: 45$ \\
Pico final & $0: 21: 50(0: 04: 01)$ & $0: 20: 01$ \\
& $0: 12: 31(0: 01: 57)$ & $0: 12: 45$ \\
\hline
\end{tabular}

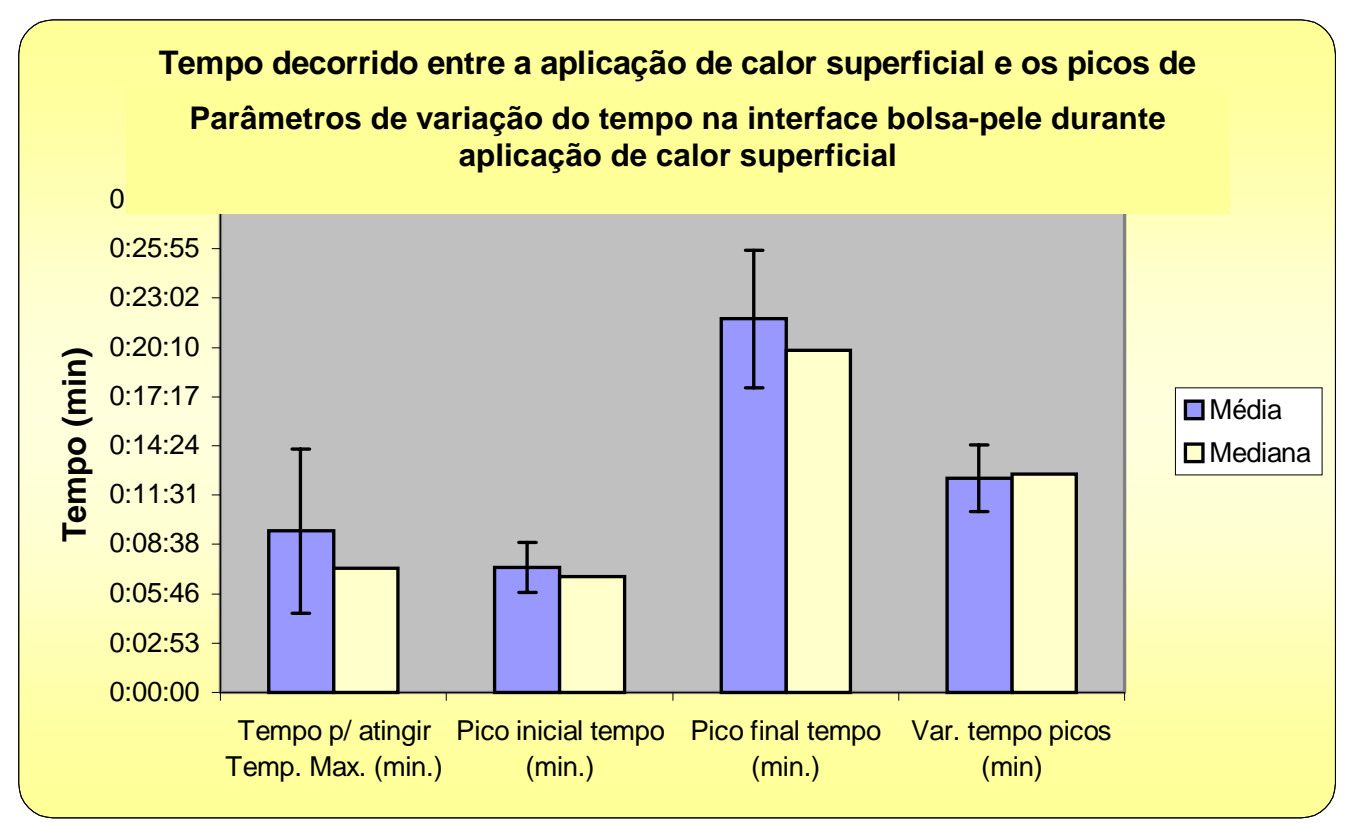

FIGURA 24 - Tempo decorrido para obtenção dos parâmetros de pico na interface bolsapele com aplicação de calor superficial. 


\subsubsection{Variação da temperatura na região muscular}

Durante a aplicação de calor superficial, o sensor intramuscular apresentou pequena variação de temperatura, representada graficamente em uma curva levemente ascendente (Figura 25$)$. A média da temperatura inicial foi $38,68^{\circ} \mathrm{C}(\mathrm{dp}=$ $0,30)$ e mediana $38,50^{\circ} \mathrm{C}$. A média de temperatura retal foi $38,85^{\circ} \mathrm{C}(\mathrm{dp}=3,69)$. A média de variação de temperatura foi $1,75^{\circ} \mathrm{C}(\mathrm{dp}=0,45)$ e mediana $1,73^{\circ} \mathrm{C}$. A temperatura máxima média foi $40,43^{\circ} \mathrm{C}(\mathrm{dp}=0,50)$ e mediana 40,37 .

A média de pico inicial de temperatura $40,40^{\circ} \mathrm{C}(\mathrm{dp}=0,52)$ e mediana $40,37^{\circ} \mathrm{C}$. A temperatura de pico final apresentou média de $39,92^{\circ} \mathrm{C}(\mathrm{dp}=0,22) \mathrm{e}$ mediana $39,95^{\circ} \mathrm{C}$. A variação entre os picos iniciais e finais da temperatura apresentou média $-0,48^{\circ} \mathrm{C}(\mathrm{dp}=0,36)$ e mediana $-0,49^{\circ} \mathrm{C}$ (Tabela 7 e Figura 26$)$.

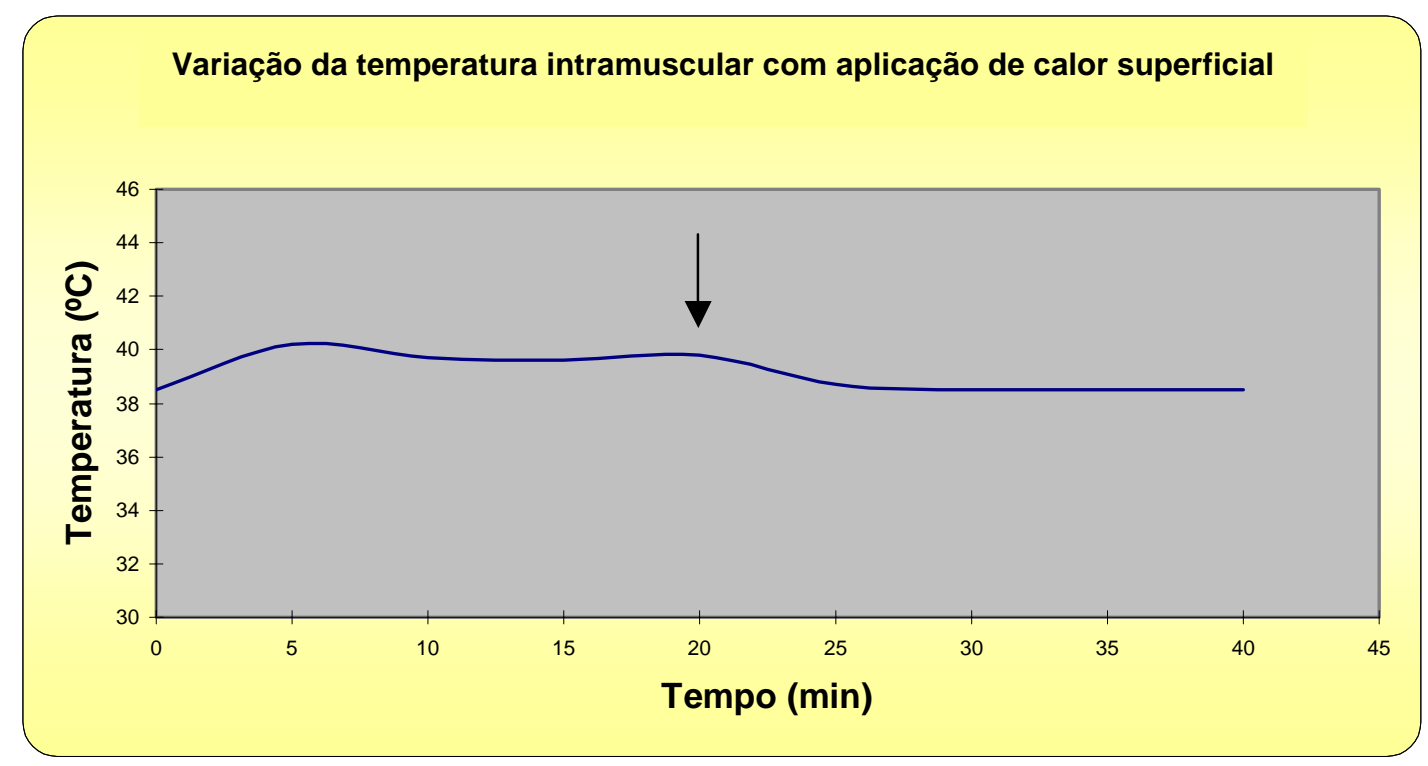

FIGURA 25 - Variação da temperatura intramuscular com aplicação de calor superficial durante 20 min e, depois, retirada (seta). 
TABELA 7 - Parâmetros de variação da temperatura intramuscular durante a aplicação de calor superficial na região cutânea.

\begin{tabular}{ccc}
\hline TEMPERATURA $^{\circ} \mathrm{C}$ & MÉDIA (dp) & MEDIANA \\
\hline Inicial & $38,68(0,30)$ & 38,50 \\
Máxima & $40,43(0,50)$ & 40,37 \\
Variação & $1,75(0,45)$ & 1,73 \\
Pico inicial & $40,40(0,52)$ & 40,37 \\
Pico final & $39,92(0,22)$ & 39,95 \\
Variação entre picos & $-0,48(0,36)$ & $-0,49$ \\
\hline
\end{tabular}

Variação da temperatura intramuscular durante aplicação de calor Parâmetros da variação de temperatura intramuscular durante a aplicação de calor superficial na região cutânea

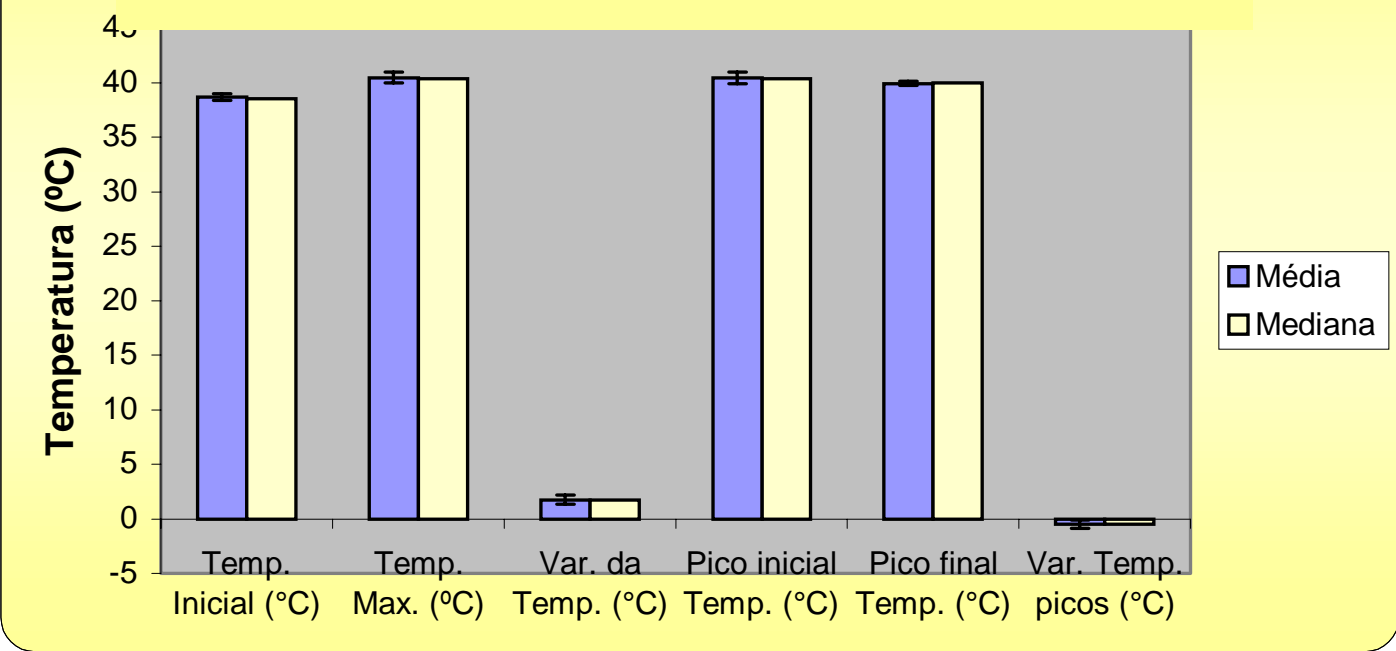

FIGURA 26 - Parâmetros da variação de temperatura intramuscular durante a aplicação de calor superficial na região cutânea.

A média do tempo para atingir o pico de temperatura máximo foi 8 min e $16 \mathrm{~s}$ $(\mathrm{dp}=4$ min e $09 \mathrm{~s})$ e mediana 6 min e $16 \mathrm{~s}$. O tempo médio para a temperatura alcançar o pico inicial foi $6 \min$ e $48 \mathrm{~s}(\mathrm{dp}=1 \min$ e $45 \mathrm{~s})$ e mediana 6 min e $16 \mathrm{~s}$. O tempo de pico final apresentou média $20 \min$ e $14 \mathrm{~s}(\mathrm{dp}=2 \mathrm{~min}$ e $06 \mathrm{~s})$ e mediana 20 min. A variação do tempo entre os picos iniciais e finais apresentou média 13 min e $26 \mathrm{~s}(\mathrm{dp}=2 \min$ e $45 \mathrm{~s})$ e mediana $13 \min$ e $12 \mathrm{~s}$. 
Após a retirada do calor, a curva mudou a sua inclinação para descendente. Na região intramuscular levou em média 12 min e na interface 14 minutos para retornarem à temperatura inicial (Tabela 8 e Figura 27).

TABELA 8 - Parâmetros de variação de tempo na região intramuscular, durante a aplicação de calor superficial na região cutânea.

\begin{tabular}{ccc}
\hline TEMPO $($ MIN) & MÉDIA (dp) & MEDIANA \\
\hline $\begin{array}{c}\text { Tempo para atingir } \\
\text { temperatura mínima }\end{array}$ & $0: 08: 16(0: 04: 09)$ & $0: 06: 16$ \\
Pico inicial & $0: 06: 48(0: 01: 45)$ & $0: 06: 16$ \\
Pico final & $0: 20: 14(0: 02: 06)$ & $0: 20: 00$ \\
Variação entre picos & $0: 13: 26(0: 02: 45)$ & $0: 13: 12$ \\
\hline
\end{tabular}

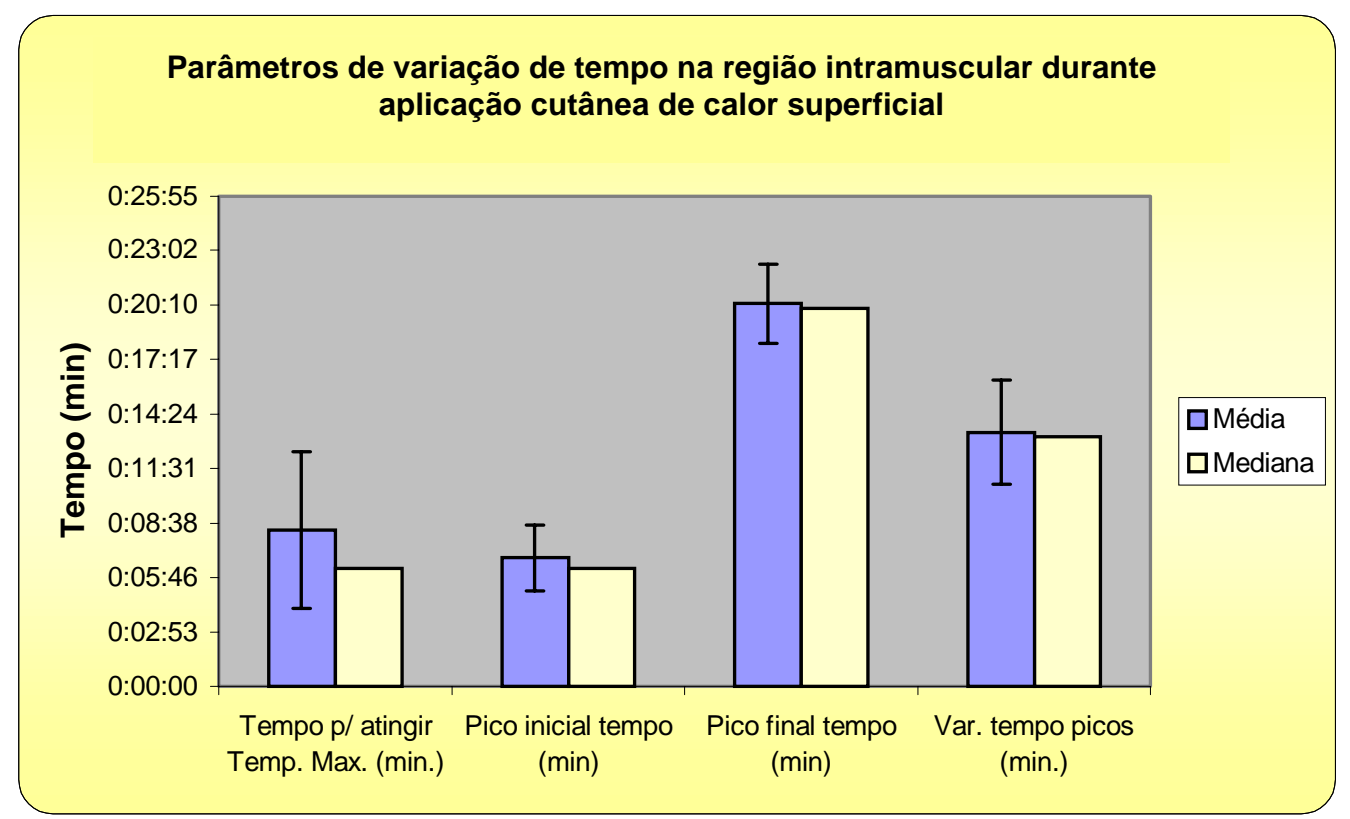

FIGURA 27 - Tempo decorrido para obtenção dos parâmetros de pico na região intramuscular com aplicação de calor superficial na região cutânea. 


\section{DISCUSSÃO}

A aplicação cutânea de frio e calor superficiais é largamente utilizada como recurso terapêutico na reabilitação, em lesões de prática esportiva em atletas profissionais, quer nos ocasionais.

Na fase aguda, a aplicação de frio com métodos diferentes prevalece, podendo ser por meio de gelo triturado, imersão em água fria $\left(1^{\circ} \mathrm{C}\right.$ a $\left.10^{\circ} \mathrm{C}\right)$ ou criomassagem (KNIGHT, 2000). Já, nas fases subaguda e crônica, prevalece a aplicação de calor superficial nas variadas formas, como banho de parafina, bolsa de gel aquecida, radiação infravermelha, forno de Bier, ou ainda, turbilhão e imersão em água aquecida em $40^{\circ} \mathrm{C}$.

A escolha adequada da terapia de frio ou calor superficial pode reduzir ou ainda impedir conseqüências do impacto de uma lesão, quer seja local ou em tecidos adjacentes, pela diminuição ou aumento da temperatura e efeitos fisiológicos diretamente a ela relacionados. Assim, haveria aumento ou diminuição do metabolismo e circulação, diminuição do espasmo muscular, redução de edema e analgesia encorajando o processo de reabilitação (LEHMANN, 1974).

Os efeitos terapêuticos da aplicação de frio e calor superficial estão 
relacionados com profundidade e tipo de tecido tratado LEHMANN (1974); LEHMANN \& DE LATEUR (1990); KAUL \& HERRING (1994); SWENSON (1996); MYER (1998); JOHNSON \& KITCHEN in KITCHEN \& BAZIN (1998); KNIGHT (2000).

Quando se aplica frio ou calor superficial, sempre há questionamento de quanto tempo haveria de variação térmica principalmente nos vários tecidos pois, no organismo, há elementos (pele, gordura, etc) que funcionam como barreiras térmicas. Além disto, o homem é animal homeotérmico, ou seja, o meio interno funciona em faixa de temperatura relativamente constante, o que vale dizer que há mecanismos fisiológicos periféricos e centrais, diretamente envolvidos com a manutenção da temperatura.

Assim, a prática mostra que a aplicação de frio e ou calor superficial são muito úteis para os pacientes. Seria a ação destes agentes apenas superficial, desencadeando reações locais e envolvendo mecanismos reflexos que atuariam, também, em estruturas profundas ou há, adicionalmente, variação térmica, apesar das barreiras anatômicas e reações fisiológicas?

A realização deste trabalho buscou investigar algumas destas hipóteses.

Em nosso modelo experimental, a mensuração da temperatura foi fator primordial para constatar variações térmicas, tanto subcutânea quanto intramuscular, motivo pelo qual optamos por um sensor térmico com precisão adequada. Ao término de cada sequiência experimental, os sensores intramuscular e da interface foram novamente calibrados para detectar alteração no aparelho. A temperatura retal foi usada como referencial.

Selecionamos o músculo longo do tronco por ter morfologia e localização 
adequadas aos nossos objetivos. Com efeito, ele é facilmente localizável, e encontrase em região de pouca movimentação, o que contribui para impedir a migração dos sensores e cateteres. Além disto, a localização dorsal dificultou o acesso do animal à região operada, quer pelas patas, quer pela boca.

Um aspecto importante foi à delimitação da área a ser resfriada ou aquecida. Utilizamos uma cinta de couro com uma abertura circular fixa, com a finalidade de dificultar o resfriamento ou aquecimento de áreas circunvizinhas e padronizar a região a ser estudada. Vários estudos como WOLF (1973), MYER (1994), MYER (1998) não relatam essa delimitação, o que representa uma falha de metodologia e prováveis repercussões nos resultados.

Tivemos várias falhas nos primeiros animais submetidos à implantação do sensor, pois, nos trabalhos pesquisados, os sensores eram de agulha, permitindo, assim, a colocação e retirada após cada procedimento. Já, em nosso experimento, o sensor permaneceu implantado por sete dias. Nesse período ocorreram algumas danificações no sistema de isolamento o que levou a perda de resultados em algumas seqüências experimentais. Porém, por outro lado, obtivemos um resultado positivo e pioneiro exatamente pelo tempo de permanência do sensor, o que possibilitou as medidas de temperaturas seqüenciais.

Para aplicação do frio, utilizamos gelo triturado $\left(0^{\circ} \mathrm{C}\right)$ em sacos plásticos, como preconizado por OOSTERVELD (1992), e tempo de aplicação 30 minutos, segundo WAYLONIS (1967); SHEPARD (1983); MEEUSEN (1986); MERRICK (1993). Para o calor superficial usamos bolsa de gel aquecida a $55^{\circ} \mathrm{C} H E A T$ TREATMENTS (1999); PORTER (1998), e tempo de aplicação de 20 minutos.

A análise descritiva dos registros gráficos da região intramuscular e interface 
mostrou modificação na temperatura com aplicação cutânea de frio, lenta no músculo e rápida na superfície; o que está de acordo com os resultados de SWENSON (1996).

Para CLARKE (1958) e ABRAMSON (1965), na fase inicial à aplicação cutânea de frio, a temperatura intramuscular pode aumentar, diminuir pouco ou não alterar. Entretanto, esses autores não determinaram claramente o período inicial de medida de temperatura. Em nosso experimento, a temperatura sempre apresentou uma queda lenta, demorando em média 17 minutos para se estabilizar, em concordância com os resultados de BIERMAN (1940) e HARTVIKSEN (1962).

A média de diminuição de temperatura no músculo foi $4,30^{\circ} \mathrm{C}$. BIERMAN (1940) obteve média de queda de temperatura de $3,30^{\circ} \mathrm{C}$, no mesmo tempo usado por nós, mas com profundidade maior do que a utilizada em nosso experimento $(5 \mathrm{~cm})$. Esses dados mostram que há queda real de temperatura em músculos mais profundos, o que sugere um efeito local direto do frio nesses tecidos.

A recuperação térmica após interrupção da aplicação de frio foi rápida e iniciada imediatamente à retirada do resfriamento. $\mathrm{O}$ retorno médio à temperatura inicial ocorreu em 24 min. A relação diminuição de temperatura local e intramuscular, seus efeitos subseqüentes e o tempo necessário para o retorno à temperatura inicial são parâmetros importantes na fisioterapia, pois podem estar relacionados ao intervalo de aplicações de frio utilizados, e prover maior eficiência do método. Assim, conhecer os limites mínimos de tempo gasto para a volta à temperatura prévia, significa alterar os intervalos médios de 4 horas utilizados na prática fisioterapêutica. De acordo com a variação de tecido subcutâneo, adiposo e muscular (barreiras térmicas) do paciente, bem como, as atividades desempenhadas 
por ele durante o intervalo entre as aplicações de frio, levarão ao reaquecimento mais rápido conforme os dados de KNIGHT (2000).

Na fisioterapia a aplicação do frio é indicada durante 20 a 30 min no máximo, independentemente da técnica utilizada para resfriar o segmento tratado e das características físicas do paciente. Nosso modelo experimental apresentou um tempo médio de 27 min para alcançar a temperatura mínima. Assim, estes resultados se extrapolados para o ser humano, com igualdade de barreiras térmicas, demonstram que 20 min é um tempo inferior aos objetivos desejados, e já 30 min o tempo ideal, salvo em indivíduos que não possuam as mesmas características.

A aplicação de calor superficial apresentou discreto aumento da temperatura intramuscular, em média $1,75^{\circ} \mathrm{C}$, que se manteve constante durante toda a aplicação. Nossos valores foram superiores aos de JOHNSON \& KITCHEN in KITCHEN \& BAZIN (1998) que obtiveram o aumento aproximado de $1^{\circ} \mathrm{C}$, na mesma medida estimada por nós. Já, comparados a LEHMANN (1966) foram inferiores e estão de acordo com VASUDEVAN (1997), pois obtivemos o aumento de temperatura intramuscular real em $3 \mathrm{~cm}$ de profundidade, sugerindo, assim, efeito local do calor superficial.

O tempo médio para atingir a elevação máxima de temperatura intramuscular em nosso experimento foi $8 \mathrm{~min}$, o que é diferente do estudo realizado por JOHNSON \& KITCHEN in KITCHEN \& BAZIN (1998), onde no mesmo tempo elevou a temperatura da pele e o tecido subcutâneo. De acordo com nossos dados, o aumento da temperatura intramuscular manteve se durante 13 minutos após aplicação do calor superficial. Não encontramos relatos de outros trabalhos que nos permitissem comparações, porém esses dados mostraram duração breve dos efeitos 
do calor superficial na região intramuscular o que pode orientar a prática fisioterapêutica, considerando a presença das diferentes barreiras térmicas existentes e motivar novos estudos sobre estes aspectos.

Nossos resultados podem ser considerados como preliminares, pois estudamos apenas uma variável da crio/termoterapia. As possíveis respostas fisiológicas às variações térmicas encontradas na literatura, são colocadas ainda muito teoricamente. Cremos que a partir da constatação da mudança profunda de temperatura, outros ensaios possam ser realizados no sentido de se investigar efeitos diretos, reflexos ou outras respostas fisiológicas. 


\section{CONCLUSÃO}

Os resultados deste presente estudo mostram que a aplicação cutânea de frio e calor superficiais produz modificações reais da temperatura em planos musculares subjacentes à área de aplicação. 


\section{REFERÊNCIAS BIBLIOGRÁFICAS}

ABRAMSON, D.I. (1965). Physiologic basis for the use of physical agents in peripheral vascular disorders. Archives of Physical Medicine in Rehabilitation. v. 46, p. $216-244$.

ABRAMSON, D. I.et al. (1967). Comparison on of wet and dry heat in raising temperature tissue. Archives of Physical Medicine in Rehabilitation. v. 46, p. 654.

BIERMAN,W. FRIEDLANDER, M. (1940) The penetrative effect of cold. Arch Phys Medicine. 21::585-592.

BING, H.I. ,CARLSTEN, A.; CHRISTIANSEN, S. (1945) The effect no muscular temperature produced by cooling normal and ultraviolet radiated skin. Acta Medicine Scandinav. 121:577-591.

CLARKE,R.S.J., HELLON,R.F.,LIND, A.R. (1958) The duration of sustained contractions of the human forearm at different muscle temperature. Journal Physiology. 143:454-473.

CUTANEOUS STIMULATION. (2000) Disponível na Internet via http:// www.stat.washington.edu/TALARIA/LS4.2.1.html. Capturado em dez 2000.

DAYTON, O. W. (1960). Athletic training and conditioning. New York, NY: Ronald Press. p. 121-127

HARTVIKSEN, K. (1962) Ice therapy in spasticity. Acta Neurology Scandinav. Suppl.3, v. 38, p. 79-84. 
HEAT TREATMENT(1999). Disponível na Internet via http://www.mylifepath.com/ article/gale/100274413. Capturado em dez. 2000.

JOHNSON, D.J. et al. (1979). Effect of cold submersion on Intramuscular Temperature of the gastrocnemus muscle. Physical Therapy. v. 59, p. 12381242.

JOHNSON, S. (ed.). (1991). A new treatment of musculoskeletal pain and injury. Reebok Instructor News. v. 4, n. 4, p. 4-5.

JOHNSON, L. , KITCHEN, S. (1998). Calor e frio: métodos de condução. In: KITCHEN. S. , BAZIN, S. Eletroterapia de Clayton. São Paulo: Manole. p. 123-136.

KAUL, M.P. HERRING, S.A. (1994) Superficial Heat and Cold. The Physian and Sportsmedicine. v. 22, n. 12:65-74.

KNIGHT, K.L. (2000). Crioterapia no Tratamento de Lesões do Esporte. São Paulo: Manole.

LEHMANN, J.F. et al. (1966). Temperature distributions in the human thigh, produced by infrared, hot pack and microwave applications. Arch. Phys. Med. v. 47, p. 291-299.

LEHMANN, J.F.,WARREN,C.G. and SCHAM,S.M. (1974) Therapeutic Heat and Cold Clinical Orthopaedics and Related Research. n.99, p. 207-245.

LEHMANN, J.F., DE LATEUR, B.J. (1990). Cryotherapy. In: LEHMANN, J. F. (ed.). Therapeutic Heat and Cold. 4.ed. Baltimore: Williams \& Wilkins. p. 590632.

LEVY, A.S. et al. (1997) Penetration of cryotherapy in treatment. The Journal of Arthroscopic and Related Surgery. v. 13, n. 4, p. 461-464.

MEEUSEN,R., LIEVENS,P. (1986) The use cryotherapy in sports injury. Sports Medicine 3:398-414.

MERRICK, M.A. et al. (1993) The effects of ice and compression wraps on temperatures at depths. Journal Athetic Train. 28: 236-245.

MYER, J.W. DRAPER,D.O, DURRANT,E. (1994) Contrast threrapy and intramuscular temperature in the human leg. Journal of Athetic Training. v. 29, n. 4, p. 318-322. 
MYER, J. W. et al. (1997) Cold and Hot-Pack Contrast Therapy: Subcutaneous and intramuscular Temperature Change. Journal of Athetic Training. v.32, n. 2, p.238-241September.

MYER.,J.W. MEASOM,G. FELLINGHAM, G.W. (1998) Temperature Changes in the Human Leg During and After Two Methods of Cryotherapy. Journal of Athetic Training. v. 33, n.1, p. 25-29.

OOSTERVELD,F.G., RASKER,K.K., JACOBS,J.W. et al. (1992) The effect of local heat and cold therapy on the intraarticular and skin surface temperature of the knee. Arthritis Rheum. 35 (2):146-151.

PORTER, M. Sports Medicine: using heat therapy. (1998) Disponível na Internet via http:// www.thehorse.com./0698/sports_medicine.html1. Capturado em dez. 2000.

SHEPARD, J. et al. (1983) Effect of cold on the blood vessel wall. Gen Pharmacology. 14:61-64.

SWENSON,C.SWÄRD,L.KARLSSON, J. (1996) Cryotherapy in Sports Medicine. Scandinavian Journal of Medicine \& Science in Sports.6:193-200.

VASUDEVAN, S. V. (1997) Physical rehabilitation in managing pain. v. 3, nov.. Disponível na Internet via http://www.halcyon.com./iasp/PCU97c.html. Capturado em dez. 2000.

WAYLONIS, G. W. (1967). The physiologic effects of ice manage. Arch. Phys. Med Rehabil. v. 48, p. 37-42.

WOLF, S.L., BASMAJIAN, J.V. (1973). Intramuscular temperature changes deep to localized cutaneous cold stimulation. Physical Therapy. v. 53, p. 1284/1288.

WORKMAN, T. B. (1999). The regeneration process of tissues through various modalities. In: Biology Senior Seminar, 410. Stan Grove, nov. Disponível na Internet via http://www.goshen.edu/Biol410/BSSpapers99/Toni.htm. Capturado em dez. 2000. 


\section{BIBLIOGRAFIA COMPLEMENTAR}

BODELSSON, M. (1990) Vascular effects of cooling, with special reference to human seritonergig, adrenergic and endothelial mechanisms. Medical dissertation. Lund: Lund University.

CHATONNET, J. CABANAC, M. (1965) The perception of thermal comfort. Int Journal Biometereorol. 9:183-193.

COHN, B.T., DRAEGER,R.I. JACKSON,D.W. (1989) The effects of cold therapyin the postoperative management of painin pacients undergoing anterior crucite ligament reconstrution. Am J Sports Med. 17 (3):344-349.

DAVIES, C. T. M., YOUNG, K. (1983). Effect of temperature on the contractile properties and muscle power of triceps surae in humans. Journal or Applied Physiology. v. 55, p. 191-193.

EKHOLM, J., SKOGLUND,S. (1960) Intra Articular Knee Joint Temperature Variations in Response to Cooling and Heating od the Skin in the Cat. ACTA Physiology Scand. 50:175-185.

HECHT,P.J. BACHMANN, S. BOOTH, R. E. Jr, et al. (1983) Effects of thremal therapy on rehabilitation after total knee arthroplasty: a prospective randomized study. Clinical Orthopaedics Sep (178):198-201.

LEHMANN, J.F., DE LATEUR, B.J. (1990). Therapeutic heat. In: LEHMANN, J. F. (ed.). Therapeutic Heat and Cold. 4.ed. Baltimore: Williams \& Wilkins. p. 444.

LOWDON, B.J.M.A., and MOORE, R.J. (1975) Determinants and nature of intramuscular temperature changes during cold therapy. American Journal of Physical Medicine. v. 54, p. 223-233. 
MCMASTER, W.C. (1982). Cryotherapy. Physician Sports Medicine. v. 10, p. 112119.

OLSON, J.E., STRANINO, V.D. (1972). A review of cryotherapy. Physical Therapy. v. 52, p. 840-853.

SLOAN,J.P.,GIDDINGS,P.,HAIN, R. (1988) Effects of cold and compression on edema. Physical Sports Medicine.16 (8):116-120. 
ANEXOS 


\section{ANEXO V}

\section{APLICAÇÃO DE FRIO}

Médias, desvios padrões e medianas das medidas na interface bolsa-pele

\begin{tabular}{|c|c|c|c|c|c|c|}
\hline $\begin{array}{c}\text { Ensaios de } \\
\text { temp. }\end{array}$ & $\begin{array}{c}\text { Temp. Inicial } \\
\left({ }^{\circ} \mathbf{C}\right)\end{array}$ & $\begin{array}{c}\text { Temp. Mín. } \\
\left({ }^{\circ} \mathbf{C}\right)\end{array}$ & $\begin{array}{c}\text { Var. da } \\
\text { Temp. }\left({ }^{\circ} \mathbf{C}\right)\end{array}$ & $\begin{array}{c}\text { Estab. } \\
\text { Temp. } \\
\text { inicial }\left({ }^{\circ} \mathbf{C}\right)\end{array}$ & $\begin{array}{c}\text { Estab. } \\
\text { Temp. } \\
\text { final }\left({ }^{\circ} \mathbf{C}\right)\end{array}$ & $\begin{array}{c}\text { Var. Estab. } \\
\text { da temp. }\left({ }^{\circ} \mathbf{C}\right)\end{array}$ \\
\hline 1EA & 32,50 & 4,51 & 27,99 & 9,79 & 4,51 & 5,28 \\
\hline 2EA & 33,50 & 8,16 & 25,34 & 10,76 & 8,16 & 2,60 \\
\hline 2EB & 36,50 & 9,90 & 26,60 & 14,58 & 9,38 & 5,20 \\
\hline 2EC & 33,30 & 7,64 & 25,66 & 12,50 & 7,56 & 4,86 \\
\hline 3EA & 36,00 & 11,11 & 24,99 & 17,01 & 11,11 & 5,90 \\
\hline 3EB & 31,60 & 7,47 & 24,13 & 7,47 & 9,65 & 2,18 \\
\hline 3EC & 32,00 & 0,00 & 32,00 & 17,19 & 12,50 & 4,69 \\
\hline 4EA & 34,60 & 10,35 & 24,25 & 15,00 & 10,35 & 4,65 \\
\hline 4EB & 33,30 & 10,24 & 23,06 & 15,97 & 10,24 & 5,73 \\
\hline 4EC & 28,30 & 11,40 & 16,09 & 17,36 & 11,40 & 5,95 \\
\hline 5DA & 24,30 & 10,94 & 24,30 & 20,00 & 10,94 & 9,06 \\
\hline 5DB & 25,20 & 10,94 & 14,26 & 16,49 & 10,94 & 5,55 \\
\hline 5DC & 27,80 & 10,24 & 17,56 & 15,04 & 10,24 & 4,80 \\
\hline 5EA & 33,50 & 14,24 & 19,26 & 15,28 & 15,28 & 0,00 \\
\hline 5EB & 33,50 & 10,42 & 23,08 & 10,42 & 13,13 & 2,71 \\
\hline 5EC & 33,50 & 13,37 & 23,13 & 15,45 & 13,37 & 2,08 \\
\hline Médias & $\mathbf{3 1 , 8 4}$ & $\mathbf{9 , 4 3}$ & $\mathbf{2 3 , 2 3}$ & $\mathbf{1 4 , 3 9}$ & $\mathbf{1 0 , 5 5}$ & $\mathbf{4 , 4 5}$ \\
\hline Desv. Pad. & $\mathbf{3 , 5 8}$ & $\mathbf{3 , 4 2}$ & $\mathbf{4 , 5 2}$ & $\mathbf{3 , 3 3}$ & $\mathbf{2 , 5 3}$ & $\mathbf{2 , 1 2}$ \\
\hline Mediana & $\mathbf{3 3 , 3 0}$ & $\mathbf{1 0 , 3 0}$ & $\mathbf{2 4 , 1 9}$ & $\mathbf{1 5 , 1 6}$ & $\mathbf{1 0 , 6 5}$ & $\mathbf{4 , 8 3}$ \\
\hline
\end{tabular}

\begin{tabular}{|c|c|c|c|c|}
\hline $\begin{array}{c}\text { Ensaios de } \\
\text { tempo }\end{array}$ & $\begin{array}{c}\text { Tempo de } \\
\text { Alcance da } \\
\text { Temp. Mín. } \\
\text { (Min.) }\end{array}$ & $\begin{array}{c}\text { Estab. tempo } \\
\text { inicial (Min.) }\end{array}$ & $\begin{array}{c}\text { Estab. tempo } \\
\text { final (Min.) }\end{array}$ & $\begin{array}{c}\text { Var. Tempo de } \\
\text { estab. (Min.) }\end{array}$ \\
\hline 1EA & $0: 28: 40$ & $0: 15: 18$ & $0: 28: 38$ & $0: 13: 20$ \\
\hline 2EA & $0: 28: 21$ & $0: 07: 13$ & $0: 28: 21$ & $0: 21: 08$ \\
\hline 2EB & $0: 28: 37$ & $0: 05: 31$ & $0: 28: 38$ & $0: 23: 07$ \\
\hline 2EC & $0: 27: 33$ & $0: 06: 48$ & $0: 27: 34$ & $0: 20: 46$ \\
\hline 3EA & $0: 29: 12$ & $0: 06: 23$ & $0: 29: 12$ & $0: 22: 49$ \\
\hline 3EB & $0: 06: 40$ & $0: 06: 40$ & $0: 28: 13$ & $0: 21: 33$ \\
\hline 3EC & $0: 20: 00$ & $0: 06: 57$ & $0: 29: 24$ & $0: 22: 27$ \\
\hline 4EA & $0: 28: 38$ & $0: 07: 54$ & $0: 28: 38$ & $0: 20: 44$ \\
\hline 4EB & $0: 28: 47$ & $0: 09: 13$ & $0: 29: 46$ & $0: 20: 33$ \\
\hline 4EC & $0: 29: 08$ & $0: 05: 00$ & $0: 29: 08$ & $0: 24: 08$ \\
\hline 5DA & $0: 28: 47$ & $0: 05: 00$ & $0: 28: 47$ & $0: 23: 47$ \\
\hline 5DB & $0: 29: 46$ & $0: 12: 12$ & $0: 29: 46$ & $0: 17: 34$ \\
\hline 5DC & $0: 30: 00$ & $0: 15: 00$ & $0: 33: 45$ & $0: 18: 45$ \\
\hline 5EA & $0: 20: 00$ & $0: 06: 23$ & $0: 29: 12$ & $0: 22: 49$ \\
\hline 5EB & $0: 06: 14$ & $0: 06: 14$ & $0: 28: 46$ & $0: 22: 32$ \\
\hline 5EC & $0: 25: 00$ & $0: 06: 23$ & $0: 25: 00$ & $0: 18: 37$ \\
\hline Médias & $\mathbf{0 : 2 4 : 4 3}$ & $\mathbf{0 : 0 8 : 0 1}$ & $\mathbf{0 : 2 8 : 5 6}$ & $\mathbf{0 : 2 0 : 5 5}$ \\
\hline Desv. Pad. & $\mathbf{0 : 0 7 : 4 6}$ & $\mathbf{0 : 0 3 : 1 7}$ & $\mathbf{0 : 0 1}: 42$ & $\mathbf{0}: 02: 46$ \\
\hline Mediana & $\mathbf{0 : 2 8 : 3 7}$ & $\mathbf{0 : 0 6 : 4 4}$ & $\mathbf{0 : 2 8 : 4 7}$ & $\mathbf{0 : 2 1 : 2 1}$ \\
\hline
\end{tabular}


Médias, desvios padrões e medianas das medidas intramusculares

\begin{tabular}{|c|c|c|c|c|c|c|}
\hline $\begin{array}{c}\text { Ensaios } \\
\text { de temp. }\end{array}$ & $\begin{array}{c}\text { Temp. } \\
\text { Inicial } \\
\left({ }^{\circ} \mathbf{C}\right)\end{array}$ & $\begin{array}{c}\text { Temp. } \\
\text { Mín. }\left({ }^{\circ} \mathbf{C}\right)\end{array}$ & $\begin{array}{c}\text { Var. da } \\
\text { Temp. } \\
\left({ }^{\circ} \mathbf{C}\right)\end{array}$ & $\begin{array}{c}\text { Estab. } \\
\text { Temp. } \\
\text { inicial }\left({ }^{\circ} \mathbf{C}\right)\end{array}$ & $\begin{array}{c}\text { Estab. } \\
\text { Temp. final } \\
\left({ }^{\circ} \mathbf{C}\right)\end{array}$ & $\begin{array}{c}\text { Var. Estab. } \\
\text { da temp. } \\
\left({ }^{\circ} \mathbf{C}\right)\end{array}$ \\
\hline 1EA & 37,90 & 30,63 & 7,27 & 35,76 & 30,63 & 5,13 \\
\hline 2EA & 38,50 & 33,40 & 5,10 & 33,40 & 36,46 & 2,94 \\
\hline 2EB & 38,20 & 35,76 & 2,44 & 35,76 & 37,24 & 2,51 \\
\hline 2EC & 38,20 & 35,00 & 3,20 & 36,11 & 35,00 & 1,11 \\
\hline 3EA & 40,30 & 37,15 & 3,15 & 37,67 & 37,15 & 0,52 \\
\hline 3EB & 39,10 & 35,87 & 3,23 & 35,24 & 35,87 & 0,63 \\
\hline 3EC & 38,10 & 34,20 & 3,90 & 35,00 & 34,20 & 0,80 \\
\hline 4EA & 39,10 & 35,42 & 3,68 & 36,63 & 35,42 & 1,21 \\
\hline 4EB & 39,20 & 35,69 & 3,51 & 36,63 & 35,69 & 0,94 \\
\hline 4EC & 39,50 & 34,01 & 5,49 & 35,76 & 34,03 & 1,73 \\
\hline 5DA & 39,70 & 36,11 & 3,59 & 37,38 & 36,11 & 1,22 \\
\hline 5DB & 39,60 & 35,76 & 3,84 & 37,15 & 35,76 & 1,39 \\
\hline 5DC & 39,50 & 35,76 & 3,74 & 37,15 & 35,76 & 1,39 \\
\hline 5EA & 39,80 & 33,68 & 6,12 & 35,00 & 33,68 & 1,32 \\
\hline 5EB & 39,20 & 33,68 & 5,52 & 35,00 & 33,68 & 1,42 \\
\hline 5EC & 38,50 & 33,51 & 4,99 & 35,00 & 33,51 & 1,49 \\
\hline Médias & $\mathbf{3 9 , 0 3}$ & $\mathbf{3 4 , 7 3}$ & $\mathbf{4 , 3 0}$ & $\mathbf{3 5 , 9 2}$ & $\mathbf{3 5 , 0 1}$ & $\mathbf{1 , 6 1}$ \\
\hline D. Pad. & $\mathbf{0 , 7 1}$ & $\mathbf{1 , 5 7}$ & $\mathbf{1 , 3 0}$ & $\mathbf{1 , 1 4}$ & $\mathbf{1 , 6 7}$ & $\mathbf{1 , 1 3}$ \\
\hline Mediana & $\mathbf{3 9 , 1 5}$ & $\mathbf{3 5 , 2 1}$ & $\mathbf{3 , 7 9}$ & $\mathbf{3 5 , 7 6}$ & $\mathbf{3 5 , 5 6}$ & $\mathbf{1 , 3 6}$ \\
\hline
\end{tabular}

\begin{tabular}{|c|c|c|c|c|}
\hline $\begin{array}{c}\text { Ensaios } \\
\text { de tempo }\end{array}$ & $\begin{array}{c}\text { Tempo de Alcance } \\
\text { da Temp. Mín. } \\
\text { (Min.) }\end{array}$ & $\begin{array}{c}\text { Estab. tempo } \\
\text { inicial (Min.) }\end{array}$ & $\begin{array}{c}\text { Estab. tempo } \\
\text { final (Min.) }\end{array}$ & $\begin{array}{c}\text { Var. Tempo de estab. } \\
\text { (Min.) }\end{array}$ \\
\hline 1EA & $0: 34: 28$ & $0: 05: 00$ & $0: 34: 28$ & $0: 29: 28$ \\
\hline 2EA & $0: 35: 39$ & $0: 20: 00$ & $0: 40: 00$ & $0: 20: 00$ \\
\hline 2EB & $0: 25: 00$ & $0: 22: 24$ & $0: 40: 00$ & $0: 17: 36$ \\
\hline 2EC & $0: 24: 22$ & $0: 10: 00$ & $0: 31: 34$ & $0: 21: 24$ \\
\hline 3EA & $0: 29: 32$ & $0: 15: 53$ & $0: 29: 33$ & $0: 14: 20$ \\
\hline 3EB & $0: 29: 29$ & $0: 10: 00$ & $0: 29: 29$ & $0: 19: 29$ \\
\hline 3EC & $0: 22: 33$ & $0: 06: 57$ & $0: 27: 38$ & $0: 20: 41$ \\
\hline 4EA & $0: 28: 47$ & $0: 20: 33$ & $0: 30: 11$ & $0: 10: 22$ \\
\hline 4EB & $0: 28: 47$ & $0: 15: 00$ & $0: 28: 47$ & $0: 13: 47$ \\
\hline 4EC & $0: 29: 12$ & $0: 20: 12$ & $0: 29: 12$ & $0: 09: 00$ \\
\hline 5DA & $0: 29: 16$ & $0: 10: 00$ & $0: 29: 16$ & $0: 19: 16$ \\
\hline 5DB & $0: 27: 30$ & $0: 10: 00$ & $0: 27: 30$ & $0: 17: 30$ \\
\hline 5DC & $0: 29: 21$ & $0: 10: 00$ & $0: 29: 21$ & $0: 19: 21$ \\
\hline 5EA & $0: 18: 43$ & $0: 13: 25$ & $0: 28: 52$ & $0: 15: 27$ \\
\hline 5EB & $0: 21: 41$ & $0: 15: 00$ & $0: 29: 12$ & $0: 14: 12$ \\
\hline 5EC & $0: 20: 51$ & $0: 15: 00$ & $0: 29: 49$ & $0: 14: 49$ \\
\hline Médias & $\mathbf{0 : 2 7 : 1 2}$ & $\mathbf{0 : 1 3 : 4 3}$ & $\mathbf{0 : 3 0 : 5 6}$ & $\mathbf{0 : 1 7}: 18$ \\
\hline D. Pad. & $\mathbf{0 : 0 4 : 4 1}$ & $\mathbf{0 : 0 5 : 1 1}$ & $\mathbf{0}: 03: 53$ & $\mathbf{0}: 04: 51$ \\
\hline Mediana & $\mathbf{0 : 2 8 : 4 7}$ & $\mathbf{0 : 1 4 : 1 2}$ & $\mathbf{0 : 2 9 : 2 5}$ & $\mathbf{0 : 1 7}: 33$ \\
\hline
\end{tabular}




\section{ANEXO VI}

\section{APLICAÇÃO DE CALOR}

Médias, desvios padrões e medianas das medidas da interface bolsa-pele

\begin{tabular}{|c|c|c|c|c|c|c|}
\hline $\begin{array}{c}\text { Ensaios de } \\
\text { temp. }\end{array}$ & $\begin{array}{c}\text { Temp. Inicial } \\
\left({ }^{\circ} \mathbf{C}\right)\end{array}$ & $\begin{array}{c}\text { Temp. Max. } \\
\left({ }^{\circ} \mathbf{C}\right)\end{array}$ & $\begin{array}{c}\text { Var. da } \\
\text { Temp. }\left({ }^{\circ} \mathbf{C}\right)\end{array}$ & $\begin{array}{c}\text { Estab. } \\
\text { Temp. } \\
\text { inicial }\left({ }^{\circ} \mathbf{C}\right)\end{array}$ & $\begin{array}{c}\text { Estab. } \\
\text { Temp. final } \\
\left({ }^{\circ} \mathbf{C}\right)\end{array}$ & $\begin{array}{c}\text { Var. Estab. } \\
\text { da temp. } \\
\left({ }^{\circ} \mathbf{C}\right)\end{array}$ \\
\hline 3EA & 36,30 & 40,71 & 4,41 & 40,71 & 35,77 & $-4,94$ \\
\hline 3EB & 33,00 & 43,70 & 10,70 & 43,70 & 43,22 & $-0,48$ \\
\hline 3EC & 35,00 & 40,75 & 5,75 & 44,75 & 40,92 & $-3,83$ \\
\hline 4EA & 27,80 & 40,85 & 13,05 & 40,85 & 39,39 & $-1,46$ \\
\hline 4EB & 30,40 & 40,43 & 10,03 & 40,43 & 40,00 & $-0,43$ \\
\hline 4EC & 31,30 & 40,13 & 8,83 & 40,13 & 40,00 & $-0,13$ \\
\hline 5DA & 28,60 & 40,37 & 11,77 & 38,77 & 40,37 & 1,60 \\
\hline 5DB & 30,60 & 40,43 & 9,83 & 39,95 & 40,43 & 0,48 \\
\hline 5EA & 33,20 & 42,10 & 8,90 & 42,10 & 39,67 & $-2,43$ \\
\hline 5EB & 33,30 & 40,43 & 7,13 & 40,43 & 39,67 & $-0,76$ \\
\hline 4EC & 33,50 & 40,23 & 6,73 & 40,23 & 38,77 & $-1,46$ \\
\hline Médias & $\mathbf{3 2 , 0 9}$ & $\mathbf{4 0 , 9 2}$ & $\mathbf{8 , 8 3}$ & $\mathbf{4 1 , 1 0}$ & $\mathbf{3 9 , 8 4}$ & $\mathbf{- 1 , 2 6}$ \\
\hline Desv. Pad. & $\mathbf{2 , 6 1}$ & $\mathbf{1 , 0 6}$ & $\mathbf{2 , 6 2}$ & $\mathbf{1 , 7 5}$ & $\mathbf{1 , 7 7}$ & $\mathbf{1 , 8 9}$ \\
\hline Mediana & $\mathbf{3 3 , 0 0}$ & $\mathbf{4 0 , 4 3}$ & $\mathbf{8 , 9 0}$ & $\mathbf{4 0 , 4 3}$ & $\mathbf{4 0 , 0 0}$ & $\mathbf{- 0 , 7 6}$ \\
\hline
\end{tabular}

\begin{tabular}{|c|c|c|c|c|}
\hline $\begin{array}{c}\text { Ensaios de } \\
\text { tempo }\end{array}$ & $\begin{array}{c}\text { Tempo de } \\
\text { Alcance da } \\
\text { Temp. Max. } \\
\text { (Min.) }\end{array}$ & $\begin{array}{c}\text { Estab. tempo } \\
\text { inicial (Min.) }\end{array}$ & $\begin{array}{c}\text { Estab. tempo } \\
\text { final (Min.) }\end{array}$ & $\begin{array}{c}\text { Var. Tempo de } \\
\text { estab. (Min.) }\end{array}$ \\
\hline 3EA & $0: 09: 07$ & $0: 09: 12$ & $0: 26: 18$ & $0: 15: 06$ \\
\hline 3EB & $0: 10: 41$ & $0: 10: 41$ & $0: 18: 32$ & $0: 07: 51$ \\
\hline 3EC & $0: 05: 53$ & $0: 05: 53$ & $0: 20: 00$ & $0: 14: 07$ \\
\hline 4EA & $0: 06: 16$ & $0: 06: 16$ & $0: 19: 58$ & $0: 13: 42$ \\
\hline 4EB & $0: 06: 45$ & $0: 06: 45$ & $0: 20: 00$ & $0: 13: 15$ \\
\hline 4EC & $0: 07: 36$ & $0: 07: 36$ & $0: 20: 00$ & $0: 12: 24$ \\
\hline 5DA & $0: 18: 44$ & $0: 07: 33$ & $0: 28: 44$ & $0: 11: 11$ \\
\hline 5DB & $0: 18: 36$ & $0: 06: 28$ & $0: 28: 44$ & $0: 12: 04$ \\
\hline 5EA & $0: 06: 11$ & $0: 06: 11$ & $0: 20: 00$ & $0: 13: 49$ \\
\hline 5EB & $0: 06: 28$ & $0: 06: 28$ & $0: 17: 56$ & $0: 11: 28$ \\
\hline 4EC & $0: 07: 15$ & $0: 07: 15$ & $0: 20: 00$ & $0: 12: 45$ \\
\hline Médias & $\mathbf{0 : 0 9 : 2 5}$ & $\mathbf{0 : 0 7 : 1 8}$ & $\mathbf{0 : 2 1 : 5 0}$ & $\mathbf{0 : 1 2 : 3 1}$ \\
\hline Desv. Pad. & $\mathbf{0 : 0 4 : 4 7}$ & $\mathbf{0 : 0 1 : 2 7}$ & $\mathbf{0 : 0 4 : 0 1}$ & $\mathbf{0 : 0 1 : 5 7}$ \\
\hline Mediana & $\mathbf{0 : 0 7 : 1 5}$ & $\mathbf{0 : 0 6 : 4 5}$ & $\mathbf{0 : 2 0 : 0 0}$ & $\mathbf{0 : 1 2 : 4 5}$ \\
\hline
\end{tabular}


Médias, desvios padrões e medianas das medidas intramusculares

\begin{tabular}{|c|c|c|c|c|c|c|}
\hline $\begin{array}{c}\text { Ensaios de } \\
\text { temp. }\end{array}$ & $\begin{array}{c}\text { Temp. } \\
\text { Inicial }\left({ }^{\circ} \mathbf{C}\right)\end{array}$ & $\begin{array}{c}\text { Temp. Max. } \\
\left({ }^{\circ} \mathbf{C}\right)\end{array}$ & $\begin{array}{c}\text { Var. da } \\
\text { Temp. }\left({ }^{\circ} \mathbf{C}\right)\end{array}$ & $\begin{array}{c}\text { Estab. } \\
\text { Temp. } \\
\text { inicial }\left({ }^{\circ} \mathbf{C}\right)\end{array}$ & $\begin{array}{c}\text { Estab. } \\
\text { Temp. final } \\
\left({ }^{\circ} \mathbf{C}\right)\end{array}$ & $\begin{array}{c}\text { Var. Estab. } \\
\text { da temp. } \\
\left({ }^{\circ} \mathbf{C}\right)\end{array}$ \\
\hline 3EA & 39,00 & 40,64 & 1,64 & 40,64 & 40,00 & $-0,64$ \\
\hline 3EB & 38,40 & 39,53 & 1,13 & 39,53 & 39,53 & 0,00 \\
\hline 3EC & 38,50 & 40,30 & 1,80 & 39,96 & 40,00 & 0,04 \\
\hline 4EA & 38,50 & 40,23 & 1,73 & 40,23 & 39,74 & $-0,49$ \\
\hline 4EB & 38,30 & 39,88 & 1,58 & 39,88 & 39,67 & $-0,21$ \\
\hline 4EC & 38,50 & 40,23 & 1,73 & 40,23 & 39,95 & $-0,28$ \\
\hline 5DA & 39,20 & 40,78 & 1,58 & 40,78 & 40,16 & $-0,62$ \\
\hline 5DB & 39,10 & 40,37 & 1,27 & 40,37 & 40,00 & $-0,37$ \\
\hline 5EA & 38,50 & 41,38 & 2,88 & 41,38 & 40,30 & $-1,08$ \\
\hline 5EB & 38,70 & 40,57 & 1,87 & 40,57 & 39,88 & $-0,69$ \\
\hline 5EC & 38,80 & 40,85 & 2,05 & 40,85 & 39,88 & $-0,97$ \\
\hline Médias & $\mathbf{3 8 , 6 8}$ & $\mathbf{4 0 , 4 3}$ & $\mathbf{1 , 7 5}$ & $\mathbf{4 0 , 4 0}$ & $\mathbf{3 9 , 9 2}$ & $-\mathbf{0 , 4 8}$ \\
\hline Desv. Pad. & $\mathbf{0 , 3 0}$ & $\mathbf{0 , 5 0}$ & $\mathbf{0 , 4 5}$ & $\mathbf{0 , 5 2}$ & $\mathbf{0 , 2 2}$ & $\mathbf{0 , 3 6}$ \\
\hline Mediana & $\mathbf{3 8 , 5 0}$ & $\mathbf{4 0 , 3 7}$ & $\mathbf{1 , 7 3}$ & $\mathbf{4 0 , 3 7}$ & $\mathbf{3 9 , 9 5}$ & $\mathbf{- 0 , 4 9}$ \\
\hline
\end{tabular}

\begin{tabular}{|c|c|c|c|c|}
\hline $\begin{array}{c}\text { Ensaios de } \\
\text { tempo }\end{array}$ & $\begin{array}{c}\text { Tempo de Alcance } \\
\text { da Temp. Max. } \\
\text { (Min.) }\end{array}$ & $\begin{array}{c}\text { Estab. tempo } \\
\text { inicial (Min.) }\end{array}$ & $\begin{array}{c}\text { Estab. tempo } \\
\text { final (Min.) }\end{array}$ & $\begin{array}{c}\text { Var. Tempo de } \\
\text { estab. (Min.) }\end{array}$ \\
\hline 3EA & $0: 06: 11$ & $0: 06: 11$ & $0: 26: 18$ & $0: 20: 07$ \\
\hline 3EB & $0: 05: 00$ & $0: 05: 00$ & $0: 20: 00$ & $0: 15: 00$ \\
\hline 3EC & $0: 10: 00$ & $0: 06: 43$ & $0: 20: 00$ & $0: 13: 17$ \\
\hline 4EA & $0: 05: 41$ & $0: 05: 41$ & $0: 20: 00$ & $0: 14: 19$ \\
\hline 4EB & $0: 19: 13$ & $0: 06: 28$ & $0: 19: 13$ & $0: 12: 45$ \\
\hline 4EC & $0: 05: 35$ & $0: 05: 35$ & $0: 18: 24$ & $0: 12: 49$ \\
\hline 5DA & $0: 10: 00$ & $0: 10: 00$ & $0: 20: 00$ & $0: 10: 00$ \\
\hline 5DB & $0: 06: 16$ & $0: 06: 16$ & $0: 20: 00$ & $0: 13: 44$ \\
\hline 5EA & $0: 10: 23$ & $0: 10: 23$ & $0: 20: 00$ & $0: 09: 37$ \\
\hline 5EB & $0: 05: 47$ & $0: 05: 47$ & $0: 18: 38$ & $0: 12: 51$ \\
\hline 5EC & $0: 06: 48$ & $0: 06: 48$ & $0: 20: 00$ & $0: 13: 12$ \\
\hline Médias & $\mathbf{0 : 0 8 : 1 6}$ & $\mathbf{0 : 0 6 : 4 8}$ & $\mathbf{0 : 2 0 : 1 4}$ & $\mathbf{0}: 13: 26$ \\
\hline Desv. Pad. & $\mathbf{0 : 0 4 : 0 9}$ & $\mathbf{0 : 0 1 : 4 5}$ & $\mathbf{0 : 0 2 : 0 6}$ & $\mathbf{0 : 0 2 : 4 5}$ \\
\hline Mediana & $\mathbf{0 : 0 6 : 1 6}$ & $\mathbf{0 : 0 6 : 1 6}$ & $\mathbf{0 : 2 0 : 0 0}$ & $\mathbf{0}: 13: 12$ \\
\hline
\end{tabular}




\section{ANEXO VII \\ MÉDIA DE TEMPO APÓS A APLICAÇÃO DE FRIO PARA O RETORNO À TEMPERATURA INICIAL}

\begin{tabular}{|c|c|c|}
\hline Animal & $\begin{array}{c}\text { Região } \\
\text { Intramuscular } \\
(\text { min })\end{array}$ & $\begin{array}{c}\text { Região Interface } \\
\text { (min) }\end{array}$ \\
\hline $1 \mathrm{EA}$ & 25 & 30 \\
\hline $2 \mathrm{EA}$ & 30 & 30 \\
\hline $2 \mathrm{~EB}$ & 25 & 25 \\
\hline $2 \mathrm{EC}$ & 25 & 20 \\
\hline 3EA & 30 & 25 \\
\hline $3 \mathrm{~EB}$ & 25 & 20 \\
\hline $3 \mathrm{EC}$ & 20 & 25 \\
\hline $4 \mathrm{EA}$ & 30 & 25 \\
\hline 4EA & 25 & 30 \\
\hline $4 \mathrm{EC}$ & 30 & 30 \\
\hline $5 \mathrm{DA}$ & 25 & 25 \\
\hline $5 \mathrm{DB}$ & 25 & 25 \\
\hline $5 \mathrm{DC}$ & 25 & 25 \\
\hline $5 \mathrm{EA}$ & 25 & 20 \\
\hline $5 \mathrm{~EB}$ & 25 & 25 \\
\hline $5 \mathrm{EC}$ & 25 & 20 \\
\hline MÉDIA & 25 & 20 \\
\hline
\end{tabular}

- Números 1 a 5 referem-se aos animais

- Letras D e E referem-se ao hemicorpo direito e/ou esquerdo

- Letras $\mathrm{A}$ a $\mathrm{C}$ referem-se às aplicações sendo $\mathrm{A}=1^{\mathrm{a}}$ aplicação; $\mathrm{B}=2^{\mathrm{a}}$ aplicação e $\mathrm{C}=3^{\mathrm{a}}$ aplicação. 


\section{ANEXO VIII}

MÉDIA DE TEMPO APÓS A APLICAÇÃO DE CALOR SUPERFICIAL PARA O RETORNO À TEMPERATURA INICIAL

\begin{tabular}{|c|c|c|}
\hline Animal & $\begin{array}{c}\text { Região } \\
\text { Intramuscular } \\
(\text { min })\end{array}$ & $\begin{array}{c}\text { Região Interface } \\
\text { (min) }\end{array}$ \\
\hline 3EA & 15 & 15 \\
\hline $3 \mathrm{~EB}$ & 15 & 15 \\
\hline $3 \mathrm{EC}$ & 15 & 20 \\
\hline $4 \mathrm{EA}$ & 10 & 15 \\
\hline $4 \mathrm{EA}$ & 10 & 15 \\
\hline $4 \mathrm{EC}$ & 12 & 15 \\
\hline $5 \mathrm{DA}$ & 10 & 13 \\
\hline $5 \mathrm{DB}$ & 10 & 15 \\
\hline $5 \mathrm{EA}$ & 15 & 10 \\
\hline $5 \mathrm{~EB}$ & 10 & 10 \\
\hline $5 \mathrm{EC}$ & 10 & 10 \\
\hline MÉDIA & 12 & 14 \\
\hline
\end{tabular}

- Números 3 a 5 referem-se aos animais

- Letras D e E referem-se ao hemicorpo direito e/ou esquerdo

- Letras $\mathrm{A}$ a $\mathrm{C}$ referem-se às aplicações sendo $\mathrm{A}=1^{\mathrm{a}}$ aplicação; $\mathrm{B}=2^{\mathrm{a}}$ aplicação $\mathrm{e}$ $\mathrm{C}=3^{\mathrm{a}}$ aplicação. 


\section{ANEXO I}

Aplicação de frio - Temperaturas da interface

\begin{tabular}{|c|c|c|c|c|c|c|c|c|c|c|c|c|c|c|c|c|}
\hline Tempo (Min.) & 1EA & 2EA & 2EB & 2EC & 3EA & 3EB & 3EC & 3EA & 3EB & 4EC & 5DA & 5DB & 5DC & 5EA & 5EB & $5 \mathrm{EC}$ \\
\hline 0 & 32,5 & 33,5 & 36,5 & 33,3 & 36,0 & 31,6 & 32,0 & 34,6 & 33,3 & 28,3 & 24,3 & 25,2 & 27,8 & 33,5 & 33,5 & 33,5 \\
\hline 5 & 19,6 & 12,4 & 16,1 & 13,8 & 18,3 & 8,6 & 18,5 & 16,8 & 17,4 & 18,2 & 20,3 & 21,3 & 21,2 & 16,2 & 11,5 & 16,2 \\
\hline 10 & 12,6 & 10,9 & 15,0 & 12,9 & 17,5 & 8,1 & 17,5 & 14,9 & 15,2 & 17,4 & 18,2 & 17,3 & 18,2 & 17,3 & 12,3 & 17,4 \\
\hline 15 & 9,9 & 9,2 & 13,0 & 10,1 & 15,1 & 10,1 & 18,1 & 13,7 & 13,8 & 14,3 & 15,1 & 16,4 & 15,4 & 16,9 & 13,4 & 16,5 \\
\hline 20 & 11,2 & 8,8 & 12,1 & 11,6 & 14,8 & 12,7 & 15.2 & 12,6 & 12,6 & 13,4 & 13,2 & 15,2 & 13,2 & 14,2 & 11,4 & 14,7 \\
\hline 25 & 6,5 & 8,9 & 10,9 & 8,1 & 14,5 & 10,7 & 12,6 & 11,5 & 11,3 & 12,6 & 11,6 & 12,7 & 10,6 & 17 & 13,6 & 13,4 \\
\hline 30 & 5,2 & 9,5 & 10,5 & 9,5 & 11,6 & 10,8 & 13,2 & 11,1 & 11,0 & 11,4 & 11,3 & 10,4 & 10,6 & 15,8 & 13,8 & 15,8 \\
\hline 35 & 17,0 & 23,1 & 27,0 & 27,6 & 24,0 & 25,6 & 25,1 & 22,0 & 23,0 & 18,4 & 16,3 & 14,8 & 10,7 & 24,5 & 24,5 & 25,5 \\
\hline 40 & 24,0 & 26,0 & 31,4 & 29,1 & 28,6 & 29,3 & 29,2 & 22,8 & 25,2 & 22,3 & 19,4 & 17,9 & 16,2 & 30,2 & 30,2 & 30,2 \\
\hline 45 & 27,9 & 28,5 & 33,4 & 32,2 & 31,7 & 31,0 & 30,0 & 27,5 & 27,3 & 24,4 & 21,2 & 19,1 & 18,3 & 33,2 & 31,6 & 32,3 \\
\hline 50 & 28,9 & 30,5 & 34,8 & 32,9 & 34,1 & 31,6 & 31,6 & 31,5 & 31,4 & 26,3 & 21,6 & 22,6 & 22,4 & 33,4 & 32,5 & 32,4 \\
\hline 55 & 30,4 & 31,8 & 35,5 & 33,3 & 35,1 & & 32,0 & 33,0 & 32,4 & 27,6 & 23,2 & 24,9 & 24,7 & 33,5 & 33,5 & 33,3 \\
\hline 60 & 32,5 & 33,5 & 36,5 & & 36,0 & & 32,0 & 34,7 & 33,3 & 28,3 & 24,3 & 25,2 & 27,8 & & & 33,5 \\
\hline
\end{tabular}




\section{ANEXO II}

Aplicação de frio - Temperatura do sensor intramuscular

\begin{tabular}{|c|c|c|c|c|c|c|c|c|c|c|c|c|c|c|c|c|}
\hline Tempo (Min.) & 1EA & 2EA & 2EB & 2EC & 3EA & 3EB & 3EC & 3EA & 3EB & 4EC & 5DA & $5 \mathrm{DB}$ & $5 D C$ & 5EA & 5EB & $5 E C$ \\
\hline 0 & 37,9 & 38,5 & 39,1 & 38,2 & 40,3 & 39,1 & 38,1 & 39,4 & 39,2 & 39,5 & 39,7 & 39,6 & 39,5 & 39,8 & 39,2 & 38,5 \\
\hline 5 & 35,8 & 37,4 & 38,0 & 37,3 & 39,0 & 38,1 & 35,6 & 38,5 & 38,4 & 38,6 & 38,7 & 38,4 & 38,7 & 37,7 & 37,7 & 37,7 \\
\hline 10 & 35,8 & 36,4 & 37,1 & 36,4 & 38,6 & 37,3 & 34,7 & 37,7 & 37,5 & 37,7 & 37,5 & 37,2 & 37,4 & 36,1 & 36,5 & 36,5 \\
\hline 15 & 35,4 & 35,7 & 36,9 & 36,2 & 37,8 & 37,2 & 34,2 & 37,3 & 37,2 & 37,2 & 37,4 & 37,1 & 37,0 & 34,5 & 35,3 & 34,7 \\
\hline 20 & 34,7 & 35,2 & 36,2 & 35,7 & 37,6 & 37,0 & 34,0 & 36,6 & 36,5 & 36,5 & 36,8 & 36,5 & 36,2 & 33,5 & 34,1 & 33,5 \\
\hline 25 & 33,1 & 34,7 & 35,5 & 34,9 & 37,6 & 36,6 & 34,0 & 36,1 & 36,0 & 36,1 & 36,2 & 35,9 & 36,1 & 33,7 & 34 & 33,8 \\
\hline 30 & 31,8 & 34,2 & 36,0 & 35,0 & 37,2 & 35,9 & 34,3 & 35,3 & 35,4 & 35,4 & 36,1 & 36,0 & 35,8 & 33,9 & 33,9 & 33,7 \\
\hline 35 & 30,6 & 33,4 & 35,8 & 35,6 & 37,8 & 37,6 & 35,4 & 37,1 & 36,8 & 37,3 & 37,3 & 37,6 & 37,4 & 36,2 & 36,2 & 36,2 \\
\hline 40 & 32,3 & 33,7 & 35,9 & 35,8 & 37,8 & 37,5 & 36,9 & 37,5 & 37,3 & 37,6 & 37,7 & 37,9 & 37,8 & 35,8 & 35,8 & 35,9 \\
\hline 45 & 34,1 & 34,5 & 37,2 & 36,5 & 38,5 & 37,1 & 37,6 & 38,1 & 37,8 & 38,2 & 38,2 & 38,3 & 38,4 & 36,6 & 36,6 & 36,6 \\
\hline 50 & 36,3 & 35,7 & 37,8 & 37,3 & 39,1 & 37,6 & 37,9 & 38,5 & 38,4 & 38,5 & 38,7 & 38,8 & 38,9 & 37,1 & 37,1 & 37,5 \\
\hline 55 & 36,9 & 37,2 & 38,3 & 37,8 & 39,6 & 37,9 & 38,1 & 38,7 & 38,6 & 38,9 & 39,4 & 39,4 & 39,5 & 38,5 & 38,5 & 38,5 \\
\hline 60 & 37,9 & 38,5 & 39,1 & 38,2 & 40,3 & 39,1 & 38,1 & 39,4 & 39,2 & 39,5 & 39,7 & 39,6 & 39,5 & 39,8 & 39,2 & 38,5 \\
\hline
\end{tabular}




\section{ANEXO III}

Aplicação de calor - Temperatura da interface

\begin{tabular}{|c|c|c|c|c|c|c|c|c|c|c|c|}
\hline Tempo (Min.) & 3EA & 3EB & 3EC & 4EA & 4EB & 4EC & 5DA & 5DB & 5EA & 5EB & 5EC \\
\hline 0 & 36,3 & 33,0 & 35,0 & 27,8 & 30,4 & 31,3 & 28,6 & 30,6 & 33,2 & 33,3 & 33,5 \\
\hline 5 & 40,1 & 40,2 & 44,4 & 40,2 & 39,7 & 39,5 & 37,8 & 39,4 & 41,7 & 39,8 & 39,6 \\
\hline 10 & 40,7 & 43,6 & 42,6 & 40,0 & 40,1 & 39,9 & 39,4 & 39,3 & 40,8 & 39,6 & 40,1 \\
\hline 15 & 40,2 & 42,9 & 41,5 & 39,0 & 39,9 & 40,1 & 39,9 & 40,2 & 40,1 & 39,5 & 39,5 \\
\hline 20 & 40,1 & 42,8 & 40,9 & 39,1 & 39,9 & 40,0 & 40,2 & 40,1 & 39,7 & 38,8 & 38,8 \\
\hline 25 & 35,9 & 36,8 & 38,1 & 34,0 & 37,4 & 37,4 & 37,3 & 36,4 & 34,5 & 33,7 & 34,8 \\
\hline 30 & 36,3 & 36,4 & 37,5 & 31,8 & 36,3 & 35,3 & 33,1 & 35,8 & 33,5 & 33,5 & 33,9 \\
\hline 35 & 36,3 & 35,3 & 36,7 & 30,0 & 33,0 & 34,2 & 28,6 & 34,6 & 33,4 & 33,3 & 33,5 \\
\hline 40 & 36,3 & 33,0 & 35,0 & 27,8 & 30,4 & 31,3 & & 30,6 & 33,2 & & 33,5 \\
\hline
\end{tabular}




\section{ANEXO IV}

Aplicação de calor - Temperatura do Sensor Intramuscular

\begin{tabular}{|c|c|c|c|c|c|c|c|c|c|c|c|}
\hline Tempo (Min.) & 3EA & 3EB & 3EC & 4EA & 4EB & 4EC & 5DA & 5DB & 5EA & 5EB & 5EC \\
\hline 0 & 39,0 & 38,4 & 38,5 & 38,5 & 38,3 & 38,5 & 39,2 & 39,1 & 38,5 & 38,7 & 38,8 \\
\hline 5 & 40,5 & 39,6 & 40,2 & 40,1 & 39,6 & 40,2 & 40,2 & 40,3 & 40,6 & 40,5 & 40,8 \\
\hline 10 & 40,4 & 39,5 & 40,1 & 39,8 & 39,8 & 39,7 & 40,8 & 40,2 & 41,4 & 40,1 & 40,3 \\
\hline 15 & 40,2 & 39,6 & 40,0 & 39,6 & 39,7 & 39,6 & 39,9 & 40,1 & 40,9 & 39,9 & 39,9 \\
\hline 20 & 40,1 & 39,5 & 39,9 & 39,7 & 39,9 & 39,8 & 40,2 & 40 & 40,4 & 39,7 & 39,8 \\
\hline 25 & 40,0 & 38,8 & 39,1 & 38,7 & 39,1 & 38,7 & 39,2 & 38,6 & 38,9 & 38,5 & 38,9 \\
\hline 30 & 39,7 & 38,9 & 38,9 & 38,6 & 38,3 & 38,5 & 39,2 & 38,2 & 38,9 & 38,4 & 38,8 \\
\hline 35 & 39,0 & 38,4 & 38,9 & 38,6 & 38,3 & 38,5 & 39,2 & & 38,9 & 38,2 & 38,8 \\
\hline 40 & 39,0 & 38,4 & 38,5 & 38,5 & 38,3 & 38,5 & 39,2 & & 38,5 & 38,1 & 38,8 \\
\hline
\end{tabular}

